\title{
CH Packaging Operations for High-Wattage Waste
}

\author{
Revision 7
}

January 2006

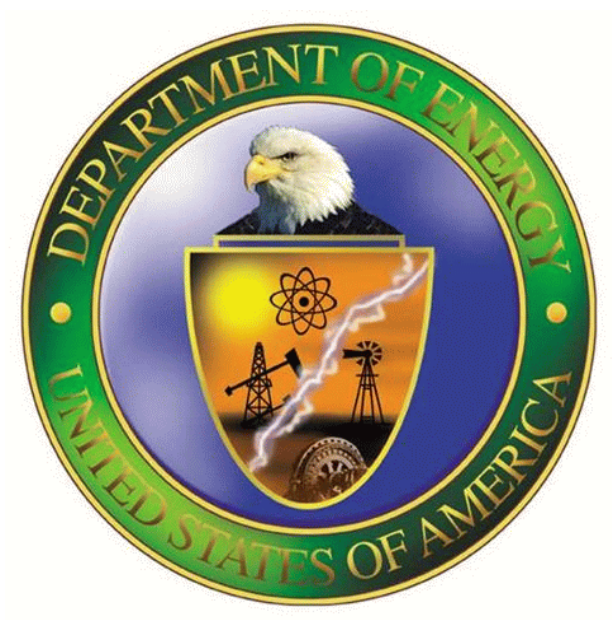

This document supersedes Revision 6 of DOE/WIPP 02-3220. 


\section{CH Packaging Operations for High-Wattage Waste}

Director, Office of Characterization and Transportation

Processing and final preparation of this paper was performed by Washington TRU Solutions LLC, the management and operating (M\&O) contractor for the Waste Isolation Pilot Plant under U.S. Department of Energy contract number DE-AC04-01AL66444. 
This document has been submitted as required to:

Office of Scientific and Technical Information

P.O. Box 62

Oak Ridge, TN 37831

(615) $576-8401$

Additional Information about this document may be obtained by calling (800) 336-9477. Copies may be obtained by contacting the National Technical Information Service, U.S. Department of Commerce, 5285 Port Royal Road, Springfield, VA 22101. 


\section{RECORD OF REVISION}

\section{Revision Reason for Revision/Change}

$0 \quad$ New $\mathrm{CH}$ Packaging Operations Manual for shipping LANL high-wattage waste. This document must be used in conjunction with DOE/WIPP 02-3183, $\mathrm{CH}$ Packaging Program Guidance, and DOE/WIPP 02-3185, CH Packaging Maintenance Manual.

1 Changes in Sections 2.17, 2.18, and 2.20, and Figure 2.1, to address results of validation process at LANL. This document must be used in conjunction with DOE/WIPP 02-3183, CH Packaging Program Guidance, and DOE/WIPP 02-3185, CH Packaging Maintenance Manual.

2 Update Figure 2.1, page 66, change contractor name from Westinghouse to Washington, and move OSTI notification to $2^{\text {nd }}$ page.

3 Adds Steps 2.16.18 and 2.16.19 to text, modifies mTorr limits in Step 2.17.20, and adds sign-off Steps 2.16.18 and 2.16.19 to Attachment 2.

4 Incorporate revised table showing wattage limits for waste code LA154 subtypes.

5 Incorporate changes from the Safety Analysis Report for the TRUPACT-II Shipping Package, Rev. 20, and DOE/WIPP 02-3184, Rev. 2.

The major changes are highlighted below:

- Page numbering changed.

- Figure 1.3 SWB Payload Assembly changed

- Added Figure 1.4 TDOP Payload Assembly

- Added references in Subsection 1.1.2 for CH-TRAMPAC, WP 08-PT.01 and WP 08-PT.02.

- Added a prerequisite action to Subsection 1.4.4 to verify payload size

- Added a NOTE to Section 1.3 about guidance for SWB activities.

- Added a note to Section 1.3 showing maximum assembly height for SWB payloads.

- Added ( \pm 2 degrees) to CAUTION in Subsection 1.3.3.

- Added a NOTE to Section 1.4 regarding guidance for TDOP operations.

- Added a CAUTION to Section 2.0.

- Added three bullets to Subsection 2.1.4 Precautions and Limitations.

- Added a NOTE in Subsection 2.3.2 for trailer tie-down guidance.

- Added a NOTE in Subsection 2.4.1 for OCA seal test port plug access.

- Added a CAUTION in Subsection 2.4.4 for ACGLF counterweight position.

- Added a NOTE in Section 2.8 for a definition of clean O-rings.

- Added two bullets in Subsection 2.8.2.

- Added Subsection 2.8.4 to remove ICV Wiper O-ring for cleaning.

- Added two bullets to Subsection 2.9.3.

- Added wording in Section 2.10 to inspect for conditions hat could impair the function of the part.

- Added Subsection 2.16.3 to verify proper assembly of payload.

- Added NOTE in Subsection 2.16.8 for payload assembly weight.

- Added wording to Subsection 2.16.20 for High-Wattage Waste limits. 
- $\quad$ Added a sign-off for Subsection 2.16.20 2.19.2, 2.19.13, 2.19.15, 2.20.16, and 2.20.17.

- Added wording to Subsection 2.17.18 to verify pressure is less than or equal to 2 Torr.

- Added Subsection 2.18.15 to perform ICV preshipment leakage rate.

- Added three bullets to 2.24.3.

- Added a WARNING to Subsection 2.24.3 no to remove ICV vent port plug if torque is relieved.

- $\quad$ Added a NOTE to Subsection 2.24.3.

- Added a HOLD POINT to Subsection 2.25.5 with a sign-off.

- Added two NOTES under Subsection 2.33.5.

- Added two bullets to Subsection 2.34.13.

- Added a NOTE to contact Packaging Maintenance Engineer in Section 3.0.

- SECTION 4.0 PRESHIPMENT LEAKAGE RATE TESTING changed to match DOE/WIPP 02-3184.

- Attachments 1 through 10 were changed to match changes in the document.

6 Editorial revision to correct Step 4.3.22 to read RETURN TO Step 2.18.16.

$7 \quad$ Major changes are highlighted below:

- Incorporate changes from DOE/WIPP 02-3184, Rev. 3.

- Provided means to document evacuation period on Attachment 2.

- Provided means to document stabilization period on Attachment 2.

- Corrected symbol in Step 2.17.26.

- Incorporate requirements for SQ-154 high-wattage waste shipments.

- Clarified the use of nitrogen or argon for inert gas backfill.

- Added a step and sign-off at Step 2.19.19 for supervisor to verify WWIS approval and final submittal.

- Corrected packaging component nomenclature. 
M\&O CONTRACTOR TECHNICAL REVIEW ORGANIZATIONS

WASHINGTON TRU SOLUTIONS

\section{CBFO REVIEW ORGANIZATIONS}

OFFICE OF CHARACTERIZATION AND TRANSPORTATION

QUALITY ASSURANCE

EDITORIAL 


\section{TABLE OF CONTENTS}

1.0 PAYLOAD PREPARATION $\ldots \ldots \ldots \ldots \ldots \ldots \ldots \ldots \ldots \ldots \ldots \ldots \ldots \ldots \ldots \ldots$

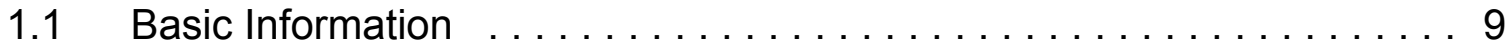

1.2 Preparing $55-$ Gallon Drum Payload Assembly $\ldots \ldots \ldots \ldots \ldots \ldots$

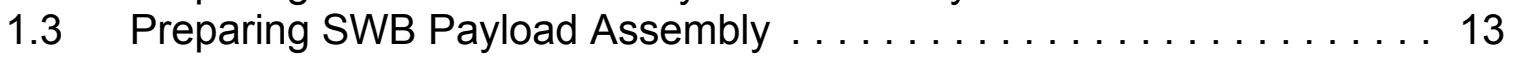

1.4 Preparing TDOP Payload Assembly $\ldots \ldots \ldots \ldots \ldots \ldots \ldots \ldots \ldots \ldots$

2.0 NORMAL OPERATING INSTRUCTIONS $\ldots \ldots \ldots \ldots \ldots \ldots \ldots \ldots \ldots . . \ldots \ldots$

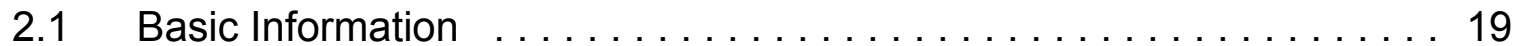

$2.2 \quad$ Packaging (Empty) Receipt . . . . . . . . . . . . . . . . . 22

2.3 Releasing Tie-Downs and Removal of Packaging from Trailer . . . . . 23

2.4 OCA Lid Removal . . . . . . . . . . . . . . . . . . . . . . 24

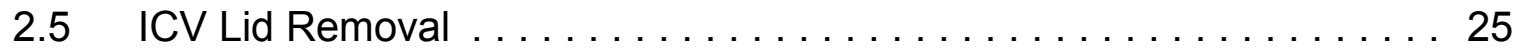

2.6 Preloading/Shipping Operational Checks and Examinations . . . . . . 2 27

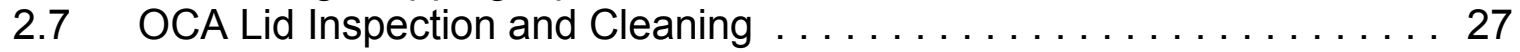

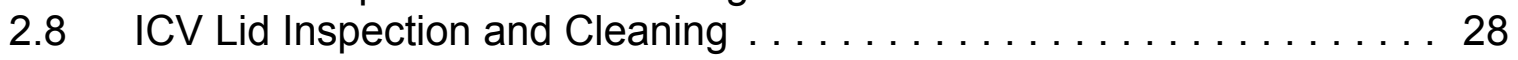

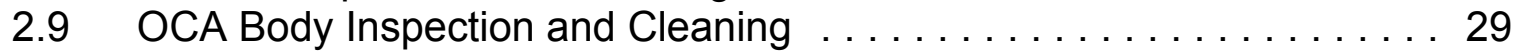

2.10 OCA Components Inspection and Cleaning .............. 30

2.11 ICV Body Inspection and Cleaning . . . . . . . . . . . . 31

2.12 ICV Components Inspection and Cleaning ............. 33

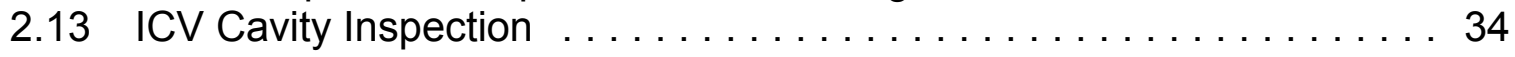

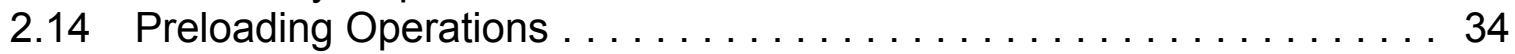

2.15 Packaging Receipt and Inspection Data Sheet Validation . . . . . . . . 34

2.16 Loading Payload Assembly . . . . . . . . . . . . . . . . . . . 34

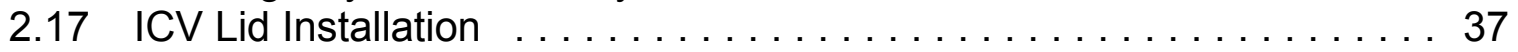

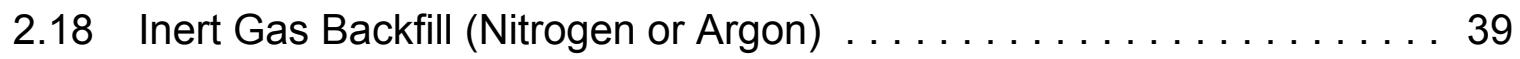

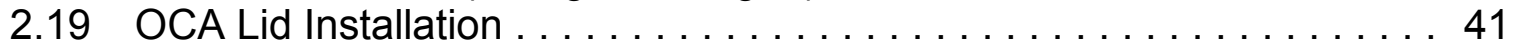

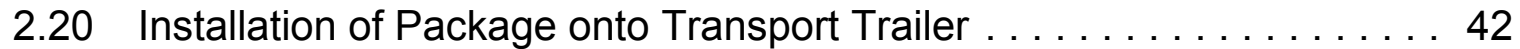

2.21 Package (Loaded) Receipt . . . . . . . . . . . . . . . . . . . . 45

2.22 Releasing Tie-Downs and Removal of Package from Trailer . . . . . 46

2.23 OCA Lid Removal . . . . . . . . . . . . . . . . . . . . . 47

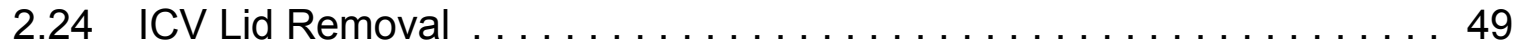

2.25 Unloading Payload Assembly . . . . . . . . . . . . . . 51

2.26 Packaging Operational Checks and Examinations . . . . . . . . . 52

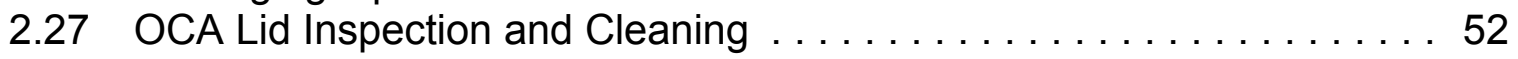

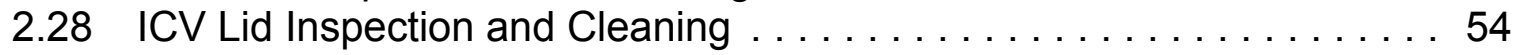

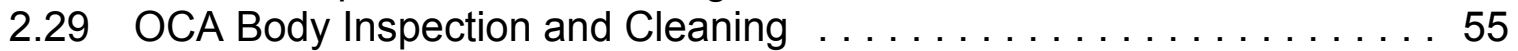

2.30 OCA Components Inspection and Cleaning .............. 56

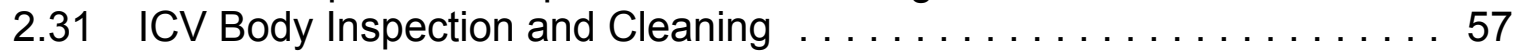

2.32 ICV Components Inspection and Cleaning .............. 58

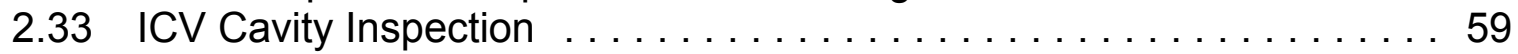

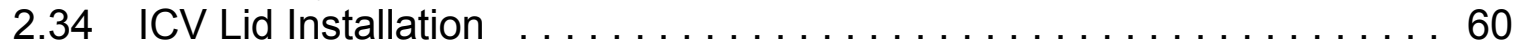

2.35 OCA Lid Installation . . . . . . . . . . . . . . . . . 61

2.36 Installation of Packaging onto Transport Trailer $\ldots \ldots \ldots \ldots \ldots 63$

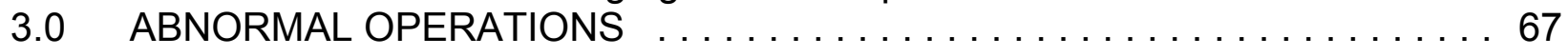

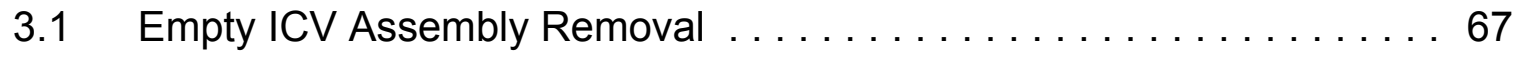

3.2 Using Heat Guns to Remove Stuck Lids ................ 68

3.3 Pressurizing with Nitrogen or Compressed Air to Remove Stuck Lids . 69

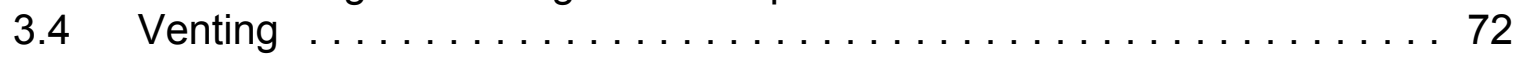


4.0 PRESHIPMENT LEAKAGE RATE TESTING $\ldots \ldots \ldots \ldots \ldots \ldots \ldots \ldots$.

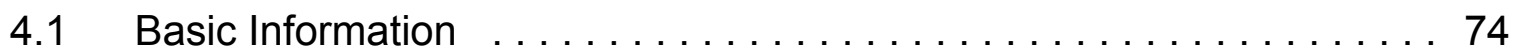

4.2 ICV Upper Main O-Ring Seal $\ldots \ldots \ldots \ldots \ldots \ldots \ldots \ldots \ldots$

$4.3 \quad$ ICV Outer Vent Port Plug Seal O-Ring $\ldots \ldots \ldots \ldots \ldots \ldots \ldots$

4.4 OCV Upper Main O-Ring Seal $\ldots \ldots \ldots \ldots \ldots \ldots \ldots \ldots \ldots$

4.5 OCV Vent Port Plug Seal O-Ring $\ldots \ldots \ldots \ldots \ldots \ldots \ldots \ldots \ldots$

Attachment 1 - High-Wattage CH Packaging Receipt and Inspection Data Sheet .. 95 Attachment 2 - High-Wattage CH Packaging Loading Data Sheet . . . . . . . . . . 96

Attachment 3 - High-Wattage Loaded CH Package Trailer Data Sheet . . . . . . . . 98

Attachment 4 - High-Wattage Loaded Package Receipt and Processing

Data Sheet . . . . . . . . . . . . . . . . . . . . 99

Attachment 5 - High-Wattage Empty Packaging Shipment Data Sheet . . . . . . 100

Attachment 6 - High-Wattage Trailer Data Sheet . . . . . . . . . . . . . . . 102

Attachment 7 - ICV Preshipment Leakage-Rate Test Data Sheet . . . . . . . . . 103

Attachment 8 - OCV Preshipment Leakage-Rate Test Data Sheet . . . . . . . 106

Attachment 9 - Time and Date Data Sheet for Shipment of High-Wattage Waste . 109

Attachment 10 - Time and Date Data Sheet for Receipt of High-Wattage Waste . 110

\section{LIST OF FIGURES}

Figure 1.1 - 55-Gallon Drum Placement . . . . . . . . . . . . . . . 15

Figure 1.2 - 55-Gallon Drum Payload Assembly . . . . . . . . . . . . . . 16

Figure 1.3 - SWB Payload Assembly $\ldots \ldots \ldots \ldots \ldots \ldots \ldots \ldots \ldots \ldots \ldots \ldots \ldots$

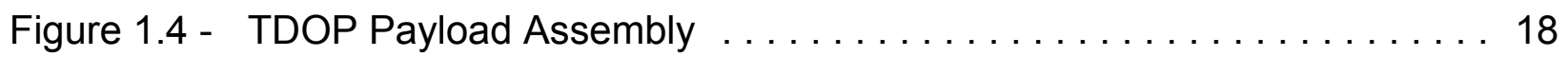

Figure 2.1 - Evacuation/Inert Gas Backfill $\ldots \ldots \ldots \ldots \ldots \ldots \ldots \ldots \ldots \ldots$

Figure 3.1 - Flow Diagram for Nitrogen Bottle/Compressed Air ICV/OCA Lid

Pressurization ....................... 73

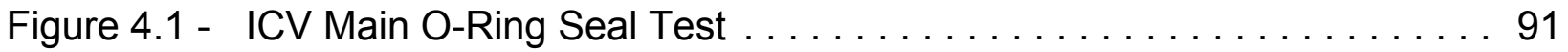

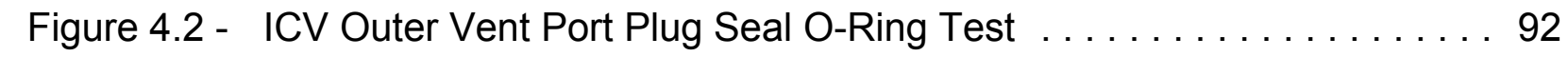

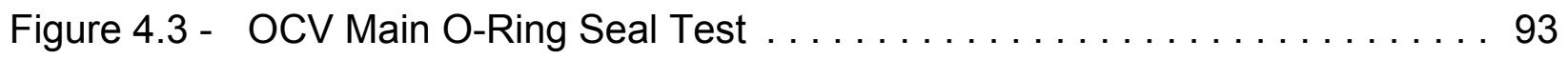

Figure 4.4 - OCV Vent Port Plug Seal O-Ring Test $\ldots \ldots \ldots \ldots \ldots \ldots . \ldots$ 


\subsection{PAYLOAD PREPARATION}

\section{CAUTION}

If the payload pallet will be placed on a square pallet for subsequent movement by forklift, care must be taken to ensure all three pockets used for lifting with the Adjustable Center of Gravity Lift Fixture (ACGLF) rest on a flat surface. Failure to ensure this may result in pallet damage due to the weight of the ACGLF driving the pallet lift point through the pallet.

\section{NOTE}

This section provides the user with instructions for assembling a payload.

All the steps in Subsections 1.2, Preparing 55-Gallon Drum Payload Assembly; 1.3, Preparing SWB Payload Assembly; and 1.4, Preparing TDOP Payload Assembly, must be completed, but may be performed in any order as long as radiological control steps are not bypassed.

\subsection{Basic Information}

1.1.1 Introduction - This procedure provides instructions for assembling the following contact-handled $(\mathrm{CH})$ packaging payload:

- Drum payload assembly

- $\quad$ Standard Waste Box (SWB) assembly

- $\quad$ Ten-Drum Overpack (TDOP)

\subsubsection{References}

\section{BASELINE DOCUMENTS}

- U.S. Nuclear Regulatory Commission

(NRC)-Docket-71-9218, Safety Analysis Report for the TRUPACT-II Shipping Package

- $\quad$ NRC-Docket-71-9218, TRUPACT-II Certificate of Compliance, No. 9218

- $\quad$ Contact-Handled Transuranic Waste Authorized Methods for Payload Control (CH-TRAMPAC), U.S. Department of Energy

- $\quad$ CH-TRU Payload Appendices

- WP 08-PT.01, Standard Waste Box Handling and Operation Manual 
- WP 08-PT.02, Ten-Drum Overpack Handling and Operation Manual

\subsubsection{Equipment}

- $\quad$ SWB ratchet straps or turnbuckles

- Drum payload pallet

- $\quad$ Guide tubes

- $\quad$ Stretch wrap

- $\quad$ Slip sheets

- Reinforcement plates

\subsubsection{Prerequisite Actions}

- $\quad$ Each waste container and payload assembly shall be verified to meet $\mathrm{CH}$ TRAMPAC requirements before shipment.

- Verify each payload container is less than the limits specified in Table 3.2-1 of the CH TRAMPAC (total external dose rate).

\subsection{Preparing 55-Gallon Drum Payload Assembly}

1.2.1 Verify cotter pins are installed in lift pin assemblies on new style pallets.

1.2.2 Place clean pallet, right side up on floor or stretch wrap machine for use as the bottom support of the drum payload assembly.

1.2.3 Place slip sheet on top of pallet.

1.2.4 Verify guide tube holes on slip sheet and pallet are aligned. 


\section{NOTE}

The diameter of all drums, including the locking ring, must be less than or equal to 24 inches (in.). This dimension should not include the locking bolt. Tapping the locking ring with a hammer while torquing the lock ring nut may assist in ensuring the drum is tightly closed. The diameter of each layer of drums should not exceed $72 \mathrm{in}$. The adhesive-backed bumper pads are excluded from the 24-in. and 72 -in. diameter limits.

\section{NOTE}

If shipping less than 14 loaded drums in a TRUPACT-II, empty dunnage drums must be used to form the payload while adhering to weight management practices (see Figure 1.1, 55-Gallon Drum Placement). Dunnage drums shall have open vent ports (i.e., not filtered or plugged).

1.2.5 Verify at least one approved filter is installed in each loaded drum in accordance with Section 2.5 of the $\mathrm{CH}$ TRAMPAC.

1.2.6 Verify all waste drums are properly labeled and drums are approved for the shipment being assembled.

\section{NOTE}

In Step 1.2.7, at least one container ID label on each drum (except the middle) must be visible when drums are assembled into a payload assembly.

\section{NOTE}

Drums in an assembly should be approximately the same height such that a flat stacking surface is achieved. That is, the maximum difference between the shortest and tallest drums in an assembly shall not exceed $1 / 2$ in., with the exception of the center drum in a seven-pack assembly, which may be up to one inch shorter but no taller than the tallest drum in the seven-pack assembly.

1.2.7 Place seven drums on slip sheet using weight distribution shown in Figure 1.1.

1.2.8 Verify locking bolt on each drum is positioned between drum gaps that do not contain guide tubes.

1.2.9 Verify heaviest seven-pack is on bottom of drum payload assembly for TRUPACT-II (see Figure 1.1).

1.2.10 Stretch wrap upper portion of drums with nine wraps so wraps extend down the sides of the drums a maximum of $22 \mathrm{in}$. with NO overlap on top of drums. 


\section{NOTE}

The reinforcing plate should rest flat on top of the drums. Tape may be used to secure the reinforcing plate to the drums prior to applying stretch wrap.

1.2.11 Place reinforcing plate on top.

1.2.12 Verify guide tube holes are aligned with bottom slip sheet/pallet holes by inserting and removing guide tubes and adjusting assembly, as required.

1.2.13 Apply nine additional wraps of stretch wrap so there is overlap on top of drums (see Figure 1.2, 55-Gallon Drum Payload Assembly).

1.2.14 Place slip sheet on top of bottom layer of drums (on top of reinforcing plate) AND align white stripe with the one on lower assembly.

1.2.15 Verify guide tube holes are aligned with bottom slip sheet/pallet holes (if desired, guide tubes may be inserted to help maintain pallet alignment).

\section{NOTE}

In Step 1.2.16, at least one container ID label on each drum (except the middle) must be visible when drums are assembled into a payload assembly.

\section{NOTE}

Drums in an assembly should be approximately the same height such that a flat stacking surface is achieved. That is, the maximum difference between the shortest and tallest drums in an assembly shall not exceed $1 / 2$ in., with the exception of the center drum in a seven-pack assembly, which may be up to one inch shorter but no taller than the tallest drum in the seven-pack assembly.

1.2.16 Place seven drums on slip sheet using weight distribution shown in Figure 1.1.

1.2.17 Verify locking bolt (on each drum) is positioned between drum gaps which will not contain guide tubes.

1.2.18 Install adhesive backed bumper pads on top chine of the six exposed drums.

1.2.19 Stretch wrap upper portion of drums with nine wraps so wraps extend down the sides of drums a maximum of $22 \mathrm{in}$. with NO overlap on top of drums. 


\section{NOTE}

The reinforcing plate should rest flat on top of the drums. Tape may be used to secure the reinforcing plate to the drums prior to applying stretch wrap.

1.2.20 Place reinforcing plate on top.

1.2.21 Verify guide tube holes are aligned with bottom slip sheet/pallet holes by inserting and removing guide tubes and adjusting assembly, as required.

1.2.22 Apply nine additional wraps of stretch wrap so there is overlap on top of drums.

1.2.23 Verify at least one container ID label on each drum (except the middle) is visible when drums are assembled into payload assembly.

1.2.24 If not already installed, insert guide tube(s) into drum payload assembly adjusting upper assembly, as required.

1.2.25 If beta-gamma, alpha, and neutron surveys are required, survey using site-specific procedures.

\subsection{Preparing SWB Payload Assembly}

\section{NOTE}

Additional guidance regarding SWB activities, such as loading, handling, filter installation, maintenance, inspection, and repair, is provided in WP 08-PT.01. This document is available on the Internet at http://www.wipp.ws/library/caolib.htm\#containers.

\section{NOTE}

The maximum SWB payload assembly height is $74-5 / 8$ in.

1.3.1 Verify approved filters are installed in each SWB and the remaining ports are plugged (if not filtered), in accordance with Section 2.5 of the CH TRAMPAC.

\section{NOTE}

If shipping only one loaded SWB in a TRUPACT-II, a second empty dunnage SWB must be used in the top position to form the payload. To allow for pressure changes, dunnage SWBs shall have open vent ports (i.e., not filtered or plugged).

1.3.2 Verify SWBs are properly labeled and SWBs are approved for the shipment being assembled. 


\section{NOTE}

An SWB forklift adapter may be used in lieu of a crane/ACGLF.

\subsubsection{Place heaviest SWB on floor.}

\section{CAUTION}

Operator shall verify two ACGLF counterweights are at 180 degrees and 000 degrees ( \pm 2 degrees) BEFORE lifting ACGLF or lid.

1.3.4 Place second SWB on top of first and align the edges.

1.3.5 Attach SWB turnbuckles or adjustable slings (in three places) to top and bottom SWBs as follows:

- $\quad$ One on each outer lift clip on one side

- One on the middle clip on the opposite side (see

Figure 1.3, SWB Payload Assembly)

1.3.6 Install SWB bumper pads (On the top SWB, the bumpers should be placed at the end of the top ribs only. On the bottom SWB, the bumpers should be placed at the end of the bottom ribs only).

1.3.7 If beta-gamma, alpha, and neutron surveys are required, survey using site-specific procedures.

\subsection{Preparing TDOP Payload Assembly (TRUPACT-II only)}

\section{NOTE}

Additional guidance regarding TDOP operations, such as handling, loading, lifting, inspection, maintenance, and repair, is provided in WP 08-PT.02. This document is available on the Internet at http://www.wipp.ws/library/caolib.htm\#containers.

1.4.1 Verify approved filters are installed and the remaining ports are plugged (if not filtered), in accordance with Section 2.5 of the $\mathrm{CH}$ TRAMPAC.

1.4.2 Verify the TDOP is properly labeled and approved for the shipment being assembled.

1.4.3 Install bumper pads on the top and bottom rib of TDOP (four pads on each rib) (see Figure 1.4 for example).

1.4.4 If beta-gamma, alpha, and neutron surveys are required, survey using site-specific procedures. 
Figure 1.1 - 55-Gallon Drum Placement

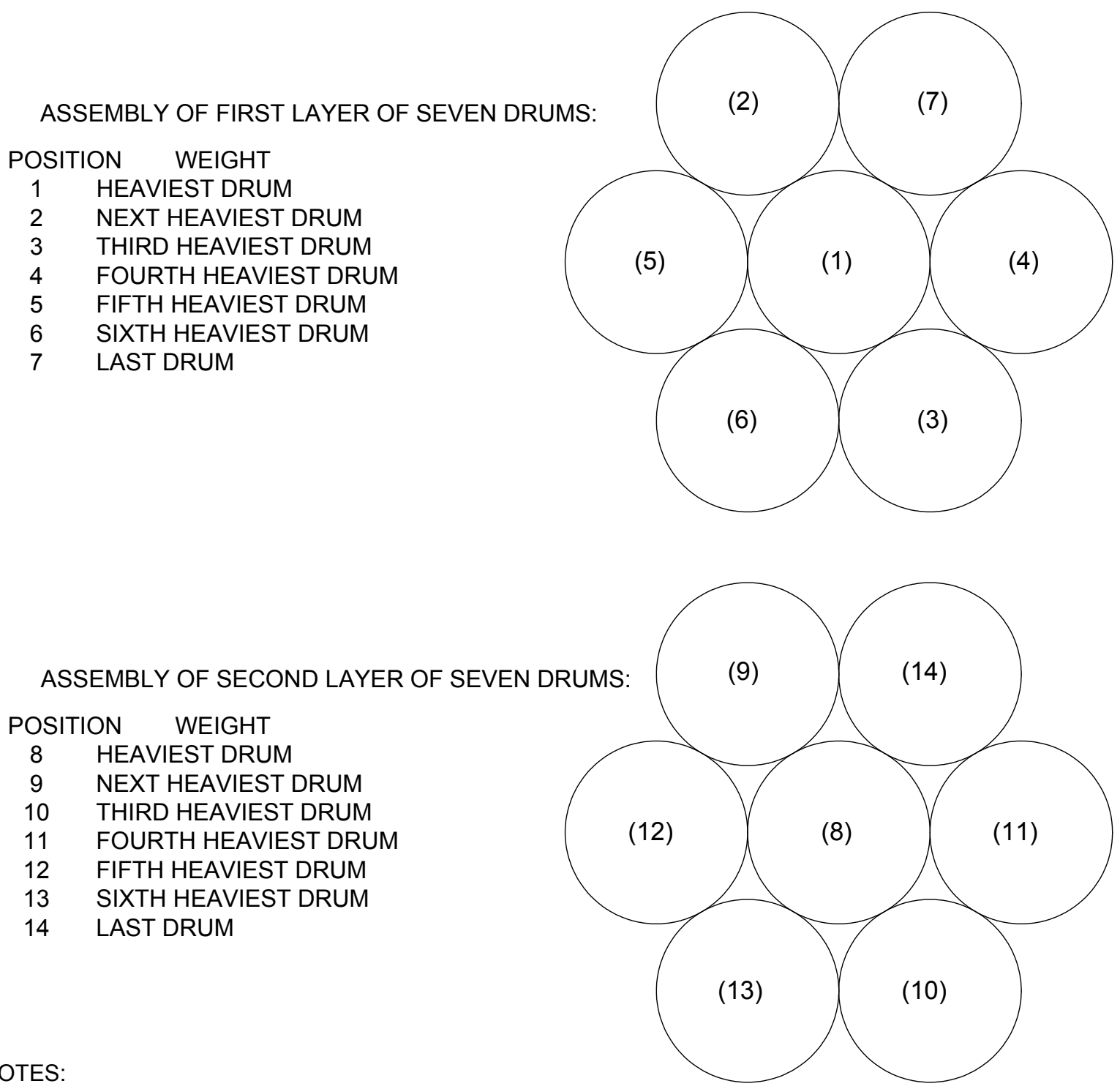

1. IF DUNNAGE IS USED, IT MAY BE PLACED AS NEEDED.

2. VERIFY THE HEAVIEST SEVEN PACK WILL COMPRISE THE LOWER LAYER OF SEVEN DRUMS.

3. DRUMS IN AN ASSEMBLY SHOULD BE APPROXIMATELY THE SAME HEIGHT SUCH THAT A FLAT STACKING SURFACE IS ACHIEVED. THAT IS, THE MAXIMUM DIFFERENCE BETWEEN THE SHORTEST AND TALLEST DRUMS IN AN ASSEMBLY SHALL NOT EXCEED $1 / 2$ IN., WITH THE EXCEPTION OF THE CENTER DRUM IN A SEVEN-PACK ASSEMBLY, WHICH MAY BE UP TO ONE INCH SHORTER BUT NO TALLER THAN THE TALLEST DRUM IN THE SEVEN-PACK ASSEMBLY.

4. TAPE MAY BE USED TO SECURE THE REINFORCEMENT SHEET TABS TO THE DRUMS PRIOR TO APPLYING STRETCH WRAP.

5. ONLY THE COMPONENTS SHOWN IN FIGURE 1.2 ARE APPROVED FOR USE IN 55-GALLON DRUM PAYLOAD ASSEMBLY (STRETCH WRAP AND TAPE NOT SHOWN FOR CLARITY). 


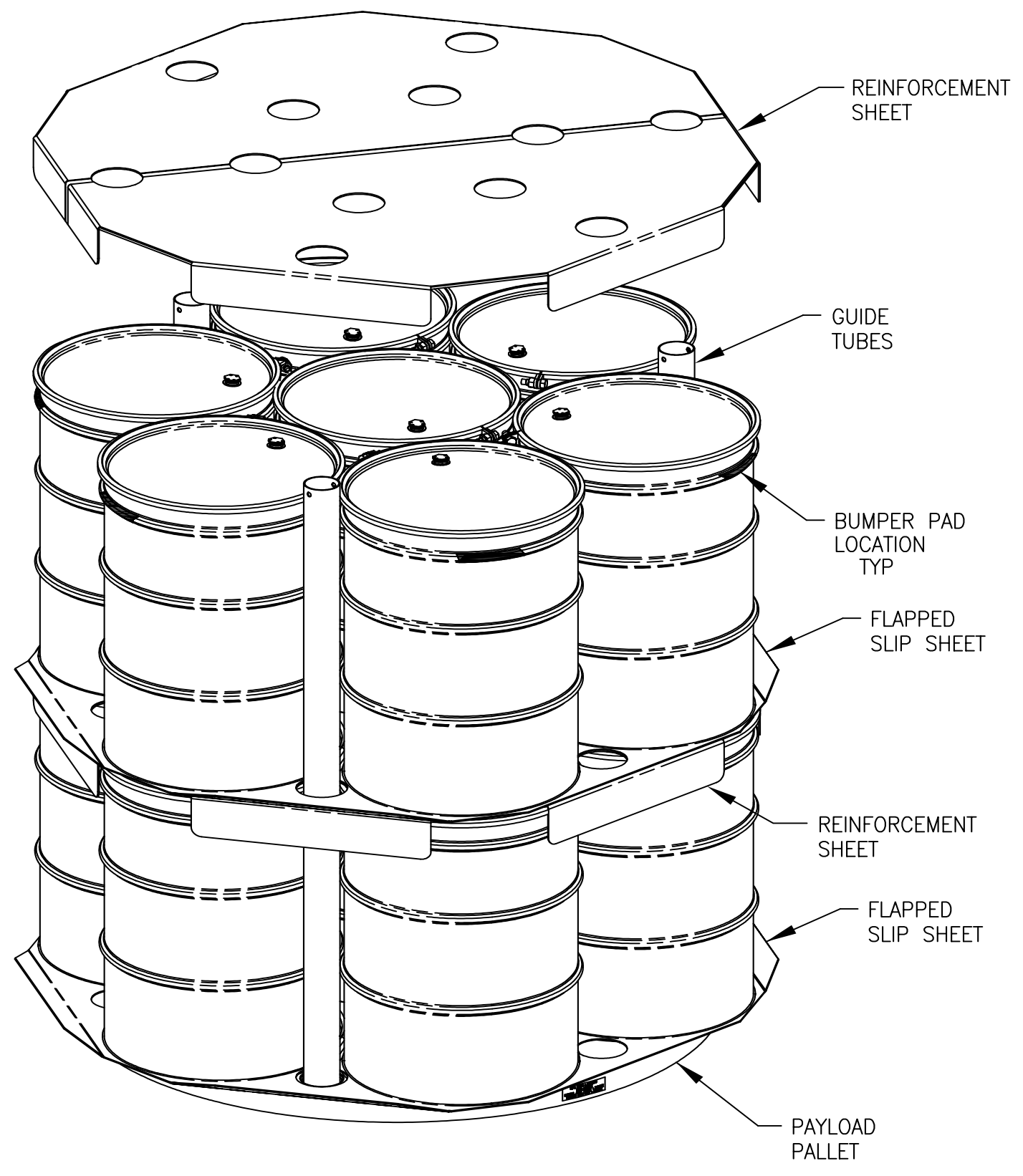


Figure 1.3 - SWB Payload Assembly

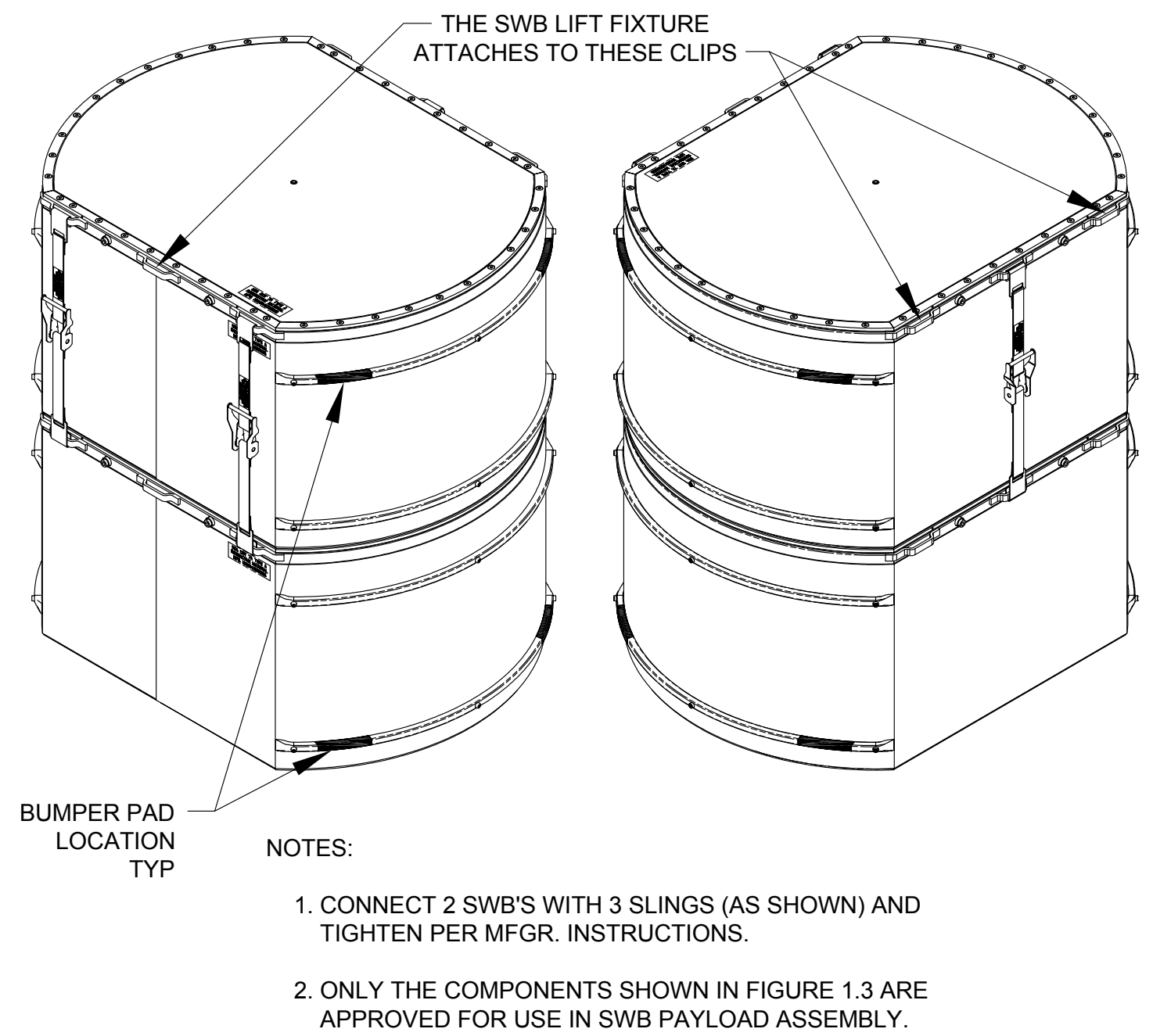

Inspection - Before each use, each SWB adjustable sling assembly shall be visually inspected to verify the webbing red wear indicator threads are not exposed due to abrasion, and the annual inspection date has not elapsed.

Before lifting, the ratchet buckle shall be visually inspected to verify the ratchet teeth are securely engaged and there are nominally three wraps (or 1-1/2 turns) of webbing around the mandrel. It is acceptable for the adjustable slings to be installed as shown in Figure 1.3, or in the reverse orientation with the handle pointed down.
The assembly shall also be checked to verify the webbing is in tension before each loading operation and before each unloading operation.

Annual Inspection - Each SWB sling assembly including webbing, ratchet buckle, and hooks shall be inspected for signs of excessive wear, cracking, or physical damage. If the webbing, ratchet buckle, or hooks are excessively worn, cracked, or damaged, the assembly shall NOT be used. Annual inspection shall be recorded. 


\begin{tabular}{|lll|}
\hline DOE/WIPP 02-3220 & Rev. 7 & Page 18 of 110 \\
\hline
\end{tabular}

Figure 1.4 - TDOP Payload Assembly

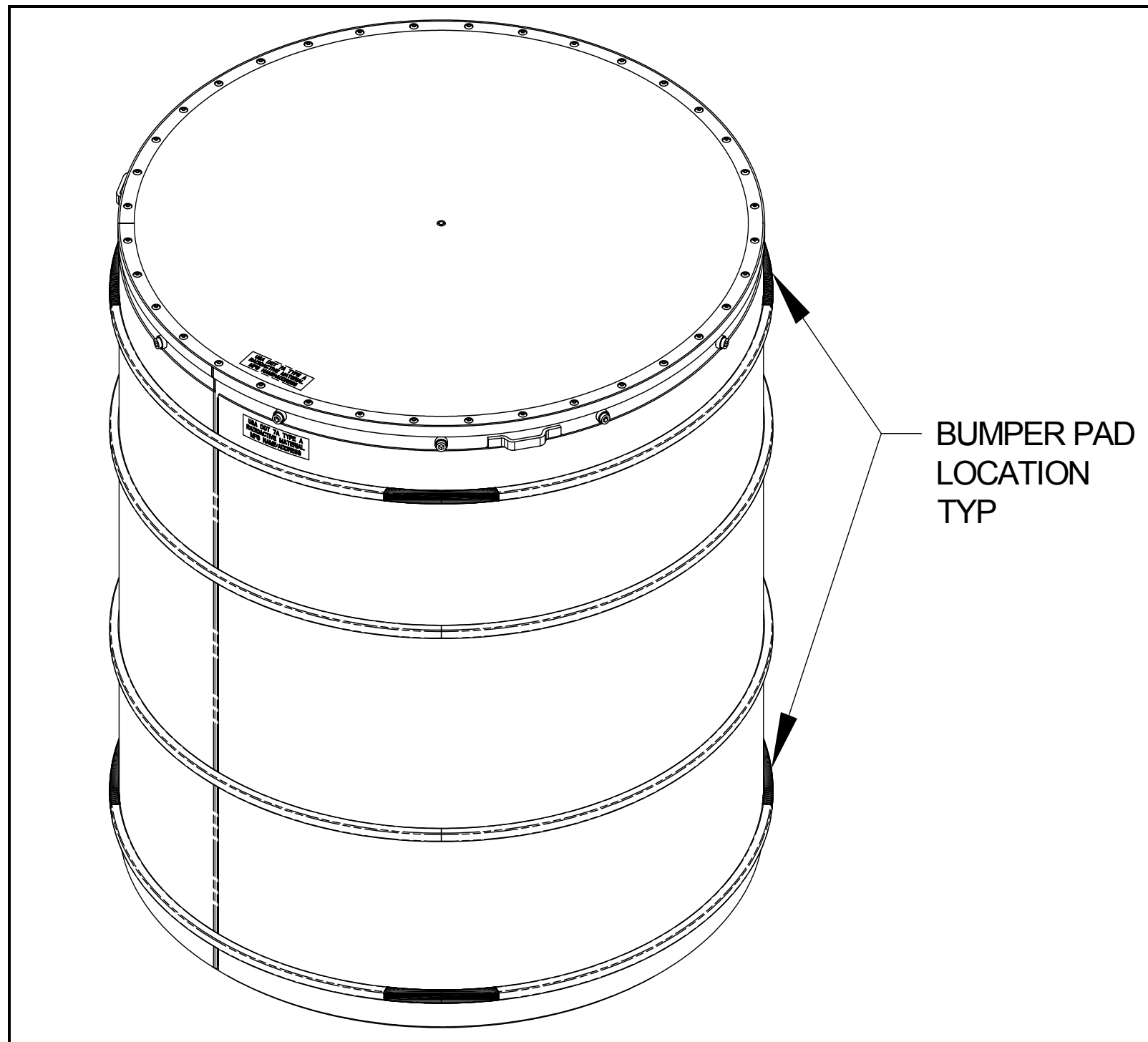

NOTES:

1. ONLY THE COMPONENTS SHOWN IN FIGURE 1.4 ARE APPROVED FOR USE IN TDOP PAYLOAD ASSEMBLY. 


\subsection{NORMAL OPERATING INSTRUCTIONS}

\section{CAUTION}

If the payload pallet will be placed on a square pallet for subsequent movement by forklift, care must be taken to ensure all three pockets used for lifting with the ACGLF rest on a flat surface. Failure to ensure this may result in pallet damage due to the weight of the ACGLF driving the pallet lift point through the pallet.

\section{NOTE}

Torquing of components that are replaced using the minor maintenance work instructions may be completed during assembly step and do not require a second or repeat torque when using minor maintenance form.

\section{NOTE}

Transport trailer operations, package loading and unloading from transport trailers, hoisting and rigging activities such as ACGLF operations, equipment checkout and shutdown, and component inspection activities must be performed, but may be performed in any order and in parallel with other activities as long as radiological control steps are not bypassed. Steps involving outer containment assembly (OCA)/inner containment vessel (ICV) lid removal/installation and payload removal/loading may be performed in parallel if there are multiple operators working on the same packaging.

\subsection{Basic Information}

2.1.1 Introduction - This procedure provides operating instructions for the following $\mathrm{CH}$ packaging:

- TRUPACT-II

\subsubsection{References}

- $\quad 49$ CFR Part 172, "Hazardous Materials Table, Special Provisions, Hazardous Materials Communications, Emergency Response Information, and Training Requirements"

- $\quad 49$ CFR Part 173, "Shippers - General Requirements for Shipments and Packagings"

- U.S. Department of Energy, Safety Analysis Report for the TRUPACT-II Shipping Package

- $\quad$ TRUPACT-II Certificate of Compliance No. 9218 
- $\quad$ Contact-Handled Transuranic Waste Authorized Methods for Payload Control (CH-TRAMPAC)

- $\quad \mathrm{CH}-\mathrm{TRU}$ Payload Appendices

- DOE/WIPP 02-3183, CH Packaging Program Guidance

- DOE/WIPP 02-3185, CH Packaging Maintenance Manual

- WP 08-PT.04, CH Packaging Trailer O\&M Manual

\subsubsection{Equipment}

- $\quad$ Calibrated Measuring and Test Equipment

- $\quad$ Pressure/vacuum gauge, 30 -in. Hg to 30 psig

- $\quad$ Torque wrench with 55 to 65 pound (lb) in. range

- $\quad$ Torque wrench with 30 to 50 pound feet (lb-ft) range

- $\quad$ Crane load cell, 10,000 lb minimum rating

- $\quad$ Other Equipment

- $\quad$ ICV/Outer Containment Vessel (OCV) vent port plug removal/pressure relief tool

- $\quad$ Miscellaneous hardware and vacuum assembly connections

- $\quad$ Vacuum pump

- $\quad$ ICV/OCV outer vent port plug removal and installation tool

- Consumable Materials

- Vacuum grease

- Nickel bearing lubricant

- Denatured alcohol

- $\quad$ Lint-free rags

- $250 \mathrm{ft}^{3}$ (minimum) of dry inert (nitrogen or argon) gas

- Evacuation/Backfill Cart

- $\quad$ Dry vacuum pump (oil-free) with a minimum flow rate of $11.9 \mathrm{scfm}$ and an ultimate base pressure of 50 mTorr or less 
- $\quad$ Evacuation/backfill line, 1-in. i.d. tubing (length as required)

- $\quad$ One 1-in. ball valve

- Compressed gas regulator (capable of regulating to 1-psi increments)

- $\quad$ Quick connect fitting, P/N SSQC8-D-810

- $\quad$ Tube reducer, P/N SS-810-R-16

- $\quad$ Flow meter capable of $75 \mathrm{cfh}$

- $\quad$ Pressure transducer with digital readout display

\subsubsection{Precautions and Limitations}

- Failure to rotate the counterweights on ACGLF to the balance position may cause ACGLF to swing uncontrollably.

- Measures shall be implemented by all users for the identification and control of parts and components. These measures shall be designed to prevent the use of incorrect or defective parts and components on the packaging.

- $\quad$ Pressure transducer and controller installed in evacuation/backfill cart must be energized at least 30 minutes before initiating evacuation process in Subsection 2.17, ICV Lid Installation.

- Jack stands are required on freestanding trailers only when loading/unloading packaging on the trailer.

- Metal tools must not be used to remove O-rings.

- $\quad$ OCV/ICV lids shall be removed using a straight (vertical) pull; side pulls are not permitted. 
2.2 Packaging (Empty) Receipt

\section{NOTE}

The packaging loading/unloading operation shall only be performed in a dry environment. In the event of precipitation during outdoor operations, the OCV and ICV cavities shall be covered to prevent precipitation from entering the package interior cavities. If precipitation does enter the interior cavities, all freestanding water shall be removed before shipment and liquid handled according to the site's waste management procedures.

2.2.1 Record OCA serial number on Attachment 1, High-Wattage $\mathrm{CH}$ Packaging Receipt and Inspection Data Sheet.

\section{SIGN-OFF}

2.2.2 Verify site representative performed the following:

- $\quad$ Released packaging for loading

- Validated shipping documents

- Inspected packaging for damage

- $\quad$ Checked nameplate to verify packages are proper for contents being shipped

\section{SIGN-OFF}

2.2.3 Verify packaging maintenance labels are legible and maintenance is current by checking maintenance labels adjacent to name plate and initial Attachment 1.

\section{SIGN-OFF}

2.2.4 Check for LEAK TEST REQUIRED tag near OCA vent port.

2.2.5 If LEAK TEST REQUIRED tag is present, remove tag and forward to supervisor so a leak test report will be sent to the WIPP M\&O $\mathrm{CH}$ Packaging Maintenance Engineer. 


\section{CAUTION}

A physical check shall be made to verify air bags on trailer have fully inflated before trailer is moved. Failure to do so may cause the tires to rub on bottom of rear package.

2.2.6 Position transport trailer in designated parking area.

2.2.7 Lower trailer jacks (landing gear) ensuring trailer is level.

2.2.8 Install wheel chocks.

2.2.9 Install trailer stands on freestanding trailers.

2.3 Releasing Tie-Downs and Removal of Packaging from Trailer

2.3.1 IF packaging will NOT be removed from trailer for loading operations, THEN GO TO Subsection 2.4, OCA Lid Removal.

2.3.2 Release tie-downs from packaging.

\section{NOTE}

Trailer tie-down guidance is provided in WP 08-PT.04. This document is available on the Internet at http://www.wipp.ws/library/caolib.htm\#containers.

2.3.3 Rotate forklift pocket covers (4) to UP position, OR remove covers and store in designated area.

2.3.4 If required, dry packaging before transport to designated area.

\section{CAUTION}

Forklift tip-back beyond level may damage package exterior surface.

2.3.5 Transfer packaging to designated area. 


\subsection{OCA Lid Removal}

2.4.1 Prepare OCA lid by removing the following:

- OCA lift pocket covers

- $\quad$ OCA lock bolts (6)

- OCV seal test port access plug and thermal plug

- OCV vent port access plug and thermal plug

\section{NOTE}

If OCA lid is turned so that the OCV seal test port plug is not accessible,

Step 2.4.2 cannot be performed; operator must proceed to Step 2.4.3.

2.4.2 Verify OCV seal test port plug is fully seated.

2.4.3 Remove OCV vent port cover.

2.4.4 Remove OCV vent port plug.

\section{CAUTION}

Operator shall verify two ACGLF counterweights are at 180 degrees and 000 degrees ( \pm 2 degrees) BEFORE lifting ACGLF or lid.

\subsubsection{Attach ACGLF to OCA lid.}

2.4.6 Install OCV vent port tool.

2.4.7 Connect vacuum line to vent port tool.

2.4.8 Start vacuum pump and evacuate to 3 to $15 \mathrm{in}$. $\mathrm{Hg}$ vacuum gauge.

2.4.9 Rotate OCV lock ring to UNLOCKED position.

2.4.10 Stop vacuum pump.

2.4.11 Disconnect vacuum line from vent port tool.

2.4.12 Remove vent port tool.

2.4.13 Let OCV vent to atmosphere. 


\section{CAUTION}

Operator shall verify two ACGLF counterweights are at 180 degrees and 000 degrees ( \pm 2 degrees) BEFORE lifting ACGLF or lid.

\section{CAUTION}

Load cell reading MUST NOT exceed 7,500 lb when weight of ACGLF is zeroed out, OR 10,000 lb when weight of ACGLF is included.

\subsubsection{Remove OCA lid.}

2.4.15 IF lid does not lift off, THEN perform the following:

[A] Contact supervisor.

[ B ] GO TO Subsection 3.2, Using Heat Guns OR Subsection 3.3, Pressurizing with Nitrogen or Compressed Air to Remove Stuck Lids, attempt to remove lid, and RETURN TO Step 2.4.16.

\subsubsection{Place OCA lid on storage stand.}

\subsection{ICV Lid Removal}

\section{CAUTION}

Operator shall verify two ACGLF counterweights are at 180 degrees and 000 degrees ( \pm 2 degrees) BEFORE lifting ACGLF or lid.

\subsubsection{Attach ACGLF to ICV lid.}

2.5.2 Remove ICV vent port cover.

2.5.3 Remove the following:

- $\quad$ ICV outer vent port plug

- ICV lock bolts (3)

- ICV seal test port plug

- $\quad$ OCV seal test port plug

2.5.4 Remove ICV inner vent port plug. 
2.5.5 Install ICV vent port tool.

2.5.6 Connect vacuum line to vent port tool.

2.5.7 Start vacuum pump and evacuate to 3 to $15 \mathrm{in}$. Hg vacuum gauge.

2.5.8 Rotate ICV lock ring to UNLOCKED position.

2.5.9 Stop vacuum pump.

2.5.10 Disconnect vacuum line from vent port tool.

2.5.11 Remove vent port tool.

2.5.12 Vent ICV to atmosphere.

\section{CAUTION}

Load cell reading MUST NOT exceed 5,000 lb when weight of ACGLF is zeroed out, OR 7,500 lb when weight of ACGLF is included.

2.5.13 Remove ICV lid using ACGLF and crane.

2.5.14 IF lid does not lift off ICV,

THEN perform the following:

[A] Contact supervisor.

[B] GO TO Subsection 3.2,

OR Subsection 3.3, attempt to remove lid, and RETURN TO Step 2.5.15.

2.5.15 Place ICV lid on storage stand.

\section{NOTE}

Use of the ACGLF with short legs to remove items from the ICV is NOT permitted.

2.5.16 Remove any payload pallets, guide tubes, slip sheets, reinforcement sheets, dunnage containers, etc. 
2.6 Preloading/Shipping Operational Checks and Examinations

2.6.1 Radiological Control Technician (RCT), IF surveys for items in Step 2.7.1, Step 2.8.1, or Step 2.9.1 have been completed previously AND results are below contamination limits, THEN enter applicable data for each step on Attachment 1.

2.6.2 RCT, IF surveys have NOT been completed previously, THEN GO TO Subsection 2.7, OCA Lid Inspection and Cleaning, Subsection 2.8, ICV Lid Inspection and Cleaning, or Subsection 2.9, OCA Body Inspection and Cleaning, as applicable.

\section{NOTE}

Subsections 2.7 through 2.13, ICV Cavity Inspection (and included steps), MUST be completed, but may be performed in any order as long as radiological control steps are not bypassed.

2.7 OCA Lid Inspection and Cleaning

2.7.1 RCT, IF survey has not been completed previously, THEN survey interior and exterior of OCA lid and record applicable data on Attachment 1.

\section{SIGN-OFF}

2.7.2 Inspect OCA lid for the following:

- Visible deformation

- Dents or abnormal flat spots $>1 / 2$ in.

- Abnormal scratches or gouges

- Obvious punctures, tears, or cracks in exposed welds

- $\quad$ Burnout plugs (3) in place and intact

- L Lift pocket tubes in place

- Distortions or cracks on or around lifting attachments

- Lift pocket covers attached and serviceable

- $\quad$ OCV locking Z-flange screws in place and torque paint unbroken; or, if no torque paint, screws torqued to $22 \mathrm{lb}$-in. 
- $\quad$ Guide plates and screws in place and screws torqued to $21 \mathrm{lb}$-in., or no looseness in plate and screws recessed.

- Seal surfaces for scratches/gouges perpendicular to machining marks

2.7.3 Remove foreign material from the following:

- $\quad$ Lock ring

- Sealing surfaces

- Test port access threads

2.7.4 Verify arrow above seal test port aligns with UNLOCKED arrow on lock ring.

2.7.5 Initial Attachment 1 to document OCA lid components and hardware are satisfactory.

\section{SIGN-OFF}

2.8 ICV Lid Inspection and Cleaning

\section{NOTE}

O-rings are considered clean when they are absent of free-standing vacuum grease, dirt, debris, and other foreign matter.

2.8.1 RCT, IF survey has NOT been completed previously, THEN survey interior and exterior of ICV lid and record applicable data on Attachment 1.

\section{SIGN-OFF}

2.8.2 Inspect ICV lid for the following:

- Visible deformation

- $\quad$ Punctures

- Abnormal scratches or gouges

- Distortions on or around lifting attachments

- Upper spacer and screws installed and torque paint unbroken; or, if no torque paint, screws torqued to $10 \mathrm{lb}$-in.

- Debris shield installed and undamaged

- Lock ring undamaged 
- $\quad$ Damaged or missing screws from wiper O-ring holder

- Seal surfaces for scratches/gouges perpendicular to machining marks

2.8.3 Remove foreign material from the following:
- Lock ring flange
- Debris shield
- Sealing surfaces

2.8.4 Remove ICV wiper O-ring.

2.8.5 Clean ICV wiper O-ring and inspect for wear or damage that could impair its function.

2.8.6 IF O-ring is damaged, THEN GO TO corresponding WI and RETURN TO Step 2.8.9.

2.8.7 Lubricate wiper O-ring with a light coat of vacuum grease.

2.8.8 Install wiper O-ring.

2.8.9 Initial Attachment 1 to document ICV lid components and hardware are satisfactory.

\section{SIGN-OFF}

2.9 OCA Body Inspection and Cleaning

2.9.1 RCT, IF survey has NOT been completed previously, THEN survey OCA body exterior and ICV body interior and record applicable data on Attachment 1.

\section{SIGN-OFF}

2.9.2 Remove upper and lower main O-rings and set aside for cleaning and inspection.

2.9.3 Inspect OCA body for the following:

- Visible deformation

- Obvious punctures or tears

- Obvious cracks in exposed welds

- Dents or abnormal flat spots $>1 / 2$ in. 
- Abnormal scratches or gouges

- $\quad$ Burnout plugs (6) in place and undamaged

- $\quad$ Forklift pocket threaded inserts (8) intact and threads undamaged

- $\quad$ Lock bolt threaded inserts (6) intact and threads undamaged

- $\quad$ Tears or fraying $>1 / 4$ in. on ceramic fiber gasket

- Lock ring stop(s) undamaged

- Upper and lower O-ring grooves and seal surfaces for scratches/gouges perpendicular to machining marks

2.9.4 Remove foreign material from the following:
- $\quad$ Test port threads
- Vent port threads
- $\quad$ Lock ring flange
- O-ring grooves
- Sealing surfaces

2.9.5 Verify air flow through OCV helium $(\mathrm{He})$ test ports.

2.9.6 Initial Attachment 1 to document OCA body inspection is satisfactory.

\section{SIGN-OFF}

2.10 OCA Components Inspection and Cleaning

\section{NOTE}

O-rings are considered clean when they are absent of free-standing vacuum grease, dirt, debris, and other foreign matter.

2.10.1 Clean and inspect the following for wear or damage that could impair their function:

- OCV vent port plug and handling O-ring

- OCV vent port cover and O-rings

- $\quad$ OCV seal test port plug and O-ring

- $\quad$ Lock bolts (6)

- $\quad$ OCV seal test port access plug

- $\quad$ OCV vent port access plug

2.10.2 IF components are damaged, 
THEN GO TO corresponding WI and RETURN TO Step 2.10.4.

2.10.3 Apply a light coat of vacuum grease to the following:

- $\quad$ OCV vent port plug threads

- $\quad$ OCV vent port cover threads and seal O-ring

- $\quad$ OCV seal test port plug threads and seal O-ring

2.10.4 Verify annulus debris seal is installed and undamaged.

2.10.5 Lightly coat the following with nickel bearing lubricant:
- $\quad$ OCA lock bolt threads (6)
- OCV seal test port access plug threads
- OCV vent port access plug threads

2.10.6 Clean and inspect upper and lower main O-rings and vent port plug seal O-ring for damage that could impair containment integrity.

2.10.7 IF O-rings are damaged, THEN GO TO corresponding WI and RETURN TO Step 2.10.10.

\section{NOTE}

Lubrication and installation of upper and lower main O-rings may be performed after Step 2.16.20, but prior to Subsection 2.19, OCA Lid Installation.

2.10.8 Lubricate upper and lower main O-rings and vent port plug seal O-ring with a light coat of vacuum grease.

2.10.9 Install upper and lower main O-rings and vent port plug seal O-ring.

2.10.10 Initial Attachment 1 to document OCA component and hardware inspections are satisfactory.

\section{SIGN-OFF}

\subsection{ICV Body Inspection and Cleaning}

2.11.1 Remove upper and lower main O-rings and set aside for cleaning and inspection. 
2.11.2 Inspect for the following:

- Lock ring stop(s) undamaged

- $\quad$ Lock bolt threaded inserts installed and threads undamaged

2.11.3 Remove foreign material from the following:

- $\quad$ Test port threads

- Vent port threads

- Lock ring flange

- $\quad$ O-ring grooves

- $\quad$ Filter ports

- $\quad$ Sealing surfaces

2.11.4 Inspect the following for deformation, scratches, or burrs:

- Upper and lower O-ring grooves and sealing surfaces for scratches/gouges perpendicular to machining marks

- Vent port threads

- $\quad$ Seal test port threads

- Lock ring flange

- Lower spacer installed with no punctures in top plate

- Lower spacer screws installed and no detectable gap between screw head and spacer top plate

2.11.5 Verify airflow through ICV He test ports.

2.11.6 Initial Attachment 1 to document ICV body inspection is satisfactory.

\section{SIGN-OFF}


2.12 ICV Components Inspection and Cleaning

\section{NOTE}

O-rings are considered clean when they are absent of free-standing vacuum grease, dirt, debris, and other foreign matter.

2.12.1 Clean and inspect the following for wear or damage that could impair their function:

- ICV vent port cover and seal

- $\quad$ ICV outer vent port plug

- $\quad$ ICV inner vent port plug and seal O-ring

- $\quad$ ICV seal test port plug and seal O-ring

- ICV lock bolts (3)

2.12.2 IF components are damaged, THEN GO TO corresponding WI and RETURN TO Step 2.12.4.

2.12.3 Apply a light coat of vacuum grease to the following:

- $\quad$ ICV vent port cover threads (and O-ring if installed)

- $\quad$ ICV outer vent port plug threads

- $\quad$ ICV inner vent port plug threads and seal O-ring

- $\quad$ ICV seal test port plug threads and seal O-ring

2.12.4 Coat ICV lock bolt threads (3) lightly with nickel bearing lubricant.

2.12.5 Clean upper and lower main O-rings and ICV outer vent port plug seal O-ring, and inspect for damage that could impair containment integrity.

2.12.6 IF O-rings are damaged,

THEN GO TO corresponding WI and RETURN TO Step 2.12.9.

\section{NOTE}

Lubrication and installation of upper and lower main O-rings may be performed after Step 2.16.21, but prior to Subsection 2.17, ICV Lid Installation.

2.12.7 Lubricate upper and lower main O-rings and ICV outer vent port plug seal O-ring with a light coat of vacuum grease.

2.12.8 Install upper and lower main O-rings and ICV outer vent port plug seal O-ring. 
2.12.9 Initial Attachment 1 to document ICV components and hardware inspections are satisfactory.

\section{SIGN-OFF}

2.13 ICV Cavity Inspection

2.13.1 Check ICV cavity for water by visually inspecting the absorbent material inserted into hole in lower spacer assembly.

\section{NOTE}

Disposal of absorbent material and water will be at direction of RCT.

2.13.2 IF water is inside ICV,

THEN perform one of the following:

- $\quad$ Remove water through center hole of lower spacer assembly using wet/dry vacuum

- Attach absorbent material to rod and insert in hole in center of lower spacer assembly

2.13.3 IF water is inside ICV, THEN GO TO Subsection 3.1, Empty ICV Assembly Removal, perform steps and RETURN TO Step 2.13.4.

2.13.4 Initial Attachment 1 to document ICV is free of water.

\section{SIGN-OFF}

\subsection{Preloading Operations}

2.14.1 Verify all preloading cleaning and inspections are complete.

\section{SIGN-OFF}

2.15 Packaging Receipt and Inspection Data Sheet Validation
2.15.1 Supervisor, review/validate and sign Attachment 1.

\section{SIGN-OFF}

\subsection{Loading Payload Assembly}

2.16.1 Record OCA serial number on Attachment 2, High-Wattage $\mathrm{CH}$ Packaging Loading Data Sheet, and Attachment 4, High-Wattage Loaded Package Receipt and Processing Data Sheet. 
2.16.2 Record pallet or SWB ratchet strap serial numbers on Attachment 2.

\section{SIGN-OFF}

2.16.3 Record shipment number, trailer number, and package number(s) on Attachment 3, High-Wattage Loaded CH Package Trailer Data Sheet.

\section{SIGN-OFF}

2.16.4 Verify payload is assembled using requirements delineated in the $\mathrm{CH}$-TRAMPAC and initial Attachment 2.

\section{SIGN-OFF}

2.16.5 Record the HIGHEST container wattage from each content code in the payload on Attachment 2.

\section{SIGN-OFF}

2.16.6 Using the highest wattage from each content code recorded in Step 2.16.5, verify the highest wattage for each container of the applicable content code is equal to or less than the limits given in the table on Attachment 2.

\section{SIGN-OFF}

\section{CAUTION}

Operator shall verify two ACGLF counterweights are at 180 degrees and 000 degrees ( \pm 2 degrees) BEFORE lifting ACGLF or lid.

2.16.7 Attach appropriate legs/adapter to ACGLF.

2.16.8 Lower ACGLF long legs into drum payload assembly guide tubes, OR lower SWB or TDOP adaptor until no load is indicated on crane load cell.

2.16.9 Lock ACGLF legs, OR attach SWB lift fixture to upper SWB or TDOP adaptor to TDOP as applicable.

2.16.10 Raise payload 2 to 6 in.

2.16.11 If necessary, balance payload using counter weight controls at ACGLF console until a reading of \pm 0.5 degrees is obtained. 


\section{NOTE}

Payload assembly weight shall be equal to or less than the limits specified in the CH-TRAMPAC.

2.16.12 Record payload assembly weight (i.e., drum [or SWBs, TDOP] + pallet + guide tubes + slip sheets) on Attachment 2 .

\section{SIGN-OFF}

2.16.13 Obtain packaging weight from WIPP WWIS [WIPP Waste Information System] Packaging Reference Data Table.

2.16.14 Record empty packaging weight on Attachment 2.

\section{SIGN-OFF}

2.16.15 Add two previously recorded weight values to calculate the total package weight and record on Attachment 2.

\section{SIGN-OFF}

2.16.16 Verify total loaded package weight for TRUPACT-II does not exceed 19,250 lb:

2.16.17 Raise and position payload assembly over ICV cavity using crane and ACGLF.

2.16.18 Verify payload is centered over ICV BEFORE lowering load.

\section{CAUTION}

Care should be exercised to avoid hitting, scraping, or binding the payload assembly against ICV body flange and internal surface.

2.16.19 Lower payload assembly into ICV.

2.16.20 Record weight positions of ACGLF on top of payload near leg opposite the electrical junction boxes.

\section{CAUTION}

Operator shall verify two ACGLF counterweights are at 180 degrees and 000 degrees ( \pm 2 degrees) BEFORE lifting ACGLF or lid. 


\section{NOTE}

Valves $\mathrm{V}-1$ and $\mathrm{V}-2$ may be cycled as necessary to obtain system pressure readings in Subsections 2.17 and 2.18.

2.17 ICV Lid Installation

2.17.1 Match ICV lid and body serial numbers and record ICV serial number on Attachment 2.

\section{SIGN-OFF}

2.17.2 Record torque wrench serial numbers and calibration due date on Attachment 2.

\section{SIGN-OFF}

\section{CAUTION}

Operator shall verify two ACGLF counterweights are at 180 degrees and 000 degrees ( \pm 2 degrees) BEFORE lifting ACGLF or lid.

2.17.3 Attach ACGLF to ICV lid.

2.17.4 Align UNLOCKED arrows and install ICV lid onto ICV body using crane and ACGLF.

2.17.5 Verify inner vent port plug is retracted into ICV vent port tool.

2.17.6 Install ICV vent port tool into ICV vent port.

\section{NOTE}

Steps 2.17.7 through 2.19.12 incorporate the use of an evacuation/backfill cart identified in Step 2.1.3.

2.17.7 Install Radiation Assessment Filter (RAF) assembly (with a filter installed) on the ICV vent port tool.

2.17.8 Verify vent port isolation valve V-4 is open.

2.17.9 Verify pressure transducer isolation valve $(\mathrm{V}-1)$ is open.

2.17.10 Verify vacuum pump isolation valve $(\mathrm{V}-2)$ is open.

2.17.11 Verify inert gas isolation valve ( $\mathrm{V}-3)$ is closed. 
2.17.12 Record ambient atmospheric pressure (Torr) on Attachment 2.

\section{SIGN-OFF}

2.17.13 Start vacuum pump and reduce pressure to a minimum of 3 in. (76 Torr), Hg LESS than the ambient pressure recorded in Step 2.17.12.

2.17.14 Rotate ICV lock ring to LOCKED position.

2.17.15 Close valve V-1.

\section{NOTE}

The ICV shall be evacuated for a minimum of twelve hours.

2.17.16 Record evacuation start time and date on Attachment 2.

\section{SIGN-OFF}

2.17.17 Open valve $\mathrm{V}-1$ and monitor pressure.

2.17.18 Verify the pressure is $\leq 2$ Torr, and perform the following:

[A] Compare the required minimum pressure (2 Torr) to the current ICV pressure.

[ B ] If the current ICV pressure is GREATER than 2 Torr, continue pumping until the ICV pressure is $\leq 2$ Torr.

2.17.19 Record final pressure (mTorr) on Attachment 2.

\section{SIGN-OFF}

2.17.20 Close valve V-2 and stop vacuum pump.

2.17.21 Record evacuation end time and date on Attachment 2.

\section{SIGN-OFF}

2.17.22 Immediately record $T_{\text {start }}$ on Attachment 2 and Attachment 9, Time and Date Data Sheet for Shipment of High-Wattage Waste.

\section{SIGN-OFF}

2.17.23 Close valve V-4 and remove RAF filter and screens from the RAF housing assembly.

2.17.24 Reassemble RAF housing assembly, excluding the filter. 


\section{HOLD POINT}

2.17.25 RCT, survey filter for contamination following site-specific procedures and initial Attachment 4.

\section{SIGN-OFF}

2.17.26 Calculate $\mathrm{T}_{\text {unload_120 }}=\mathrm{T}_{\text {start }}+120$ hours (LA154) or $\mathrm{T}_{\text {unload_240 }}=\mathrm{T}_{\text {start }}$ +240 hours (SQ154) and record on Attachment 4.

\section{SIGN-OFF}

\section{NOTE}

The value for $\mathrm{T}_{\text {unload_120 }}$ must be $\leq 120$ hours or 5 days for all LA154

Content Codes.

The value for $T_{\text {unload_240 }}$ must be $\leq 240$ hours or 10 days for all SQ154

Content Codes.

2.18 Inert Gas Backfill (Nitrogen or Argon)

2.18.1 Open valve V-4.

2.18.2 Open valve V-3.

2.18.3 Open valve on gas supply source.

2.18.4 Adjust flow meter to a flow rate of about $60 \mathrm{cfh}$.

\section{CAUTION}

Do not allow pressure inside ICV to exceed the ambient atmospheric pressure recorded in Step 2.17.12 by more than 25 Torr.

2.18.5 Monitor pressure inside ICV.

2.18.6 When pressure inside ICV is equal to the ambient atmospheric pressure recorded in Step 2.17.12 (+25, -5 Torr), close valve V-3.

2.18.7 Adjust flow regulator fully to stop the flow and close valve on top of gas supply source.

2.18.8 Record stabilization start time and date on Attachment 2. 
2.18.9 Allow a 2-hour stabilization period. Monitor pressure inside ICV. If pressure inside ICV does not decrease below the ambient atmospheric pressure recorded in Step 2.17.12 (-5 Torr), after the 2-hour stabilization period, the backfill process is complete. GO TO Step 2.18.11.

2.18.10 IF pressure inside ICV decreases below the ambient atmospheric pressure recorded in Step 2.17.12 (-5 Torr), within the 2-hour stabilization period,

THEN perform the following:

[A] Open valve on gas supply source.

[B] Open valve V-3.

[C ] Adjust flow regulator slowly to bring pressure inside ICV to the ambient atmospheric pressure recorded in Step 2.17.12 (+25, -5 Torr).

[D ] Close valve on gas supply.

2.18.11 When backfill process is complete, close valve V-1.

2.18.12 Record stabilization end time and date on Attachment 2.

\section{SIGN-OFF}

2.18.13 Install ICV inner vent port plug.

2.18.14 Disconnect vacuum line from ICV vent port tool.

2.18.15 Remove ICV vent port tool.

2.18.16 Torque inner vent port plug to 55 to $65 \mathrm{lb}$-in. and initial Attachment 2.

\section{SIGN-OFF}

2.18.17 Perform ICV preshipment leakage rate test per Section 4.0, Preshipment Leakage Rate Testing, and initial Attachment 2.

\section{SIGN-OFF}

2.18.18 Install ICV lock bolts (3).

2.18.19 Torque each ICV lock bolt to 28 to $32 \mathrm{lb}-\mathrm{ft}$ and initial Attachment 2. 
2.19 OCA Lid Installation

2.19.1 Match OCA lid and body serial numbers.

2.19.2 Record OCA serial number on Attachment 2 .

\section{SIGN-OFF}

\section{CAUTION}

Operator shall verify two ACGLF counterweights are at 180 degrees and 000 degrees ( \pm 2 degrees) BEFORE lifting ACGLF or lid.

2.19.3 Attach ACGLF to OCA lid.

2.19.4 Align UNLOCKED arrows and install OCA lid onto OCA body.

2.19.5 Verify OCV vent port plug is retracted into OCV vent port tool.

2.19.6 Install OCV vent port tool into OCV vent port.

2.19.7 Connect vacuum line to OCV vent port tool.

2.19.8 Start vacuum pump and evacuate to 3 to $15 \mathrm{in}$. $\mathrm{Hg}$ vacuum gauge.

2.19.9 Rotate OCV lock ring to LOCKED position.

2.19.10 Stop vacuum pump.

2.19.11 IF existing connection will be used for OCV leak test, THEN GO TO Step 2.19.13.

2.19.12 Disconnect vacuum line from vent port tool.

2.19.13 GO TO Section 4.0, perform OCV preshipment leakage rate test.

\section{SIGN-OFF}

2.19.14 Install OCA lock bolts (6).

2.19.15 Torque each OCA lock bolt to 28 to $32 \mathrm{lb}$-ft and initial Attachment 2.

\section{SIGN-OFF}

2.19.16 Install OCA lift pocket covers. 
2.19.17 Install tamper-indicating security seal in both lock bolt on OCA thermal shield and OCV vent port access plug.

2.19.18 Record tamper-indicating security seals serial numbers on Attachment 2.

\section{SIGN-OFF}

2.19.19 Supervisor, verify that the containers and payload assembly have been approved in the WWIS and the final submittal has occurred.

\section{SIGN-OFF}

2.19.20 Supervisor, review/validate and sign Attachment 2.

\section{SIGN-OFF}

2.20 Installation of Package onto Transport Trailer

\section{NOTE}

When loading packages on trailer, or loading payload into packaging that is already on trailer, the following applies:

- $\quad$ Packages having a gross weight difference (heaviest to lightest) of $2,000 \mathrm{lb}$ or less can be considered equal and do not require a specific sequence for positioning on the trailer.

- Packages having a gross weight difference (heaviest to lightest), greater than 2,000 lb shall be positioned on the trailer as follows:

\begin{tabular}{|l|l|l|l|l|}
\hline & *1. Heaviest & Medium & Lightest & \\
\cline { 2 - 4 } & 2. Heaviest & Lightest & Medium & \\
\cline { 2 - 4 } TRAILER \\
FRONT & *3. Heaviest & Lightest & None & \multirow{2}{*}{ REAR } \\
\cline { 2 - 4 } & 4. Lightest & Heaviest & None & \\
\cline { 2 - 4 } & 5. Heaviest & None & None & \\
\hline
\end{tabular}

* Preferred method

2.20.1 Record the following on Attachment 3.

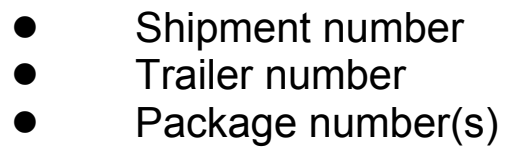

\section{SIGN-OFF}


2.20.2 Verify annual trailer inspection is current.

2.20.3 Record trailer inspection performed date on Attachment 3.

\section{SIGN-OFF}

\section{NOTE}

Trailer tie-down guidance is provided in WP 08-PT.04. This document is available on the Internet at http://www.wipp.ws/library/caolib.htm\#containers.

2.20.4 Inspect tie-downs for the following:

- Damage

- Defects

2.20.5 IF packaging was removed for loading operations, THEN perform the following:

[A] Position transport trailer in designated area.

[B ] Lower trailer jacks (landing gear), ensuring trailer is level.

[ C ] Install wheel chocks.

[D ] Install jack stands on freestanding trailers.

\section{CAUTION}

Forklift tip-back beyond level may damage package exterior surface.

[E] Transport package to transport trailer.

[ F ] Load package designated for position \#1 onto trailer with vent port on driver side of trailer.

[ G ] If applicable, load package designated for position \#2 onto trailer with vent port on driver side of trailer.

[ $\mathrm{H}$ ] If applicable, load package designated for position \#3 onto trailer with vent port on driver side of trailer. 


\section{NOTE}

Trailer tie-down guidance is provided in WP 08-PT.04. This document is available on the Internet at http://www.wipp.ws/library/caolib.htm\#containers.

[ I ] Install four tie-down assemblies for each package loaded on trailer.

[ J ] Install package forklift pocket access covers.

2.20.6 Record package positions and weights on Attachment 3.

\section{SIGN-OFF}

\section{NOTE}

The total weight of tractor, trailer, and payload cannot exceed $80,000 \mathrm{lb}$.

2.20.7 Record total weight of all loaded packages as payload weight on Attachment 3.

\section{SIGN-OFF}

2.20.8 Verify package(s) is in compliance with 49 CFR Part 172 , Subpart D, "Marking"; Subpart E, "Labeling"; and Subpart F, "Placarding," and initial Attachment 3.

\section{SIGN-OFF}

2.20.9 Complete information transfer to shipping papers, including packaging pallet ID numbers and SWB ratchet strap serial numbers, as required, for the specific shipment.

2.20.10 Verify shipping papers are in accordance with 49 CFR Part 172 , Subpart C, "Shipping Papers," and initial Attachment 3.

\section{SIGN-OFF}

2.20.11 Record date and time (as $\mathrm{T}_{\text {ship }}$ ) shipment is ready to depart from the site on Attachment 3 and Attachment 9.

\section{SIGN-OFF}
2.20.12 Calculate $\mathrm{T}_{\text {loading }}=\mathrm{T}_{\text {ship }}-\mathrm{T}_{\text {start }}=$ Attachment 3 and Attachment 9. Hours and record on 
2.20.13 Verify $\mathrm{T}_{\text {loading }}<24$ hours and initial both Attachment 3 and Attachment 9.

\section{SIGN-OFF}

2.20.14 If $\mathrm{T}_{\text {loading }}>24$ hours, GO TO Subsection 3.4, Venting.

2.20.15 Transportation Certification Official (TCO), review/validate entries on Attachment 9 and sign.

2.20.16 Initial for trailer loading complete on Attachment 3.

\section{SIGN-OFF}

2.20.17 Supervisor, perform the following:

[A ] Review/validate entries on Attachment 3 and sign.

[B ] Copy Attachments 4 and 9 to include with shipping papers.

[ C ] Notify WIPP Central Monitoring Room of pending shipment.

\section{SIGN-OFF}

\subsection{Package (Loaded) Receipt}

\section{NOTE}

The package unloading operation shall only be performed in a dry environment. In the event of precipitation during outdoor unloading or loading operations, OCV and ICV cavities shall be covered to prevent precipitation from entering the interior cavities. If precipitation does enter interior cavities, all freestanding water shall be removed before shipment and liquid handled according to the site's waste management procedures.

\subsubsection{Verify OCA serial number is recorded on Attachment 4.}

\section{SIGN-OFF}

2.21.2 Record $\mathrm{T}_{\text {arrive }}$, time and date on Attachment 4 and Attachment 10, Time and Date Data Sheet for Receipt of High-Wattage Waste.

\section{SIGN-OFF}

2.21.3 Calculate $T_{\text {unload_24 }}=T_{\text {arrive }}+24$ and record on Attachment 4.

\section{SIGN-OFF}




\begin{tabular}{|lll|}
\hline DOE/WIPP 02-3220 & Rev. 7 & Page 46 of 110 \\
\hline
\end{tabular}

\section{NOTE}

The value for $\mathrm{T}_{\text {unload_24 }}$ must be $\leq 24$ hours.

2.21.4 Notify site representative that shipment shall be unloaded before either $T_{\text {unload_120, }} T_{\text {unload_240 }}$, or $T_{\text {unload_24 }}$, whichever is sooner, and record choice as $T_{\text {final }}$ on Attachment 4.

\section{SIGN-OFF}

2.21.5 Verify site representative has performed the following and initial Attachment 4:

$$
\begin{array}{ll}
\text { - } \quad \text { Validated shipping documents } \\
\text { - } \quad \text { Released package(s) for unloading }
\end{array}
$$

\section{SIGN-OFF}

2.21.6 Survey package for external radiation and contamination using site-specific procedures and initial Attachment 4.

\section{SIGN-OFF}

\section{CAUTION}

A physical check shall be made to verify air bags on the trailer have fully inflated before trailer is moved. Failure to do so may cause the tires to rub on bottom of rear TRUPACT-II.

2.21.7 Position transport trailer in designated area.

2.21.8 Lower trailer jacks (landing gear), ensuring trailer is level.

2.21.9 Install wheel chocks.

2.21.10 Install trailer stands on freestanding trailers.

2.22 Releasing Tie-Downs and Removal of Package from Trailer

2.22.1 IF package will NOT be removed from trailer, THEN GO TO Subsection 2.23, OCA Lid Removal.

2.22.2 Release tie-downs from packaging. 


\section{NOTE}

Additional trailer tie-down guidance is provided in WP 08-PT.04. This document is available on the Internet at http://www.wipp.ws/library/caolib.htm\#containers.

2.22.3 Rotate four forklift pocket covers to UP position, OR remove four covers and store in designated area.

2.22.4 If required, dry package before transport to designated area.

\section{CAUTION}

Forklift tip-back beyond level may damage package exterior surface.

\subsubsection{Transfer package to unloading area.}

\subsection{OCA Lid Removal}

2.23.1 Remove and dispose of security seals.

2.23.2 If seal is broken or missing, follow applicable site policy.

2.23.3 Remove the following components to prepare OCA lid for removal:

- OCA lift pocket covers

- OCV seal test port access plug and thermal plug

- OCV vent port access plug and thermal plug

- $\quad$ OCA lock bolts (6)

\section{NOTE}

If OCA lid is turned so that the OCV seal test port plug is not accessible, Step 2.23.4 cannot be performed, and operator must proceed to Step 2.23.5.

2.23.4 Verify OCV seal test port plug is fully seated.

2.23.5 Remove OCV vent port cover.

\section{NOTE}

Torque on OCV vent port plug may be relieved prior to installation of OCV vent port tool.

2.23.6 Install OCV vent port tool.

2.23.7 Retrieve OCV vent port plug into vent port tool. 
2.23.8 Connect vacuum line to vent port tool.

2.23.9 Start vacuum pump and evacuate to 3 to $15 \mathrm{in}$. $\mathrm{Hg}$ vacuum gauge.

2.23.10 Rotate OCV lock ring to UNLOCKED position.

2.23.11 Stop vacuum pump.

2.23.12 Disconnect vacuum line from vent port tool.

2.23.13 Remove vent port tool.

\section{CAUTION}

Operator shall verify two ACGLF counterweights are at 180 degrees and 000 degrees ( \pm 2 degrees) BEFORE lifting ACGLF or lid.

2.23.14 Attach ACGLF to OCA lid.

\section{CAUTION}

Load cell reading MUST NOT exceed $7,500 \mathrm{lb}$ when weight of ACGLF is zeroed out, OR $10,000 \mathrm{lb}$ when weight of ACGLF is included.

2.23.15 Raise OCA lid slowly about 6 in. above the top of ICV lid, OR as directed by RCT.

2.23.16 IF lid does not lift off, THEN perform the following:

[A] Contact Supervisor.

[ B ] GO TO Subsection 3.2 or Subsection 3.3, attempt to remove lid, and RETURN TO Step 2.23.17.

\section{HOLD POINT}

2.23.17 RCT, survey OCA lid interior surface and ICV lid exterior surface for radiation/contamination following site-specific procedures.

\section{SIGN-OFF}

2.23.18 Place OCA lid on storage stand. 


\subsection{ICV Lid Removal}

\section{CAUTION}

Operator shall verify two ACGLF counterweights are at 180 degrees and 000 degrees ( \pm 2 degrees) BEFORE lifting ACGLF or lid.

2.24.1 Attach ACGLF to ICV lid.

2.24.2 Remove ICV vent port cover.

2.24.3 Remove the following:

$\begin{array}{ll}- & \text { ICV outer vent port plug } \\ - & \text { ICV seal test port plug } \\ - & \text { ICV lock bolts (3) } \\ \text { - } & \text { OCV seal test port plug }\end{array}$

\section{WARNING}

ICV inner vent port plug MUST NOT be removed if torque is relieved prior to installing ICV vent port tool. Plug removal may result in contamination of personnel and area.

\section{NOTE}

Torque on ICV inner vent port plug may be relieved prior to installation of ICV vent port tool.

2.24.4 Install ICV vent port tool.

2.24.5 Connect vacuum hose to vent port tool.

2.24.6 Retrieve ICV inner vent port plug into ICV vent port tool.

\section{CAUTION}

Vacuum should not exceed 15 -in. Hg when attempting to open ICV.

2.24.7 Start vacuum pump and evacuate to 3 to $15 \mathrm{in}$. $\mathrm{Hg}$ vacuum gauge. 


\begin{tabular}{|lll} 
DOE/WIPP 02-3220 & Rev. 7 & Page 50 of 110
\end{tabular}

2.24.8 Record $\mathrm{T}_{\text {ICV_open }}$ on Attachment 4.

SIGN-OFF

2.24.9 Record date and time ICV was vented and verify within 24 hours of $\mathrm{T}_{\text {arrive }}$ on Attachment 10.

\section{SIGN-OFF}

2.24.10 Rotate ICV lock ring to UNLOCKED position.

2.24.11 Stop vacuum pump.

2.24.12 Disconnect vacuum line from ICV vent port tool.

\section{HOLD POINT}

2.24.13 RCT, survey for radiation/contamination using site-specific procedures.

\section{SIGN-OFF}

2.24.14 Remove ICV vent port tool and ICV inner vent port plug.

\section{WARNING}

In Step 2.24.15 the ICV body may have an inert atmosphere. Entry shall be prohibited until body has been vented.

\section{CAUTION}

Load cell reading MUST NOT exceed $5,000 \mathrm{lb}$ when weight of ACGLF is zeroed out, OR 7,500 lb when weight of ACGLF is included.

2.24.15 Raise ICV lid slowly to clear ICV body and hold it about $2 \mathrm{ft}$ above the top of ICV body flange, OR as directed by RCT.

2.24.16 IF lid does not lift off ICV, THEN perform the following:

[A] Contact Supervisor.

[B ] GO TO Subsection 3.2, OR Subsection 3.3, attempt to remove lid, and RETURN TO Step 2.24.17. 


\section{HOLD POINT}

2.24.17 RCT, survey ICV lid interior surface and top of payload for radiation/contamination using site-specific procedures.

\section{SIGN-OFF}

2.24.18 Place ICV lid on storage stand.

2.25 Unloading Payload Assembly

\section{CAUTION}

Operator shall verify two ACGLF counterweights are at 180 degrees and 000 degrees ( \pm 2 degrees) BEFORE lifting ACGLF or lid.

2.25.1 Attach ACGLF with appropriate legs/adaptor to payload.

2.25.2 Position ACGLF counterweights to predetermined positions as marked on top of payload.

\section{NOTE}

Steps 2.25 .3 and 2.25 .4 are to be performed concurrently to remove payload.

2.25.3 Raise payload assembly slowly.

2.25.4 Inspect payload for damage and initial Attachment 4.

\section{SIGN-OFF}

\section{HOLD POINT}

2.25.5 RCT, survey payload assembly as it is raised for radiation/contamination using site-specific procedures.

\section{SIGN-OFF}

2.25.6 If payload is damaged, follow site-specific procedures.

2.25.7 Place payload assembly in designated area.

2.25.8 Supervisor, review/validate and sign Attachment 4 .

\section{SIGN-OFF}


2.26 Packaging Operational Checks and Examinations

2.26.1 Record OCA serial number on Attachment 5, High-Wattage Empty Packaging Shipment Data Sheet.

\section{SIGN-OFF}

2.26.2 Record torque wrench serial numbers and calibration due date on Attachment 5.

\section{SIGN-OFF}

2.26.3 Verify packaging maintenance labels are legible and maintenance is current by checking maintenance labels adjacent to name plate and initial Attachment 5.

\section{SIGN-OFF}

2.26.4 RCT, IF surveys for items in Step 2.27.1, Step 2.28.1, or Step 2.29.1 have been completed previously AND results are below contamination limits, THEN enter applicable data for each step on Attachment 5.

2.26.5 RCT, IF surveys have NOT been completed previously, THEN GO TO Subsection 2.27, OCA Lid Inspection and Cleaning; Subsection 2.28, ICV Lid Inspection and Cleaning; or Subsection 2.30, OCA Components Inspection and Cleaning, as applicable.

\section{NOTE}

Subsections 2.27 through 2.33, ICV Cavity Inspection (and included steps), must be completed, but may be performed in any order as long as radiological control steps are not bypassed.

2.27 OCA Lid Inspection and Cleaning

2.27.1 RCT, IF survey has NOT been completed previously, THEN survey OCV lid interior and exterior and record applicable data on Attachment 5.

\section{SIGN-OFF}


2.27.2 Inspect OCA lid for the following:

- Visible deformation

- Dents or abnormal flat spots $>1 / 2$ in.

- Abnormal scratches or gouges

- Obvious punctures, tears, or cracks in exposed welds

- $\quad$ Burnout plugs (3) in place and intact

- Lift pocket tubes in place

- Distortions or cracks on or around lifting attachments

- Lift pocket covers attached and serviceable

- $\quad$ OCV locking $Z$ flange screws in place and torque paint unbroken; or, if no torque paint, screws torqued to $22 \mathrm{lb}$-in.

- $\quad$ Guide plates and screws in place and screws torqued to $21 \mathrm{lb}$-in., or no looseness in plate and screws recessed.

- Seal surfaces for scratches/gouges perpendicular to machining marks

2.27.3 Remove foreign material from the following:

- Lock ring flange

- $\quad$ Sealing surfaces

- Test port access threads

2.27.4 Verify arrow above seal test port aligns with UNLOCKED arrow on lock ring.

2.27.5 Initial Attachment 5 to document OCA lid components and hardware are satisfactory.

\section{SIGN-OFF}


2.28 ICV Lid Inspection and Cleaning

\section{NOTE}

O-rings are considered clean when they are absent of free-standing vacuum grease, dirt, debris, and other foreign matter.

2.28.1 RCT, IF survey has NOT been completed previously, THEN survey ICV lid interior and exterior and record applicable data on Attachment 5.

\section{SIGN-OFF}

2.28.2 Inspect ICV lid for the following:

- Visible deformation

- $\quad$ Punctures

- Abnormal scratches or gouges

- Distortions on or around lifting attachments

- Upper spacer and screws installed and torque paint unbroken; or, if no torque paint, screws torqued to $10 \mathrm{lb}$-in.

- Debris shield installed and undamaged

- $\quad$ Lock ring undamaged

- $\quad$ Damaged or missing screws from wiper O-ring holder

- Seal surfaces for scratches/gouges perpendicular to machining marks

2.28.3 Remove foreign material from the following:

- Lock ring flange

- Debris shield

- $\quad$ Sealing surfaces

2.28.4 Remove ICV wiper O-ring.

2.28.5 Clean ICV wiper O-ring and inspect for wear or damage that could impair its function.

2.28.6 IF O-ring is damaged, THEN GO TO corresponding WI and RETURN TO Step 2.28.9.

2.28.7 Lubricate wiper O-ring with a light coat of vacuum grease. 
2.28.8 Install wiper O-ring.

2.28.9 Initial Attachment 5 to document ICV lid, components, and hardware are satisfactory.

\section{SIGN-OFF}

2.29 OCA Body Inspection and Cleaning

2.29.1 RCT, IF survey was NOT completed previously, THEN survey OCA body exterior and ICV body interior and record applicable data on Attachment 5.

\section{SIGN-OFF}

2.29.2 Remove upper and lower main O-rings and set aside for cleaning and inspection.

2.29.3 Inspect OCA body for the following:

- Visible deformation

- Obvious punctures or tears

- Obvious cracks in exposed welds

- Dents or abnormal flat spots $>1 / 2$ in.

- Abnormal scratches or gouges

- $\quad$ Burnout plugs (6) in place and undamaged

- $\quad$ Forklift pocket threaded inserts (8) intact and threads undamaged

- $\quad$ Lock bolt threaded inserts (6) intact and threads undamaged

- $\quad$ Tears or fraying $>1 / 4$ in. on ceramic fiber gasket

- $\quad$ Lock ring stop(s) undamaged

- Upper and lower O-ring grooves and seal surfaces for scratches/gouges perpendicular to machining marks 
2.29.4 Remove foreign material from the following:
- $\quad$ Test port and threads
- Vent port and threads
- Lock ring flange
- $\quad$ Sealing surfaces
- $\quad$ O-ring grooves

2.29.5 Verify airflow through OCV He test ports.

2.29.6 Initial Attachment 5 to document OCA body inspection is satisfactory.

\section{SIGN-OFF}

\subsection{OCA Components Inspection and Cleaning}

\section{NOTE}

O-rings are considered clean when they are absent of free-standing vacuum grease, dirt, debris, and other foreign matter.

2.30.1 Clean and inspect the following for wear or damage that could impair their function:

- OCV vent port cover and O-rings

- $\quad$ OCV vent port access plug

- $\quad$ OCV vent port plug and handling O-ring

- OCV seal test port access plug

- OCV seal test port plug and O-ring

- $\quad$ Lock bolts (6)

2.30.2 IF components are damaged,

THEN GO TO corresponding WI and RETURN TO Step 2.30.4.

2.30.3 Apply a light coat of vacuum grease to the following:

- $\quad$ OCV vent port plug threads

- $\quad$ OCV vent port cover threads and seal O-ring

- $\quad$ OCV seal test port plug threads and seal O-ring

2.30.4 Verify annulus debris seal is installed and undamaged.

2.30.5 Apply a light coat of nickel bearing lubricant to the following:
- $\quad$ OCA lock bolt threads (6)
- OCV seal test port access plug threads
- OCV vent port access plug threads 
2.30.6 Clean upper and lower main O-rings and vent port plug seal O-ring, and inspect for damage that could impair containment integrity.

2.30.7 IF O-rings are damaged,

THEN GO TO corresponding WI and RETURN TO Step 2.30.10.

2.30.8 Lubricate upper and lower main O-rings and vent port plug seal

O-ring with a light coat of vacuum grease.

2.30.9 Install upper and lower main O-rings and vent port plug seal O-ring.

2.30.10 Initial Attachment 5 to document OCA component and hardware inspections are satisfactory.

\section{SIGN-OFF}

\subsection{ICV Body Inspection and Cleaning}

2.31.1 Remove upper and lower main O-rings and set aside for cleaning and inspection.

2.31.2 Inspect ICV body for the following:

- $\quad$ Lock ring stop(s) undamaged

- $\quad$ Lock bolt threaded inserts (3) installed and threads undamaged

2.31.3 Remove foreign material from the following:

- $\quad$ Test port threads

- Vent port threads

- $\quad$ O-ring grooves

- $\quad$ Filter ports

- $\quad$ Sealing surfaces

- Lock ring flange

2.31.4 Inspect the following for deformation, scratches, or burrs:

- Upper and lower O-ring grooves and seal surfaces for scratches/gouges perpendicular to machining marks

- Vent port threads

- $\quad$ Seal test port threads

- Lock ring flange 
- Lower spacer installed with no punctures in top plate

- Lower spacer screws installed and no detectable gap between screw head and spacer top plate

2.31.5 Verify airflow through ICV He test ports.

2.31.6 Initial Attachment 5 to document ICV body inspection is satisfactory.

\section{SIGN-OFF}

2.32 ICV Components Inspection and Cleaning

\section{NOTE}

O-rings are considered clean when they are absent of free-standing vacuum grease, dirt, debris, and other foreign matter.

2.32.1 Clean and inspect the following for wear or damage that could impair their function:
- $\quad$ ICV vent port cover and seal
- ICV outer vent port plug
- $\quad$ ICV inner vent port plug and seal O-ring
- $\quad$ ICV seal test port plug and seal O-ring
- ICV lock bolts (3)

2.32.2 IF components are damaged, THEN GO TO corresponding WI and RETURN TO Step 2.32.4.

2.32.3 Apply a light coat of vacuum grease to the following:

- $\quad$ ICV vent port cover threads (and O-ring if installed)

- $\quad$ ICV outer vent port plug threads

- $\quad$ ICV inner vent port plug threads and seal O-ring

- $\quad$ ICV seal test port plug threads and seal O-ring

2.32.4 Apply a light coat of nickel bearing lubricant to threads of ICV lock bolts (3).

2.32.5 Clean and inspect upper and lower main O-rings and ICV outer vent port plug seal O-ring for damage that could impair containment integrity.

2.32.6 IF O-rings are damaged, THEN GO TO corresponding WI and RETURN TO Step 2.32.9.

2.32.7 Lubricate upper and lower main O-rings and ICV outer vent port plug seal O-ring with a light coat of vacuum grease. 
2.32.8 Install upper and lower main O-rings and ICV outer vent port plug seal O-ring.

2.32.9 Initial Attachment 5 to document ICV components and hardware inspections are satisfactory.

\section{SIGN-OFF}

2.33 ICV Cavity Inspection

2.33.1 Check ICV cavity for water by visually inspecting the absorbent material inserted into hole in lower spacer assembly.

\section{NOTE}

Disposal of absorbent material and water will be at direction of RCT.

2.33.2 IF water is inside ICV, THEN remove water as follows:

- Remove water through center hole of lower spacer assembly using wet/dry vacuum.

- Attach absorbent material to rod and insert in hole in center of lower spacer assembly.

2.33.3 IF water is inside ICV, THEN GO TO Subsection 3.1, perform steps and RETURN TO Step 2.33.4.

2.33.4 Initial Attachment 5 to document ICV is free of water.

\section{SIGN-OFF}

2.33.5 Verify all preshipment inspections are complete and initial Attachment 5.

\section{SIGN-OFF}

\section{NOTE}

If items are loaded into the ICV, the ACGLF may be used with the long or short legs.

\section{NOTE}

If the ACGLF with short legs is used to load items into the ICV, a separate technician shall guide the cables into and out of the ICV to prevent damage to the lower seal flange.

2.33.6 If applicable, load pallets, guide tubes and other items into ICV. 
2.34 ICV Lid Installation

2.34.1 Match ICV lid and body serial numbers.

2.34.2 Record ICV serial number on Attachment 5.

\section{SIGN-OFF}

\section{CAUTION}

Operator shall verify two ACGLF counterweights are at 180 degrees and 000 degrees ( \pm 2 degrees) BEFORE lifting ACGLF or lid.

\subsubsection{Attach ACGLF to ICV lid.}

2.34.4 Align UNLOCKED arrows and install ICV lid onto ICV body using crane and ACGLF.

2.34.5 Install ICV vent port tool into ICV vent port.

2.34.6 Connect vacuum line to ICV vent port tool.

2.34.7 Start vacuum pump and evacuate to 3 to $15 \mathrm{in}$. $\mathrm{Hg}$ vacuum gauge.

2.34.8 Rotate ICV lock ring to LOCKED position.

2.34.9 Stop vacuum pump.

2.34.10 Disconnect vacuum line from vent port tool.

2.34.11 Remove ICV vent port tool.

2.34.12 Let ICV vent to atmosphere.

2.34.13 Install and torque the following components:

- $\quad$ ICV inner vent port plug; torque to 55 to $65 \mathrm{lb}$-in.

- $\quad$ ICV seal test port plug; torque to 55 to $65 \mathrm{lb}$-in.

- $\quad$ OCV seal test port plug; torque to 55 to $65 \mathrm{lb}$-in.

- ICV lock bolts (3); torque to 28 to $32 \mathrm{lb}-\mathrm{ft}$.

2.34.14 Install ICV outer vent port plug; torque to 55 to $65 \mathrm{lb}$-in.

2.34.15 Install ICV vent port cover; torque to 55 to $65 \mathrm{lb}$-in. 
2.34.16 Initial on Attachment 5 that ICV hardware and OCV seal test port plug are torqued within designated range.

\section{SIGN-OFF}

2.35 OCA Lid Installation

2.35.1 Match OCA lid and body serial numbers.

2.35.2 Record OCA serial number on Attachment 5 .

\section{SIGN-OFF}

\section{CAUTION}

Operator shall verify two ACGLF counterweights are at 180 degrees and 000 degrees ( \pm 2 degrees) BEFORE lifting ACGLF or lid.

\subsubsection{Attach ACGLF to OCA lid.}

2.35.4 Align UNLOCKED arrows and install OCA lid onto OCA body.

2.35.5 Install OCV vent port tool into OCV vent port.

2.35.6 Connect vacuum line to OCV vent port tool.

2.35.7 Start vacuum pump and evacuate to 3 to $15 \mathrm{in}$. $\mathrm{Hg}$ vacuum gauge.

2.35.8 Rotate OCV lock ring to LOCKED position.

2.35.9 Stop vacuum pump.

2.35.10 Disconnect vacuum line from vent port tool.

2.35.11 Remove OCV vent port tool.

2.35.12 Let OCV vent to atmosphere.

2.35.13 Install OCV vent port plug; torque to 55 to $65 \mathrm{lb}$-in.

2.35.14 Install OCV vent port cover; torque to 55 to $65 \mathrm{lb}$-in. 
2.35.15 Install the following:

- OCV seal test port thermal plug and access plug; torque access plug to 35 to $45 \mathrm{lb}-\mathrm{ft}$.

- $\quad$ OCV vent port thermal plug and access plug; torque access plug to 35 to $45 \mathrm{lb}-\mathrm{ft}$.

- OCA lock bolts (6); torque to 28 to $32 \mathrm{lb}$-ft.

- OCA lift pocket covers.

2.35.16 Initial on Attachment 5 that OCV/OCA hardware is torqued within designated range.

\section{SIGN-OFF}

2.35.17 Verify preshipment preparations are complete and unit is ready for transport and initial Attachment 5.

\section{SIGN-OFF}

2.35.18 Supervisor, review/validate and sign Attachment 5 .

\section{SIGN-OFF}


2.36 Installation of Packaging onto Transport Trailer

\section{NOTE}

When loading packages on trailer, or loading payload into packaging that is already on trailer, the following applies:

- $\quad$ Packages having a gross weight difference (heaviest to lightest) of $2,000 \mathrm{lb}$ or less can be considered equal and do not require a specific sequence for positioning on the trailer.

- $\quad$ Packages having a gross weight difference (heaviest to lightest), greater than 2,000 lb shall be positioned on the trailer as follows:

\begin{tabular}{|l|l|l|l|l|}
\hline \multirow{4}{*}{$\begin{array}{l}\text { TRAILER } \\
\text { FRONT }\end{array}$} & *1. Heaviest & Medium & Lightest & \\
\cline { 2 - 4 } & 2. Heaviest & Lightest & Medium & \multirow{4}{*}{ TRAILER } \\
\cline { 2 - 4 } & *3. Heaviest & Lightest & None & \\
\cline { 2 - 4 } & 4. Lightest & Heaviest & None & \\
\cline { 2 - 4 } & 5. Heaviest & None & None & \\
\hline
\end{tabular}

* Preferred method

2.36.1 Record the following on Attachment 6, High-Wattage Trailer Data Sheet:

$$
\begin{array}{ll}
\text { - } & \text { Shipment number } \\
\text { - } & \text { Trailer number } \\
\text { Packaging number(s) }
\end{array}
$$

\section{SIGN-OFF}

2.36.2 Verify annual trailer inspection is current.

2.36.3 Record trailer inspection performed date on Attachment 6.

\section{SIGN-OFF}

\section{NOTE}

Additional trailer tie-down guidance is provided in WP 08-PT.04. This document is available on the Internet at http://www.wipp.ws/library/caolib.htm\#containers.

2.36.4 Inspect tie-downs for the following:

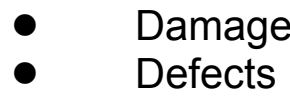


2.36.5 IF TRUPACT-II was removed for unloading operations, THEN perform the following:

[A] Position transport trailer in designated area.

[B ] Lower trailer jacks (landing gear) ensuring trailer is level.

[ C ] Install wheel chocks.

[D ] Install jack stands on freestanding trailers.

\section{CAUTION}

Tip-back beyond level may damage package exterior surface.

[ E ] Transport packaging to transport trailer.

[ F ] Load packaging designated for position \#1 onto trailer with vent port on driver side of trailer.

[ G ] If applicable, load packaging designated for position \#2 onto trailer with vent port on driver side of trailer.

[ $\mathrm{H}$ ] If applicable, load packaging designated for position \#3 onto trailer with vent port on driver side of trailer.

\section{NOTE}

Additional trailer tie-down guidance is provided in WP 08-PT.04. This document is available on the Internet at http://www.wipp.ws/library/caolib.htm\#containers.

[ I ] Install four tie-down assemblies for each packaging loaded on trailer.

[ J ] Install packaging forklift pocket access covers.

2.36.6 Record packaging serial number(s) and weights on Attachment 6 .

\section{SIGN-OFF}

2.36.7 Record total weight of all loaded packaging as payload weight on Attachment 6.

\section{SIGN-OFF}


2.36.8 Verify shipment is in compliance with 49 CFR Part 172, Subpart D and Subpart E, and initial Attachment 6.

\section{SIGN-OFF}

2.36.9 Complete information transfer to shipping documents as required for the specific shipment.

2.36.10 Verify shipping papers are complete, and initial Attachment 6.

\section{SIGN-OFF}

2.36.11 Initial for trailer loading complete on Attachment 6 .

\section{SIGN-OFF}

2.36.12 Supervisor, review/validate entries and sign Attachment 6.

\section{SIGN-OFF}


Figure 2.1 - Evacuation/Inert Gas Backfill

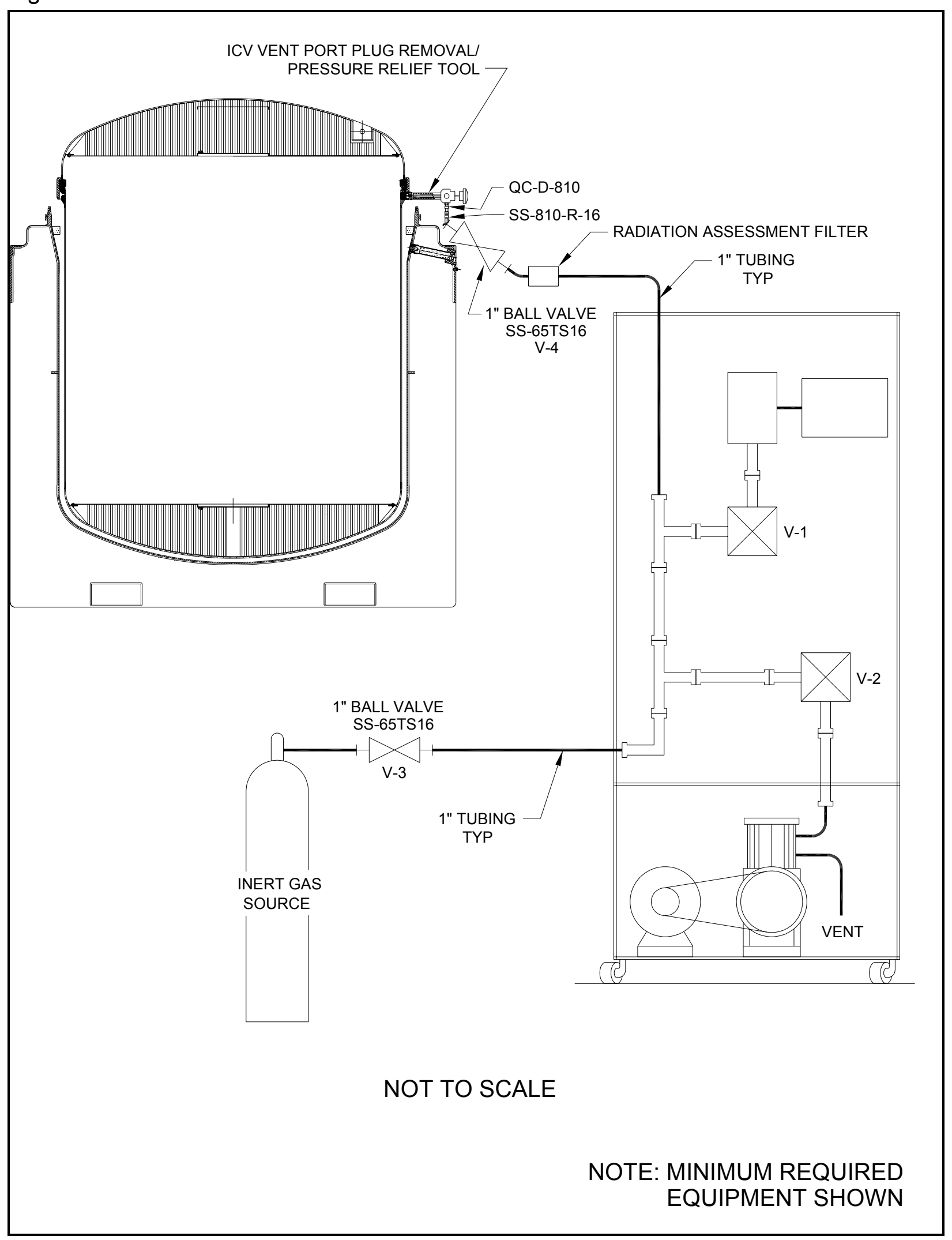




\subsection{ABNORMAL OPERATIONS}

\section{NOTE}

WIPP Packaging Maintenance Engineer shall be contacted when performing Sections 3.1, 3.2, or 3.3.

3.1 Empty ICV Assembly Removal - (if water found in ICV or annual maintenance only)

3.1.1 Verify ICV lid has been installed and locked.

3.1.2 Mark ICV and OCA with match lines using a low-chloride marker. (These marks will be used to orient the ICV in the OCV during reinstallation.)

\section{CAUTION}

Operator shall verify two ACGLF counterweights are at 180 degrees and 000 ( \pm 2 degrees) degrees respectively.

\subsubsection{Attach ACGLF to ICV lid.}

3.1.4 If annulus debris seal is present, remove and set aside for later use.

\section{CAUTION}

Load cell reading MUST NOT exceed $5,000 \mathrm{lb}$ when weight of ACGLF is zeroed out, OR 7,500 lb when weight of ACGLF is included.

3.1.5 Remove empty ICV assembly from OCV body using crane and ACGLF.

\section{NOTE}

If required by site-specific policy to ensure personnel safety, RCT shall survey OCV interior for radiation/contamination BEFORE initiating OCV inspection process.

3.1.6 Inspect visually for presence of water in bottom of OCV.

3.1.7 If freestanding water is NOT observed in bottom of OCV body, GO TO Step 3.1.11. 


\section{CAUTION}

Operator shall obtain protective clothing and equipment in accordance with site Safety Manual before entering OCV cavity. Operator also shall enter the OCV cavity using precautions to preclude damage to OCV body sealing flange.

3.1.8 Use wet/dry vacuum and/or absorbent materials to remove freestanding water.

\section{NOTE}

Cleaning and waste materials shall be managed according to site waste management procedures.

3.1.9 Remove equipment and exit OCV cavity using precautions not to damage OCV body sealing flange.

3.1.10 Verify OCV is free of standing water.

\section{CAUTION}

Operator shall verify two ACGLF counterweights are at 180 degrees and 000 ( \pm 2 degrees) degrees respectively.

\section{NOTE}

When Step 3.1.11 is complete, ICV vent port should be within $1 \mathrm{ft}$ of OCV vent port and the ICV should be sitting vertically within the OCV (i.e., not leaning to the side).

3.1.11 Reinstall ICV assembly into OCV body using crane and ACGLF.

3.1.12 If annulus debris seal was removed in Step 3.1.4, reinstall annulus debris seal.

3.2 Using Heat Guns to Remove Stuck Lids

3.2.1 Heat ICV or OCV lid O-rings (as necessary) for up to 1 hour using heat guns. 


\section{CAUTION}

Operator shall verify two ACGLF counterweights are at 180 degrees and 000 ( \pm 2 degrees) degrees respectively.

\section{CAUTION}

When lifting ICV lid, load cell reading MUST NOT exceed 5,000 lb when weight of ACGLF is zeroed out, OR $7,500 \mathrm{lb}$ when weight of ACGLF is included.

\section{CAUTION}

When lifting OCA lid, load cell reading MUST NOT exceed 7,500 lb when weight of ACGLF is zeroed out, OR $10,000 \mathrm{lb}$ when weight of ACGLF is included.

3.2.2 Attempt to raise lid using the slowest possible speed.

3.2.3 Raise lid as directed by RCT and RETURN TO normal operations.

3.3 Pressurizing with Nitrogen or Compressed Air to Remove Stuck Lids

3.3.1 Obtain the following:

- $\quad$ Nitrogen bottle with $\geq 500 \mathrm{lb}$ pressure or other air source capable of being regulated in 1-psi increments

- $\quad$ Pressure Assembly (Figure 3.1, Flow Diagram for Nitrogen Bottle/Compressed Air ICV/OCA Lid Pressurization)

- If not already installed, ICV/OCV vent port tools, as applicable

3.3.2 Perform the following for compressed air or nitrogen:

[ A ] Assemble Pressure Assembly (see Figure 3.1 for example of a pressure assembly).

[B ] If not already installed, install vent port tool hand-tight.

[ C ] Connect Pressure Assembly to quick disconnect on vent port tool. 
[D] Close valve V-1.

[ E ] Close valve V-2.

[ F ] Verify supply valve is closed.

[ G ] Verify back pressure relief valve is fully backed-off.

[ $\mathrm{H}$ ] Verify pressure regulator is fully backed off.

[ I ] Connect supply line and regulator to nitrogen-bottle or compressed air source.

[ J ] Open supply valve and adjust $\mathrm{N}_{2}$ or air supply regulator to a maximum of 150 psig.

[K] Adjust R1 to about 2.1 psig.

[ L ] Adjust R2 until it begins to relieve pressure.

[ M ] Adjust R1 to fully backed off.

[N] Bleed briefly through $\mathrm{V}-1$.

[O ] Adjust R1 to about 1 psig.

3.3.3 Verify counterweights are at 180 degrees and 000 degrees. 


\section{WARNING}

The ICV or OCV should not be pressurized above 2 psi to avoid personnel injury. A loaded ICV MUST NOT be pressurized unless precautions are taken to prevent possible contamination when lid is raised.

\section{CAUTION}

When lifting ICV lid, load cell reading MUST NOT exceed 5,000 lb when weight of ACGLF is zeroed out, OR 7,500 lb when weight of ACGLF is included.

\section{CAUTION}

When lifting OCV lid, load cell reading MUST NOT exceed 7,500 lb when weight of ACGLF is zeroed out, OR $10,000 \mathrm{lb}$ when weight of ACGLF is included.

3.3.4 Attempt to lift lid using crane at the slowest rate possible while monitoring load cell.

3.3.5 Perform the following while attempting to lift lid with crane:

[A ] Throttle valve V-2, keeping pressure $\leq 2$ psi.

[B ] When lid becomes loose, close V-2.

[ C ] Close supply valve.

[D ] Open V-1 to depressurize assembly.

[E ] Disconnect supply line from pressure assembly.

[ F ] Disconnect pressure assembly from vent port tool.

[ G ] Disconnect vent port tool and survey tool if applicable.

[ H ] Disconnect supply line and regulator from nitrogen bottle or compressed air source.

3.3.6 Raise lid as directed by RCT AND continue with normal operations. 
3.3.7 IF after pressurizing to 2 psi lid still does not lift, THEN contact the WIPP M\&O Contractor $\mathrm{CH}$ Packaging Maintenance Engineer.

3.4 Venting

\section{NOTE}

In the event a sealed package cannot be shipped within the time frame set forth in the TRUPACT-II Packaging SAR, the package must be vented.

3.4.1 IF venting is required, THEN perform applicable Subsections 2.23, OCA Lid Removal; and 2.24, ICV Lid Removal.

3.4.2 Wait three minutes.

3.4.3 GO TO Subsection 2.17, reinstall lids using Subsections 2.17 and 2.19. 
Figure 3.1 - Flow Diagram for Nitrogen Bottle/Compressed Air ICV/OCA Lid Pressurization

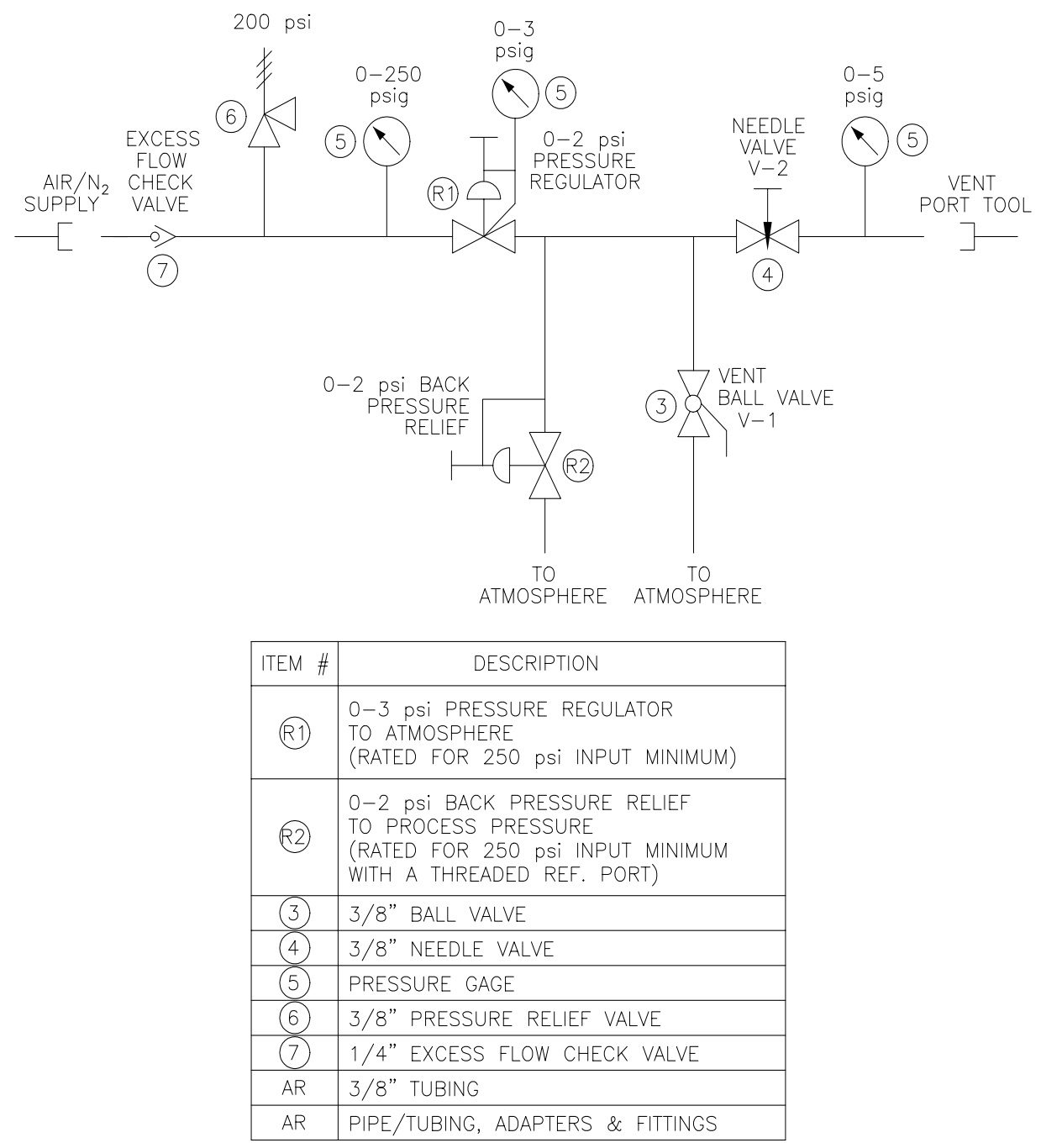




\subsection{PRESHIPMENT LEAKAGE RATE TESTING}

\subsection{Basic Information}

4.1.1 Introduction - This procedure provides instructions for performing ICV and OCV preshipment leakage rate tests on the following packaging seals, using a nondestructive He leak test:

- $\quad$ ICV upper main O-ring seal

- $\quad$ ICV outer vent port plug seal O-ring

- OCV upper main O-ring seal

- $\quad$ OCV vent port plug seal O-ring

\subsubsection{References}

- U.S. Department of Energy, Safety Analysis Report for the TRUPACT-II Shipping Package

- DOE/WIPP 02-3183, CH Packaging Program Guidance

- DOE/WIPP 02-3185, CH Packaging Maintenance Manual

- $\quad$ ANSI N 14.5, 1997, Radioactive Materials Leakage Tests on Packages for Shipment

- ASNT, Recommended Practice No. SNT-TC-1A, June 1980

- $\quad$ WP 13-RP.01, Test Report for WP 13-QA1082 Procedure Qualification

\subsubsection{Equipment}

\section{MEASURING AND TEST EQUIPMENT}

- Varian 938-41 or 959 Helium Leak Detector with 7 to $14 \mathrm{cfm}$ mechanical vacuum pump

- $\quad$ Roughing pump

- He leak standard for calibrating leak detector

- $\quad$ Pressure/vacuum gauge, $30-\mathrm{in}$. $\mathrm{Hg}$ to $30 \mathrm{psig}$

- Temperature measuring device, $32^{\circ} \mathrm{F}$ to $120^{\circ} \mathrm{F}$ $\left(0^{\circ} \mathrm{C}\right.$ to $\left.50^{\circ} \mathrm{C}\right)$

- Ambient atmospheric pressure measuring device 
- Watch or stopwatch, digital or sweep second hand (no calibration required)

- Torque wrench with 10 to $65 \mathrm{lb}$-in range

- Torque wrench with 30 to $50 \mathrm{lb}$-ft range

SPECIAL TEST EQUIPMENT

- $\quad I C V / O C V$ vent port plug removal/pressure relief tools

- $\quad$ ICV/OCV vent port plug/cover removal and installation tools

- ICV/OCV seal leak check tools

- ICV/OCV leak detection tools

- Miscellaneous hardware and test connections

\section{CONSUMABLE MATERIALS}

- Welding grade $\mathrm{He}$ (with certificate of conformance)

- $\quad$ Argon or nitrogen (purge gas)

\subsubsection{Precautions and Limitations}

The following leak test procedure may be used, or each user may develop and qualify a procedure in accordance with the guidelines of ANSI N14.5, 1997. Sites that opt to qualify their own leak test procedure must submit procedure qualification record and procedure to Site Documents@wipp.ws, for approval.

- Leak testing of $\mathrm{CH}$ packaging shall be performed by personnel qualified in accordance with the American Society for Nondestructive Testing Practice No. SNT-TC-1A, June 1980 edition and supplement.

- $\quad$ This procedure is qualified per WP 13-RP.01, Test Report for WP 13-QA1082 Procedure Qualification for the Varian 938-41 and 959 MSLD and test line configuration defined in that report. $\mathrm{CH}$ packaging users adopting this leak test must not deviate from the test configuration(s) used to qualify the procedure.

- $\quad$ The He leak detector shall be calibrated to a minimum sensitivity of $1.3 \times 10^{-7}$ standard cubic centimeters per second (scc/s) He. 
The leakage rate acceptance criteria of $\leq 1.0 \times 10^{-7} \mathrm{scc} / \mathrm{s}$ of air equates to a leakage rate of $\leq 2.6 \times 10^{-7} \mathrm{scc} / \mathrm{s} \mathrm{He}$. The He leakage rate is only valid for a component of $\geq 4.4^{\circ} \mathrm{C}$. The acceptable He leakage rate increases with temperature, but as a conservative measure, an acceptance criteria of $\leq 2.6 \times 10^{-7} \mathrm{scc} / \mathrm{s}$ He will be used.

\subsubsection{Prerequisite Actions}

- Verify air flow through leak check and leak detection tools.

- Verify packaging surface is free of contaminates that might mask a leak. The interior and exterior surfaces shall be dry.

\subsection{ICV Upper Main O-Ring Seal}

4.2.1 Record the following on Attachment 7, ICV Preshipment LeakageRate Test Data Sheet:

- $\quad$ ICV body serial number $(\mathrm{S} / \mathrm{N})$

- ICV lid S/N

- Date of leak test

- He leak detector $\mathrm{S} / \mathrm{N}$ and model

- Pressure/vacuum gauge $S / N$ and calibration due date

- Thermometer $\mathrm{S} / \mathrm{N}$ and calibration due date

- Torque wrench $\mathrm{S} / \mathrm{Ns}$ and calibration due dates

- $\quad$ Standard leak $\mathrm{S} / \mathrm{N}$ and calibration due date

- $\quad$ Barometer S/N and calibration due date

- He source connected to backfill system

\section{SIGN-OFF}

\section{NOTE}

Steps 4.2.15 through 4.2.19 may be performed in parallel with Steps 4.2.2 through 4.2.14.

4.2.2 Measure ICV surface temperature.

4.2.3 If temperature is less than $4.4^{\circ} \mathrm{C}$, stop test until surface temperature $\geq 4.4^{\circ} \mathrm{C}$.

4.2.4 Record ICV surface temperature on Attachment 7.

\section{SIGN-OFF}

4.2.5 Verify outer vent port plug is retracted into ICV vent port plug removal/pressure relief tool. 
4.2.6 Install ICV vent port tool into ICV vent port.

4.2.7 Attach vacuum pump assembly and He gas supply to vent port tool (see Figure 4.1, ICV Main O-Ring Seal Test).

4.2.8 Open isolation valve to vacuum pump.

4.2.9 Start vacuum pump.

4.2.10 Record ambient atmospheric pressure (Patm) on Attachment 7.

\section{SIGN-OFF}

4.2.11 Evacuate ICV vent port cavity to $90 \%$ vacuum $(90 \%$ of atmospheric pressure) or better.

4.2.12 Record vacuum reading (V1) on Attachment 7.

\section{SIGN-OFF}

4.2.13 Calculate He concentration correction factor (CCF) as follows:

$$
\mathrm{CCF}=\frac{\mathrm{Patm}}{\mathrm{V} 1}
$$

\subsubsection{Record CCF on Attachment 7.}

\section{SIGN-OFF}

4.2.15 Perform pretest calibration of leak detector (to the temperaturecorrected standard leak value) and record results on Attachment 7.

\section{SIGN-OFF}

4.2.16 Install ICV seal leak check tool in ICV seal test port.

4.2.17 Connect leak detector to ICV leak check tool (see Figure 4.1).

4.2.18 Verify isolation valve open.

4.2.19 Evacuate space between O-ring seals through ICV seal test port.

4.2.20 Close vacuum pump isolation valve AND stop vacuum pump. 


\section{NOTE}

To measure $\mathrm{a} \leq 2.6 \times 10^{-7} \mathrm{scc} / \mathrm{s} \mathrm{He}$ leakage rate, the indicated $\mathrm{He}$ background will be allowed to stabilize at $7 \times 10^{-7} \mathrm{scc} / \mathrm{s} \mathrm{He}$ or less and remain below the limit for a minimum of 3 minutes.

\subsubsection{Record He background (RB) on Attachment 7 .}

\section{SIGN-OFF}

4.2.22 Open He valve and backfill cavity with $\mathrm{He}$ to a pressure slightly greater than atmospheric pressure (+1 psi, $-0 \mathrm{psi})$.

4.2.23 Close He valve.

4.2.24 Record backfill pressure reading on Attachment 7 .

\section{SIGN-OFF}

4.2.25 Begin timing for 3-minute dwell time.

4.2.26 Monitor pressure gauge and add $\mathrm{He}$ as required to maintain $\mathrm{He}$ atmosphere in the cavity.

\section{NOTE}

A dwell time of 3 minutes will be used to determine leakage rate of ICV upper main O-ring seal.

4.2.27 Record displayed He reading (RT) after 3-minute dwell time on Attachment 7.

\section{SIGN-OFF}

\section{NOTE}

Steps 4.3.1 through 4.3.6 may be performed in parallel with Steps 4.2.28 through 4.2.35.

4.2.28 Remove test assembly from leak detector.

4.2.29 Install calibrated leak to leak detector.

4.2.30 Perform post-test calibration deviation check of leak detector and record results on Attachment 7.

\section{SIGN-OFF}

4.2.31 Calculate the ICV upper main O-ring seal leakage rate using the correct condition below and record on Attachment 7: 


\section{NOTE}

If the He background (RB) is greater than the displayed He reading at the end of dwell time (RT), the value of (RT) will be substituted for the value of (RB) when performing leak rate calculations. If condition [ $C$ ] applies, and this note is applicable to that condition (ending up with a negative number), zero will be used as the leakage rate.

\section{NOTE}

The difference between displayed He reading (DR) with standard leak installed, including Zero Reading Variance (if applicable) and Temperature Correction Value (TC), is used to determine post-test calibration deviation. Additional guidance is provided in DOE/WIPP 02-3183, Section 4.2.9.

[A] If there is no difference in the Temperature Correction Value (TC) from the displayed He reading with standard leak installed (DR), use the following equation: subtract the He background at the start of test (RB) from the displayed $\mathrm{He}$ reading at end of test (RT). The leakage rate is $(R T-R B) \times C C F$. This equals the leakage rate for this segment of the test.

[B ] If Temperature Correction Value (TC) is LESS than the displayed $\mathrm{He}$ reading with standard leak installed (DR), use the following calculation: (RT + calibration deviation $R B) \times C C F$. This equals the leakage rate for this segment of the test under this condition of recalibration.

[ C ] If Temperature Correction Value (TC) is MORE than the displayed He reading with standard leak installed (DR), use the following calculation: (RT - calibration deviation $\mathrm{RB}) \times \mathrm{CCF}$. This equals the leakage rate for this segment of the test under this condition of recalibration.

\section{SIGN-OFF}

4.2.32 If the acceptance criterion is satisfied $\left(\leq 2.6 \times 10^{-7} \mathrm{scc} / \mathrm{s}\right.$ of $\left.\mathrm{He}\right)$, this segment of the test procedure is complete. 


\section{NOTE}

The leakage rate acceptance criterion is $\leq 2.6 \times 10^{-7} \mathrm{scc} / \mathrm{s} \mathrm{He}$.

4.2.33 IF ICV upper main O-ring seal leakage rate is $>2.6 \times 10^{-7} \mathrm{scc} / \mathrm{s} \mathrm{He}$, THEN perform the following:

[A] Isolate leak path.

[ B ] GO TO WI-CH.02, replace O-ring seal(s) and/or repair seal surface(s) per WI-CH.12; repeat leak test.

[ C ] If after repeated testing it is apparent the seal cannot pass the test, prepare nonconformance report (NCR) and record on Attachment 7.

\section{SIGN-OFF}

4.2.34 Remove ICV seal leak check tool and associated leak test equipment from ICV seal test port.

4.2.35 Install ICV seal test port plug.

4.2.36 Torque ICV seal test port plug to 55 to $65 \mathrm{lb}$-in. and record on Attachment 7.

\section{SIGN-OFF}

\subsection{ICV Outer Vent Port Plug Seal O-Ring}

\section{NOTE}

The following test should be performed immediately after Subsection 4.2, ICV Upper Main O-Ring Seal, while the He atmosphere is still present in the ICV vent port cavity and to minimize He saturation of O-rings before test completion.

4.3.1 Disconnect vacuum pump assembly and He supply from ICV vent port tool.

4.3.2 Install ICV outer vent port plug.

4.3.3 Remove vent port tool.

4.3.4 Torque ICV outer vent port plug to 55 to $65 \mathrm{lb}$-in and record on Attachment 7.

\section{SIGN-OFF}

4.3.5 Purge vent port to flush out residual He. 
4.3.6 Install a clean ICV leak detection tool in ICV vent port.

\section{NOTE}

If Step 4.3.7 begins within 1 hour of completing the ICV upper main O-ring seal leak test, THEN the pretest calibration is not required. The post-test calibration result can be used for the ICV outer vent port plug O-ring seal pretest calibration, provided no post-test calibration deviation was recorded.

4.3.7 Perform pretest calibration of leak detector (to the temperaturecorrected standard leak value).

4.3.8 Record pretest calibration results on Attachment 7.

\section{SIGN-OFF}

4.3.9 Connect leak detector to ICV leak detection tool (see Figure 4.2, ICV Outer Vent Port Plug Seal O-Ring Test).

4.3.10 Verify isolation valve is OPEN.

4.3.11 Evacuate ICV leak detection tool.

\section{NOTE}

To measure $\mathrm{a} \leq 2.6 \times 10^{-7} \mathrm{scc} / \mathrm{s}$ He leakage rate with a He atmosphere already present, indicated $\mathrm{He}$ background will be $\leq 2.6 \times 10^{-7} \mathrm{scc} / \mathrm{s} \mathrm{He}$ BEFORE the start of the dwell time.

Dwell time for ICV outer vent port plug seal O-ring test is 3 minutes. An initial indication does NOT necessarily indicate a leak. Some residual He may still be detected.

4.3.12 Record displayed He reading (RT) after 3-minute dwell time on Attachment 7.

\section{SIGN-OFF}

4.3.13 Remove test assembly from leak detector.

4.3.14 Install calibrated leak to leak detector.

4.3.15 Perform post-test calibration deviation check of leak detector and record results on Attachment 7.

\section{SIGN-OFF}

4.3.16 Calculate ICV outer vent port plug seal O-ring leakage rate using the appropriate condition below and record on Attachment 7: 


\section{NOTE}

The difference between displayed He reading (DR) with standard leak installed, including Zero Reading Variance (if applicable) and Temperature Correction Value (TC), is used to determine post-test calibration deviation. Additional guidance is provided in DOE/WIPP 02-3183, Section 4.2.9.

[A ] If there is no difference in the Temperature Correction Value (TC) from the displayed He reading with standard leak installed (DR), the displayed He reading at end of test $(R T) \times C C F$ equals the leakage rate for this segment of the test.

[ B ] If Temperature Correction Value (TC) is LESS than the displayed $\mathrm{He}$ reading with standard leak installed (DR), use the following calculation: (RT + calibration deviation) $\times$ CCF. This equals the leakage rate for this segment of the test under this condition of recalibration.

[ C ] If Temperature Correction Value (TC) is MORE than the displayed He reading with standard leak installed (DR), use the following calculation: (RT - calibration deviation) $\times$ CCF. This equals the leakage rate for this segment of the test under this condition of recalibration.

\section{SIGN-OFF}

4.3.17 If the acceptance criterion is satisfied $\left(\leq 2.6 \times 10^{-7} \mathrm{scc} / \mathrm{s}\right.$ of $\left.\mathrm{He}\right)$, this segment of the test procedure is complete.

\section{NOTE}

The leakage rate acceptance criterion is $\leq 2.6 \times 10^{-7} \mathrm{scc} / \mathrm{s} \mathrm{He}$.

4.3.18 IF ICV outer vent port plug seal O-ring leakage rate is $>2.6 \times 10^{-7} \mathrm{scc} / \mathrm{s} \mathrm{He}$,

THEN perform the following:

[A ] Isolate leak path.

[ B ] GO TO WI-CH.01, replace O-ring seal(s) and/or repair seal surface(s) per WI-CH.12, repeat leak test.

[ C ] If after repeated testing it is apparent the seal cannot pass test, prepare NCR and record on Attachment 7.

\section{SIGN-OFF}

4.3.19 Remove ICV leak detection tool from ICV vent port. 
4.3.20 Install ICV vent port cover.

4.3.21 Torque ICV vent port cover to 55 to $65 \mathrm{lb}$-in. and initial Attachment 7.

\section{SIGN-OFF}

\subsubsection{RETURN TO Step 2.18.18.}

\subsection{OCV Upper Main O-Ring Seal}

4.4.1 Record the following on Attachment 8, OCV Preshipment Leakage Rate Test Data Sheet:

- OCV body S/N

- OCV lid S/N

- Date of leak test

- He leak detector S/N and model

- $\quad$ Pressure/vacuum gauge S/N and calibration due date

- Thermometer S/N and calibration due date

- $\quad$ Torque wrench S/Ns and calibration due dates

- Standard leak S/N and calibration due date

- Barometer S/N and calibration due date

- He source connected to backfill system

\section{SIGN-OFF}

\section{NOTE}

Steps 4.4.12 through 4.4.17 may be performed in parallel with Steps 4.4.2 through 4.4.11.

4.4.2 Measure OCV surface temperature and record on Attachment 8.

\section{SIGN-OFF}

4.4.3 If temperature is less than $4.4^{\circ} \mathrm{C}$, stop test until surface temperature $\geq 4.4^{\circ} \mathrm{C}$.

4.4.4 Attach vacuum pump assembly and He gas supply to vent port tool (see Figure 4.3).

4.4.5 Open isolation valve to vacuum pump.

4.4.6 Start vacuum pump.

4.4.7 Record ambient atmospheric pressure (Patm) on Attachment 8. 
4.4.8 Evacuate OCV cavity to $90 \%$ vacuum ( $90 \%$ of atmospheric pressure) or better.

4.4.9 Record vacuum reading (V1) on Attachment 8.

\section{SIGN-OFF}

4.4.10 Calculate He concentration correction factor as follows:

$$
\mathrm{CCF}=\frac{\text { Patm }}{\mathrm{V} 1}
$$

\subsubsection{Record CCF on Attachment 8.}

\section{SIGN-OFF}

4.4.12 Perform pretest calibration of leak detector (to the temperaturecorrected standard leak value).

4.4.13 Record pretest calibration results on Attachment 8.

\section{SIGN-OFF}

4.4.14 Install OCV seal leak check tool in OCV seal test port.

4.4.15 Connect leak detector to OCV leak check tool (see Figure 4.3, OCV Main O-Ring Seal Test).

4.4.16 Verify isolation valve open.

4.4.17 Evacuate space between O-ring seals through OCV seal test port.

4.4.18 Close vacuum pump isolation valve AND stop vacuum pump.

\section{NOTE}

To measure a $2.6 \times 10^{-7} \mathrm{scc} / \mathrm{s}$ He leakage rate, the indicated $\mathrm{He}$ background will be allowed to stabilize at $\leq 7 \times 10^{-7} \mathrm{scc} / \mathrm{s} \mathrm{He}$ and remain below the limit for a minimum of 3 minutes.

4.4.19 Record He background (RB) on Attachment 8.

\section{SIGN-OFF}

4.4.20 Open He valve and backfill OCV cavity with He to a pressure slightly greater than atmospheric pressure (+1 psi, $-0 \mathrm{psi})$.

4.4.21 Close He valve. 
4.4.22 Record backfill pressure reading on Attachment 8 .

\section{SIGN-OFF}

4.4.23 Begin timing for 3-minute dwell time.

4.4.24 Monitor pressure gauge and add $\mathrm{He}$ as required to maintain $\mathrm{He}$ atmosphere in the cavity.

\section{NOTE}

A dwell time of 3 minutes will be used to determine leakage rate of OCV upper main O-ring seal.

4.4.25 Record displayed He reading (RT) after 3-minute dwell time on Attachment 8.

\section{SIGN-OFF}

\section{NOTE}

Steps 4.5.1 through 4.5.6 may be performed in parallel with Steps 4.4.26 through 4.4.34.

4.4.26 Remove test assembly from leak detector.

4.4.27 Install calibrated leak to leak detector.

4.4.28 Perform post-test calibration deviation check of leak detector and record results on Attachment 8.

\section{SIGN-OFF}

4.4.29 Calculate OCV main O-ring seal leakage rate using the appropriate condition below and record on Attachment 8: 


\section{NOTE}

If the He background (RB) is greater than the displayed He reading at the end of dwell time (RT), the value of (RT) will be substituted for the value of (RB) when performing leak rate calculations. If condition [ $C$ ] applies, and this note is applicable to that condition (ending up with a negative number), zero will be used as the leakage rate.

\section{NOTE}

The difference between displayed He reading (DR) with standard leak installed, including Zero Reading Variance (if applicable) and Temperature Correction Value (TC), is used to determine post-test calibration deviation. Additional guidance is provided in DOE/WIPP 02-3183, Section 4.2.9.

[A] If there is no difference in the Temperature Correction Value (TC) from the displayed He reading with standard leak installed (DR), use the following equation: subtract the He background at the start of test (RB) from the displayed $\mathrm{He}$ reading at end of test (RT). The leakage rate is $(R T-R B) \times C C F$. This equals the leakage rate for this segment of the test.

[B ] If Temperature Correction Value (TC) is LESS than the displayed $\mathrm{He}$ reading with standard leak installed (DR), use the following calculation: (RT + calibration deviation $\mathrm{RB}) \times \mathrm{CCF}$. This equals the leakage rate for this segment of the test under this condition of recalibration.

[ C ] If Temperature Correction Value (TC) is MORE than the displayed He reading with standard leak installed (DR), use the following calculation: (RT - calibration deviation $\mathrm{RB}) \times \mathrm{CCF}$. This equals the leakage rate for this segment of the test under this condition of recalibration.

\section{SIGN-OFF}

4.4.30 If acceptance criterion is satisfied $\left(\leq 2.6 \times 10^{-7} \mathrm{scc} / \mathrm{s}\right.$ of $\left.\mathrm{He}\right)$, this segment of the test procedure is complete. 


\section{NOTE}

The leakage rate acceptance criterion is $\leq 2.6 \times 10^{-7} \mathrm{scc} / \mathrm{s} \mathrm{He}$.

4.4.31 IF OCV main O-ring seal leakage rate is $>2.6 \times 10^{-7} \mathrm{scc} / \mathrm{s} \mathrm{He}$, THEN perform the following:

[A] Isolate leak path.

[ B ] GO TO WI-CH.02, replace O-ring seal(s) and/or repair seal surface(s) per WI-CH.12, and repeat leak test.

[ C ] If after repeated testing it is apparent the seal cannot pass test, prepare NCR and record on Attachment 8.

\section{SIGN-OFF}

4.4.32 Remove OCV seal leak check tool and associated leak test equipment from OCV seal test port.

4.4.33 Install OCV seal test port plug.

4.4.34 Torque OCV seal test port plug to 55 to $65 \mathrm{lb}$-in and record on Attachment 8.

\section{SIGN-OFF}

\subsection{OCV Vent Port Plug Seal O-Ring}

\section{NOTE}

The following test should be performed immediately after Subsection 4.4, OCV Upper Main O-Ring Seal, while the He atmosphere is still present in the OCV cavity and to minimize He saturation of the O-rings before test completion.

4.5.1 Disconnect vacuum pump assembly and He supply from OCV vent port tool.

4.5.2 Install OCV vent port plug.

4.5.3 Remove vent port tool.

4.5.4 Torque OCV vent port plug to 55 to $65 \mathrm{lb}$-in. and record on Attachment 8.

\section{SIGN-OFF}

4.5.5 Purge vent port to flush out residual He. 
4.5.6 Install a clean OCV leak detection tool in OCV vent port.

\section{NOTE}

If Step 4.5.7 begins within 1 hour of completing the OCV upper main O-ring seal leak test, THEN the pretest calibration is not required. The post-test calibration result can be used for the OCV outer vent port plug O-ring seal pretest calibration, provided no post-test calibration deviation was recorded.

4.5.7 Perform pretest calibration of leak detector (to the temperaturecorrected standard leak value).

4.5.8 Record pretest calibration results on Attachment 8.

\section{SIGN-OFF}

4.5.9 Connect leak detector to OCV leak detection tool (see Figure 4.4, OCV Vent Port Plug O-Ring Seal Test).

4.5.10 Verify isolation valve is OPEN.

4.5.11 Evacuate OCV leak detection tool.

\section{NOTE}

To measure $\mathrm{a} \leq 2.6 \times 10^{-7} \mathrm{scc} / \mathrm{s}$ He leakage rate with a He atmosphere already present, the indicated He background will be $\leq 2.6 \times 10^{-7} \mathrm{scc} / \mathrm{s} \mathrm{He}$ before the start of the dwell time.

Dwell time for OCV vent port plug seal O-ring test is 3 minutes. An initial indication does NOT necessarily indicate a leak. Some residual He may still be detected.

4.5.12 Record displayed He reading (RT) after 3-minute dwell time on Attachment 8.

\section{SIGN-OFF}

4.5.13 Remove test assembly from leak detector.

4.5.14 Install calibrated leak to leak detector.

4.5.15 Perform post-test calibration deviation check of leak detector and record results on Attachment 8.

\section{SIGN-OFF}


4.5.16 Calculate OCV vent port plug seal O-ring leakage rate using the appropriate condition below and record on Attachment 8:

\section{NOTE}

The difference between displayed He reading (DR) with standard leak installed, including Zero Reading Variance (if applicable) and Temperature Correction Value (TC), is used to determine post-test calibration deviation. Additional guidance is provided in DOE/WIPP 02-3183, Section 4.2.9.

[A] If there is no difference in the Temperature Correction Value (TC) from the displayed He reading with standard leak installed (DR), the displayed He reading at end of test $(\mathrm{RT}) \times \mathrm{CCF}$ equals the leakage rate for this segment of the test.

[B ] If Temperature Correction Value (TC) is LESS than the displayed He reading with standard leak installed (DR), use the following calculation: (RT + calibration deviation) $\times$ CCF. This equals the leakage rate for this segment of the test under this condition of recalibration.

[ C ] If Temperature Correction Value (TC) is MORE than the displayed $\mathrm{He}$ reading with standard leak installed (DR), use the following calculation: (RT - calibration deviation) $\times$ CCF. This equals the leakage rate for this segment of the test under this condition of recalibration.

\section{SIGN-OFF}

4.5.17 If acceptance criterion is satisfied $\left(\leq 2.6 \times 10^{-7} \mathrm{scc} / \mathrm{s}\right.$ of $\left.\mathrm{He}\right)$, this segment of the test procedure is complete.

\section{NOTE}

The leakage rate acceptance criterion is $\leq 2.6 \times 10^{-7} \mathrm{scc} / \mathrm{s} \mathrm{He}$.

4.5.18 IF OCV vent port plug seal O-ring leakage rate is

$>2.6 \times 10^{-7} \mathrm{scc} / \mathrm{s} \mathrm{He}$,

THEN perform the following:

[A ] Isolate leak path.

[ B ] GO TO WI-CH.01, replace O-ring seal(s) and/or repair seal surface(s) per WI-CH.12, and repeat leak test.

[ C ] If after repeated testing it is apparent the seal cannot pass test, prepare NCR and record on Attachment 8. 
4.5.19 Remove OCV leak detection tool from OCV vent port.

4.5.20 Install OCV vent port cover.

4.5.21 Torque OCV vent port cover to 55 to $65 \mathrm{lb}$-in. and record on Attachment 8.

\section{SIGN-OFF}

4.5.22 Install OCV seal test port thermal plug and access plug.

4.5.23 Torque OCV seal test port access plug to 35 to $45 \mathrm{lb}-\mathrm{ft}$ and record on Attachment 8.

\section{SIGN-OFF}

4.5.24 Install OCV vent port thermal plug and access plug.

4.5.25 Torque OCV vent port access plug to 35 to $45 \mathrm{lb}$-ft and record on Attachment 8.

\section{SIGN-OFF}

4.5.26 RETURN TO Step 2.19.14. 
Figure 4.1 - ICV Main O-Ring Seal Test

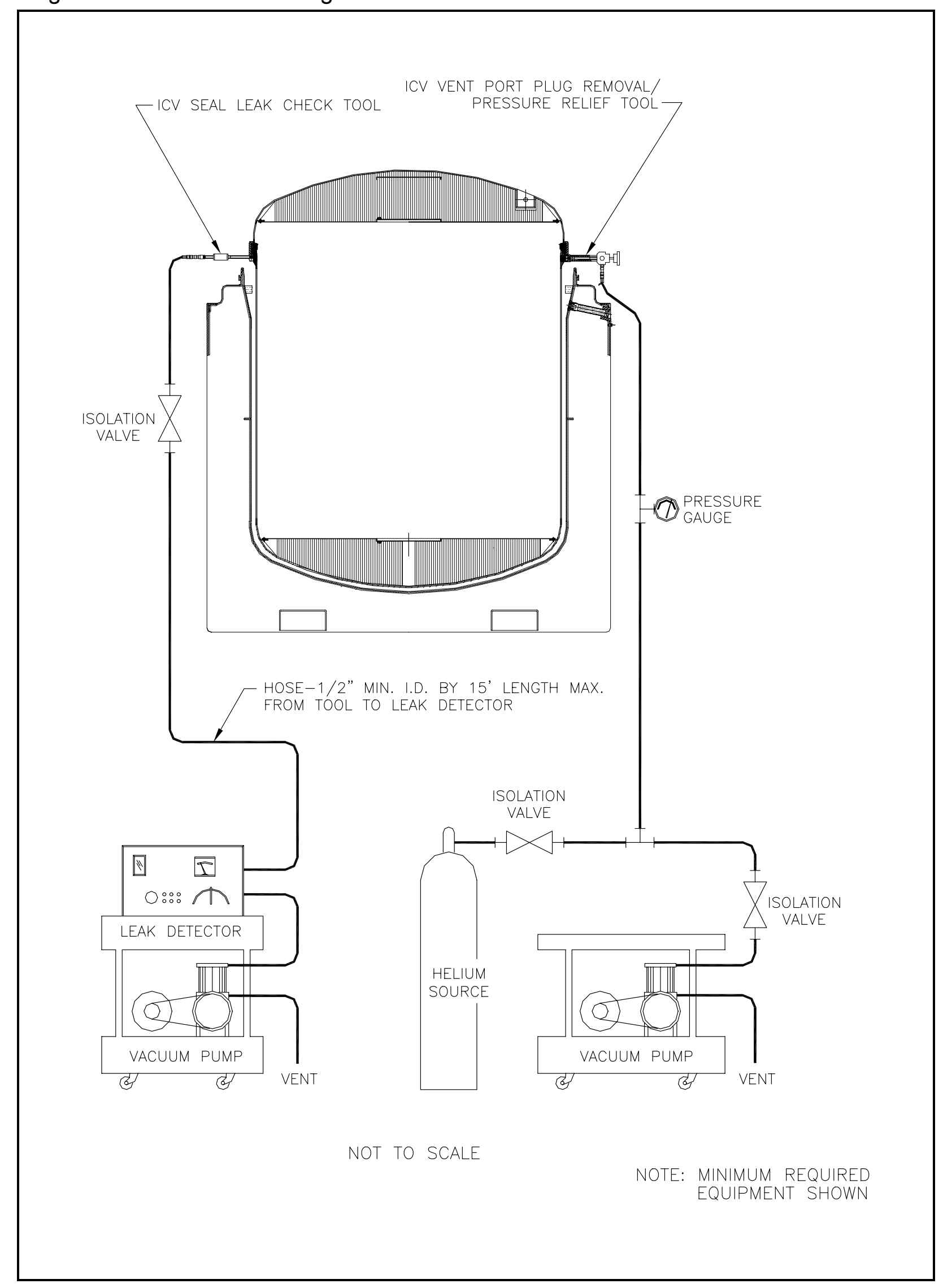


Figure 4.2 - ICV Outer Vent Port Plug Seal O-Ring Test

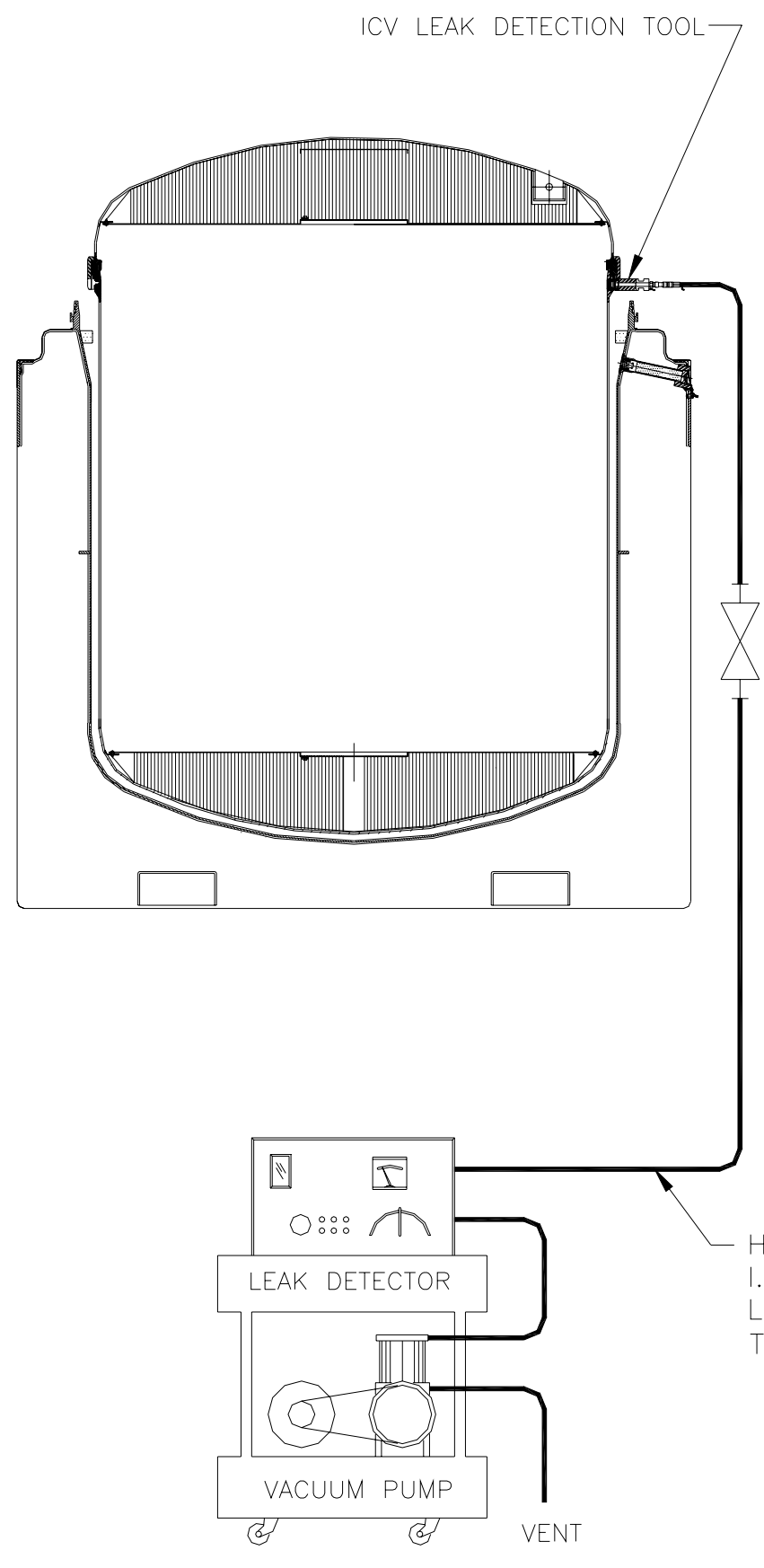


Figure 4.3 - OCV Main O-Ring Seal Test

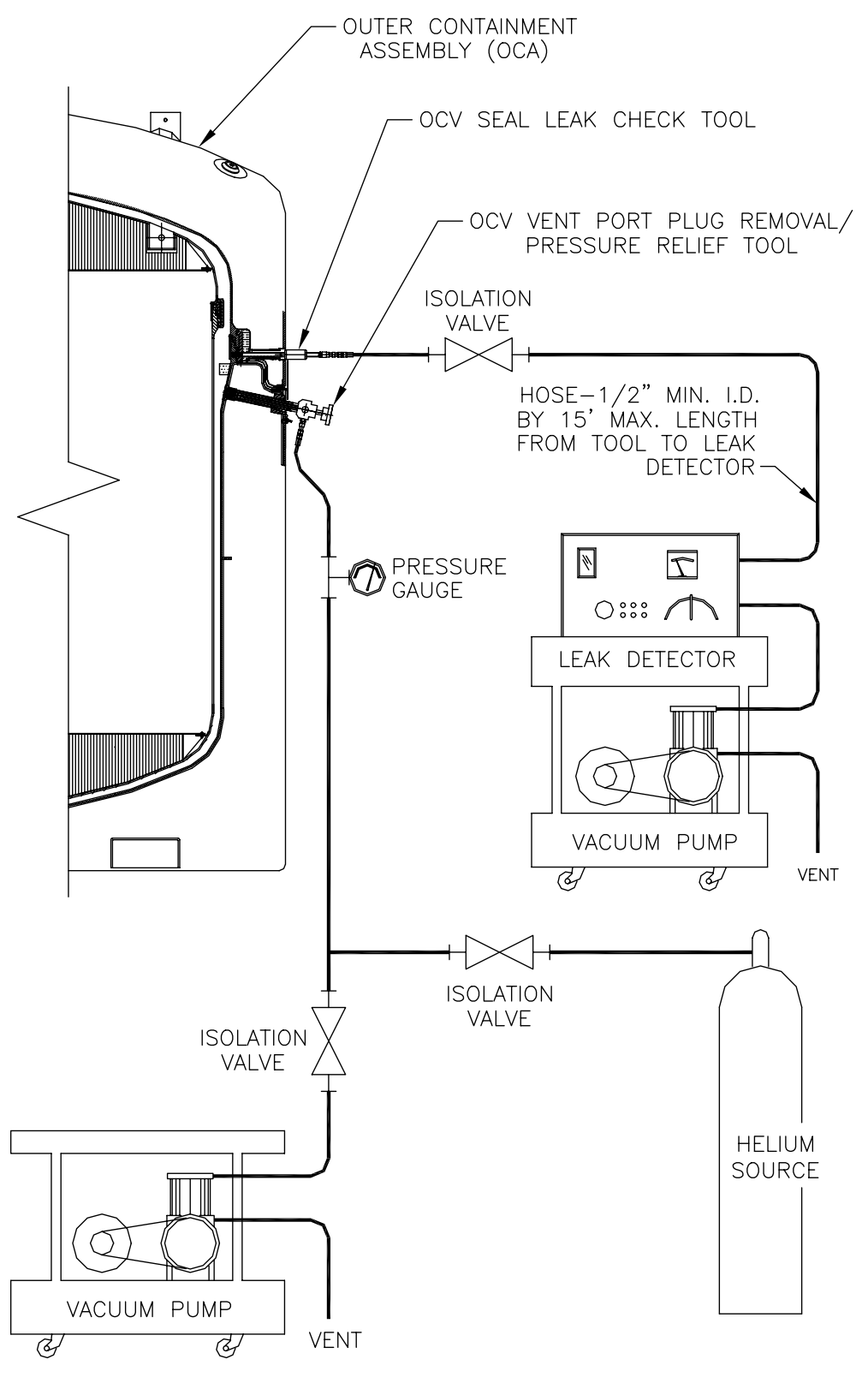

NOT TO SCALE 
Figure 4.4 - OCV Vent Port Plug Seal O-Ring Test

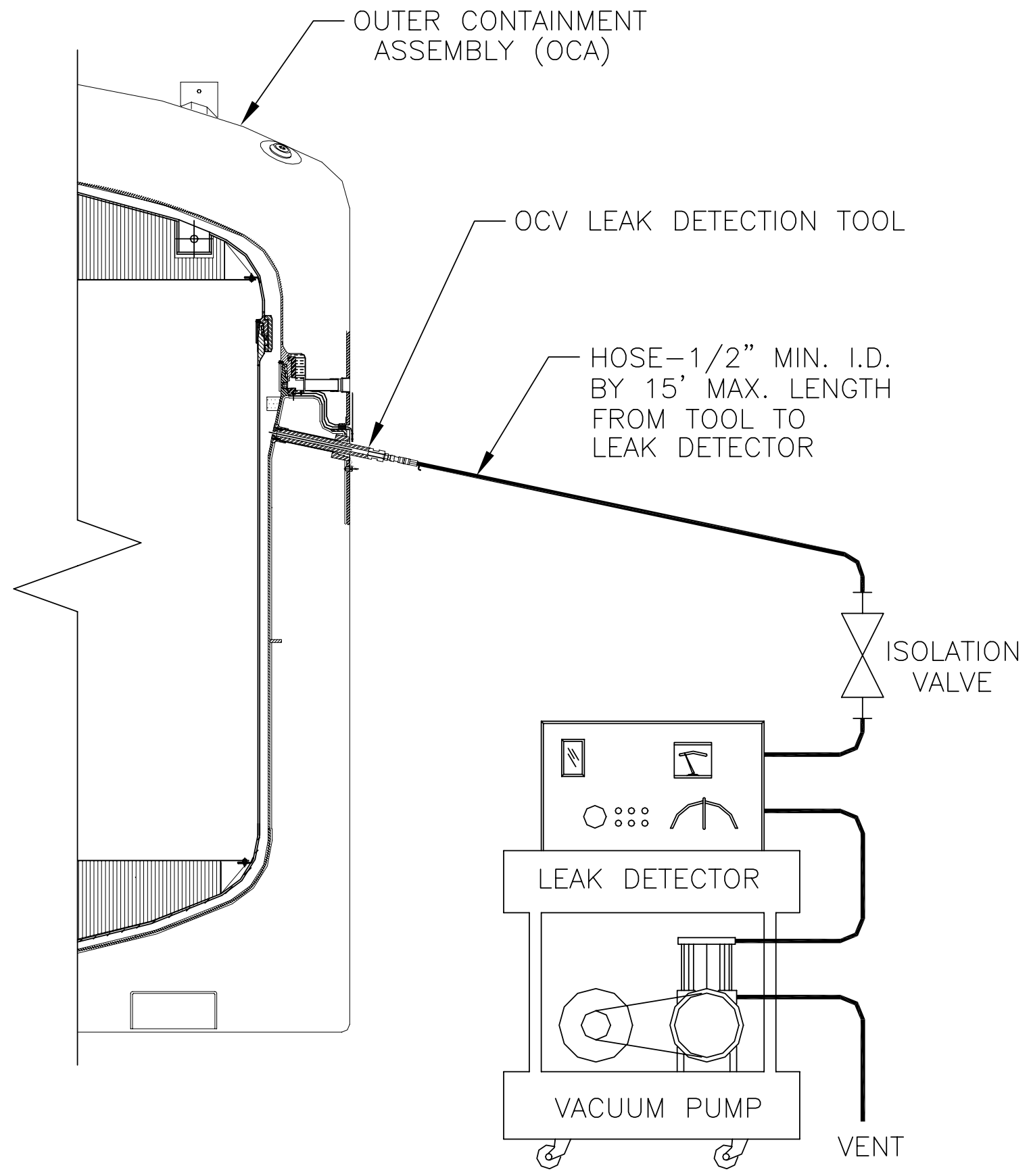

NOT TO SCALE

NOTE: 1. MINIMUM REQUIRED EQUIPMENT SHOWN 


\section{Attachment 1 - High-Wattage CH Packaging Receipt and Inspection Data Sheet}

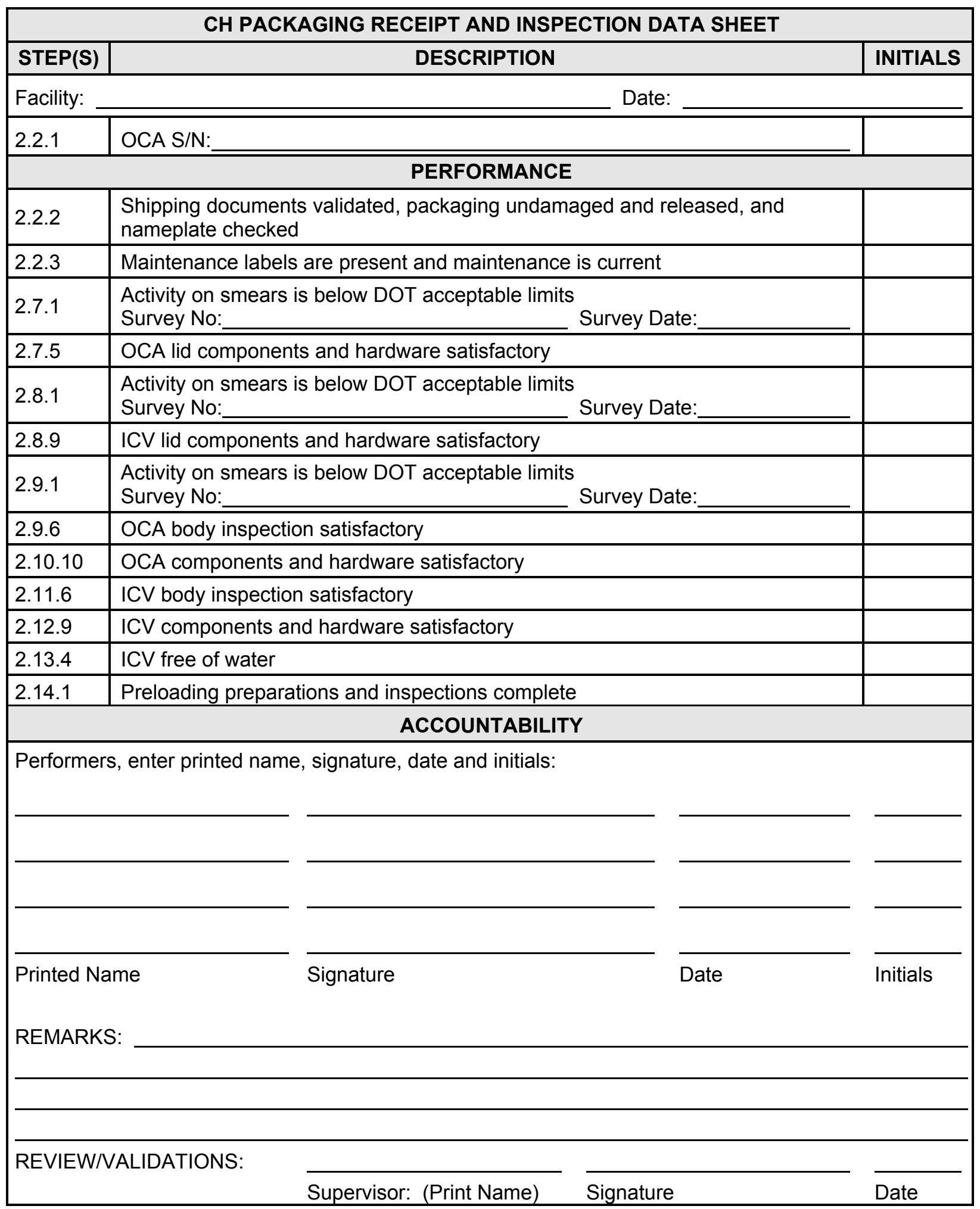




\section{Attachment 2 - High-Wattage CH Packaging Loading Data Sheet}

\begin{tabular}{|c|c|c|c|}
\hline \multicolumn{4}{|c|}{ CH PACKAGING LOADING DATA SHEET } \\
\hline STEP(S) & \multicolumn{2}{|r|}{ DESCRIPTION } & INITIALS \\
\hline \multicolumn{3}{|l|}{ Facility:__ } & \\
\hline 2.16 .1 & \multicolumn{2}{|l|}{ OCA S/N: } & \\
\hline \multicolumn{4}{|c|}{ PERFORMANCE } \\
\hline 2.16 .2 & \multicolumn{2}{|c|}{$\begin{array}{l}\text { Pallet S/N: } \\
\text { SWB Ratchet Strap S/Ns: }\end{array}$} & \\
\hline 2.16 .4 & \multicolumn{2}{|c|}{ Payload assembled in accordance with the $\mathrm{CH}$-TRAMPAC } & \\
\hline 2.16 .5 & $\begin{array}{l}\text { Highest ACTUA } \\
\text { Content Code Lf } \\
\text { Content Code LA } \\
\text { Content Code LA } \\
\text { Content Code LA } \\
\text { Content Code SC } \\
\text { Content Code SC } \\
\text { Content Code SC } \\
\text { Content Code SC } \\
\text { Content Code SC } \\
\text { Content Code SC } \\
\text { Content Code SC }\end{array}$ & \begin{tabular}{lr}
\multicolumn{2}{c}{ container wattage $=$} \\
$154 \mathrm{~A}$ & watts \\
$154 \mathrm{~B}$ & watts \\
$154 \mathrm{C}$ & watts \\
$154 \mathrm{D}$ & watts \\
$2154 \mathrm{~A}$ & watts \\
$2154 \mathrm{~B}$ & watts \\
2154C & watts \\
2154D & watts \\
2154E & watts \\
2154F & watts \\
2154G & watts
\end{tabular} & \\
\hline \multirow[t]{12}{*}{2.16 .6} & Content Code & Check box if ACTUAL container wattage is $\leq \mathrm{V}$ & \\
\hline & LA154A & $1.8219 \square$ & \\
\hline & LA154B & $2.4053 \square$ & \\
\hline & LA154C & $1.6762 \square$ & \\
\hline & LA154D & $2.0513 \square$ & \\
\hline & SQ154A & $0.9670 \quad \square$ & \\
\hline & SQ154B & $1.4230 \square$ & \\
\hline & SQ154C & $1.0886 \square$ & \\
\hline & SQ154D & $1.3233 \square$ & \\
\hline & SQ154E & $0.8752 \square$ & \\
\hline & SQ154F & $2.3247 \quad \square$ & \\
\hline & SQ154G & $0.9412 \quad \square$ & \\
\hline 2.16 .12 & \multicolumn{2}{|c|}{ Payload assembly weight: } & \\
\hline 2.16 .14 & \multicolumn{2}{|c|}{ Empty packaging weight:_ } & \\
\hline 2.16 .15 & \multicolumn{2}{|c|}{$\begin{array}{l}\text { Loaded package total weight: } \\
\text { Not to exceed: }(19,250 \mathrm{lb}-\overline{\text { TRUPACT-II })}\end{array}$} & \\
\hline 2.17 .1 & \multicolumn{2}{|c|}{ ICV serial number: } & \\
\hline 2.17 .2 & Torque wrench & Due: & \\
\hline & Torque wrench & Due: & \\
\hline
\end{tabular}




\section{Attachment 2 - High-Wattage CH Packaging Loading Data Sheet}

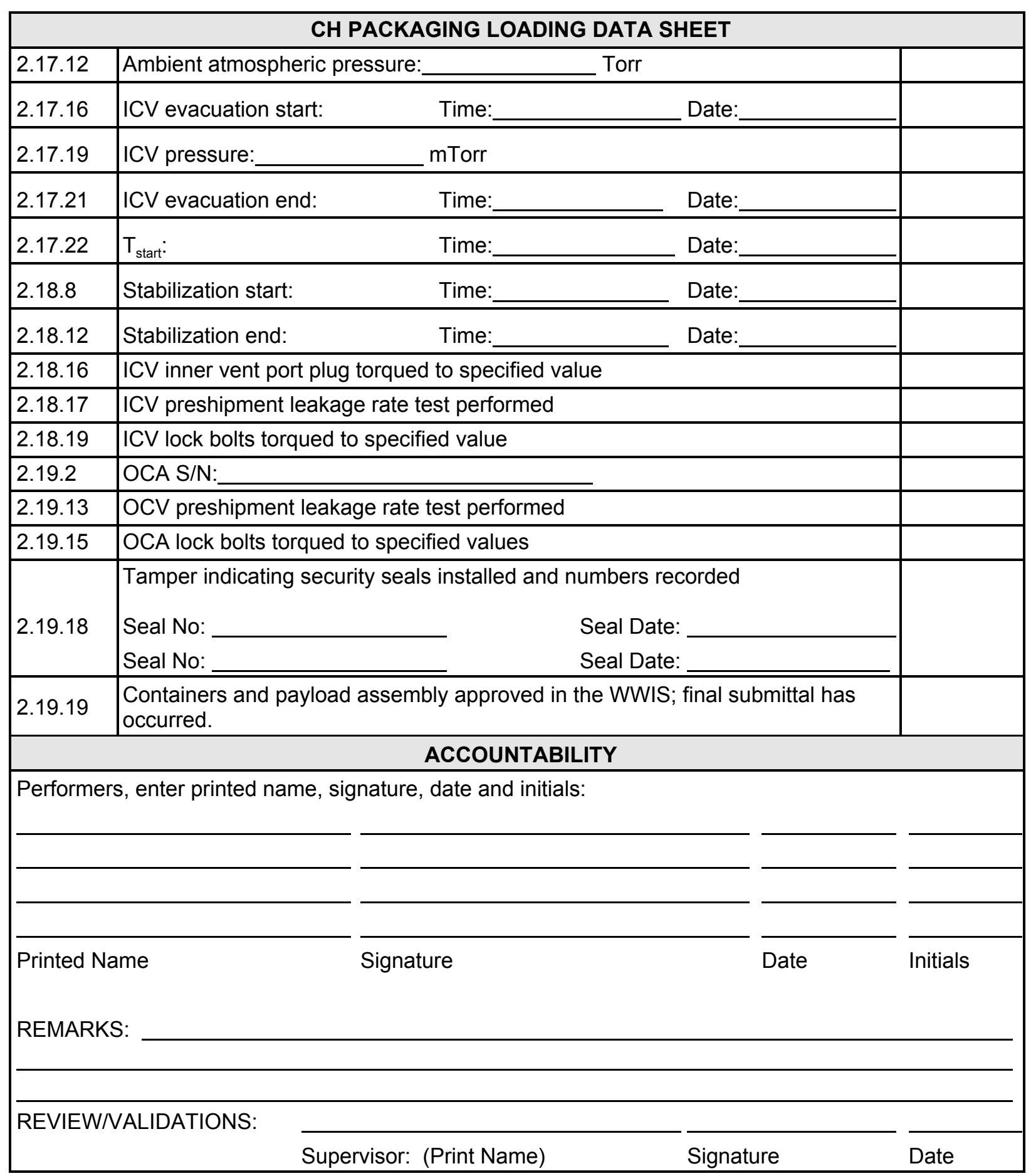




\section{Attachment 3 - High-Wattage Loaded CH Package Trailer Data Sheet}

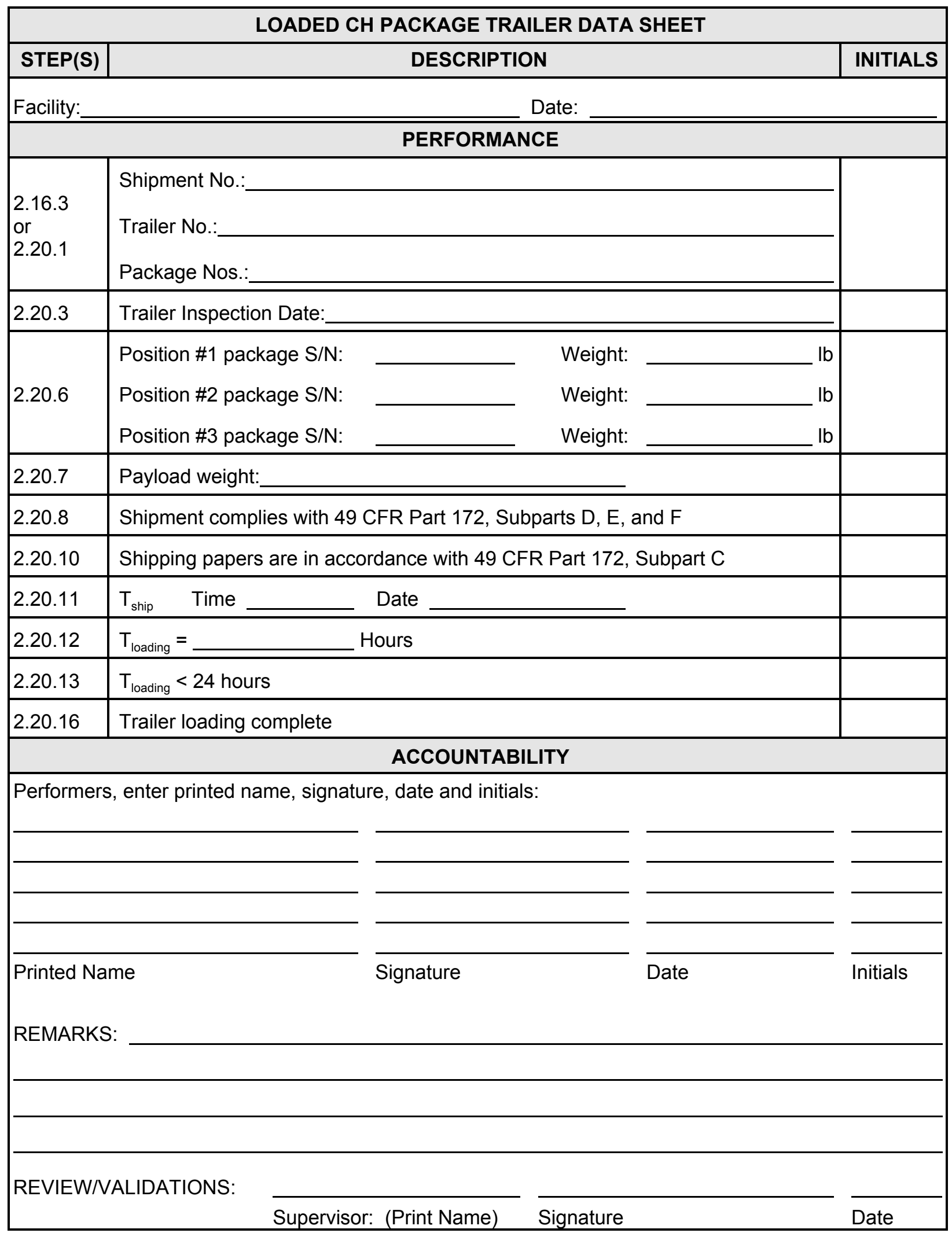




\section{Attachment 4 - High-Wattage Loaded Package Receipt and Processing Data Sheet}

\begin{tabular}{|c|c|c|c|c|}
\hline \multicolumn{5}{|c|}{ LOADED PACKAGE RECEIPT AND PROCESSING DATA SHEET } \\
\hline STEP(S) & \multicolumn{3}{|c|}{ DESCRIPTION } & INITIALS \\
\hline \multicolumn{5}{|l|}{ Facility: } \\
\hline \multicolumn{5}{|c|}{ PERFORMANCE } \\
\hline $\begin{array}{c}2.16 .1 \\
\text { or } \\
2.21 .1\end{array}$ & \multicolumn{3}{|l|}{ OCA serial number: } & \\
\hline 2.17 .25 & \multicolumn{3}{|c|}{ Filter surveyed for contamination } & \\
\hline 2.17 .26 & \multicolumn{2}{|l|}{$\begin{array}{l}\mathrm{T}_{\text {unload_120 }}=\mathrm{T}_{\text {start }}+120 \text { hours } \\
\text { or } \\
\mathrm{T}_{\text {unload_240 }}=\mathrm{T}_{\text {start }}+240 \text { hours }\end{array}$} & Date: & \\
\hline 2.21 .2 & \multicolumn{2}{|l|}{$\mathrm{T}_{\text {arrive }}=$ Actual } & Date: & \\
\hline 2.21 .3 & \multicolumn{2}{|l|}{$\mathrm{T}_{\text {unload_24 }}=\mathrm{T}_{\text {arrive }}+24$ hours } & Date: & \\
\hline 2.21 .4 & \multicolumn{2}{|r|}{ Time: } & Date: & \\
\hline 2.21 .5 & \multicolumn{3}{|c|}{ Shipping documents validated, package undamaged and released } & \\
\hline 2.21 .6 & \multicolumn{3}{|c|}{ Package external survey complete and below DOT acceptable limits } & \\
\hline 2.23 .17 & \multicolumn{3}{|c|}{ Activity on smears at or below acceptable limits } & \\
\hline 2.24 .8 & $\mathrm{~T}_{\text {ICV_open }}=$ Actual & Time: & Date: & \\
\hline 2.24 .13 & \multicolumn{3}{|c|}{ Activity on smears at or below acceptable limits } & \\
\hline 2.24 .17 & \multicolumn{3}{|c|}{ Activity on smears at or below acceptable limits } & \\
\hline 2.25 .4 & \multicolumn{3}{|l|}{ Payload inspected for damage } & \\
\hline 2.25 .5 & \multicolumn{3}{|c|}{ Activity on smears at or below acceptable limits } & \\
\hline \multicolumn{5}{|c|}{ ACCOUNTABILITY } \\
\hline \multicolumn{5}{|c|}{ Performers, enter printed name, signature, date and initials: } \\
\hline Printed $\mathrm{N}$ & Signature & & Date & Initials \\
\hline \multicolumn{5}{|c|}{ REMARKS: } \\
\hline \multicolumn{5}{|c|}{ REVIEW/VALIDATIONS: } \\
\hline & Superviso & (Print Name) & Signature & Date \\
\hline
\end{tabular}




\section{Attachment 5 - High-Wattage Empty Packaging Shipment Data Sheet}

\begin{tabular}{|c|c|c|}
\hline \multicolumn{3}{|c|}{ EMPTY PACKAGING SHIPMENT DATA SHEET } \\
\hline STEP(S) & DESCRIPTION & INITIALS \\
\hline \multicolumn{3}{|l|}{ Facility: } \\
\hline \multicolumn{3}{|c|}{ PERFORMANCE } \\
\hline 2.26 .1 & OCA S/N: & \\
\hline \multirow[t]{2}{*}{2.26 .2} & Torque wrench $\mathrm{S} / \mathrm{N}:$ & \\
\hline & Torque wrench $\mathrm{S} / \mathrm{N}:$ & \\
\hline 2.26 .3 & Packaging maintenance is current & \\
\hline 2.27 .1 & $\begin{array}{l}\text { OCA lid interior and exterior survey complete and below DOT acceptable limits: } \\
\text { Survey No: } \\
\end{array}$ & \\
\hline 2.27 .5 & OCA lid components and hardware satisfactory & \\
\hline 2.28 .1 & $\begin{array}{l}\text { ICV lid interior and exterior survey complete and below DOT acceptable limits: } \\
\text { Survey No: }\end{array}$ & \\
\hline 2.28 .9 & ICV lid components and hardware satisfactory & \\
\hline 2.29 .1 & $\begin{array}{l}\text { OCA body exterior and ICV body interior surveys complete and below DOT } \\
\text { acceptable limits. Survey No: Survey Date: }\end{array}$ & \\
\hline 2.29 .6 & OCA body inspection satisfactory & \\
\hline 2.30 .10 & OCA components and hardware satisfactory & \\
\hline 2.31 .6 & ICV body inspection satisfactory & \\
\hline 2.32 .9 & ICV components and hardware satisfactory & \\
\hline 2.33 .4 & ICV free of water & \\
\hline 2.33 .5 & Preshipment inspections complete & \\
\hline 2.34 .2 & ICV serial number: & \\
\hline 2.34 .16 & $\begin{array}{l}\text { ICV hardware and OCV seal test port plug torqued within designated range: } \\
\square \text { ICV inner vent port plug } \\
\square \text { ICV seal test port plug } \\
\square \text { OCV seal test port plug } \\
\square \text { ICV lock bolt(s) at } 28 \text { to } 32 \mathrm{lb}-\mathrm{ft} \\
\square \text { ICV outer vent port plug } \\
\square \text { ICV vent port cover }\end{array}$ & \\
\hline 2.35 .2 & OCA serial number: & \\
\hline 2.35 .16 & $\begin{array}{l}\text { OCV hardware torqued within designated range: } \\
\square \text { OCV vent port plug } \\
\square \text { OCV vent port cover } \\
\square \text { OCV seal test port access plug at } 35 \text { to } 45 \mathrm{lb} \text {-ft } \\
\square \text { OCV vent port access plug at } 35 \text { to } 45 \mathrm{lb}-\mathrm{ft}\end{array}$ & \\
\hline
\end{tabular}




\begin{tabular}{|lll|}
\hline DOE/WIPP 02-3220 & Rev. 7 & Page 101 of 110
\end{tabular}

| Attachment 5 - High-Wattage Empty Packaging Shipment Data Sheet

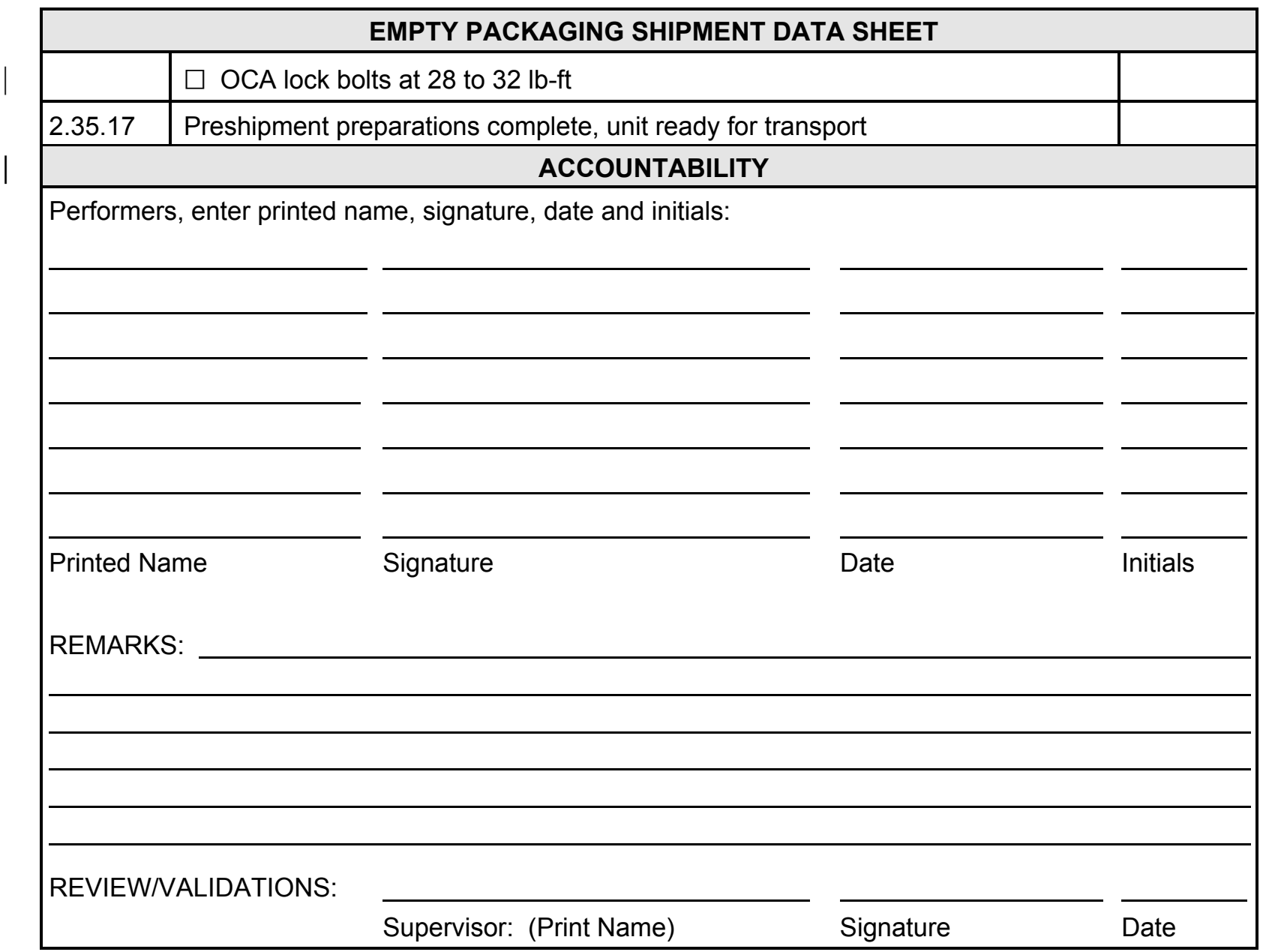




\section{Attachment 6 - High-Wattage Trailer Data Sheet}

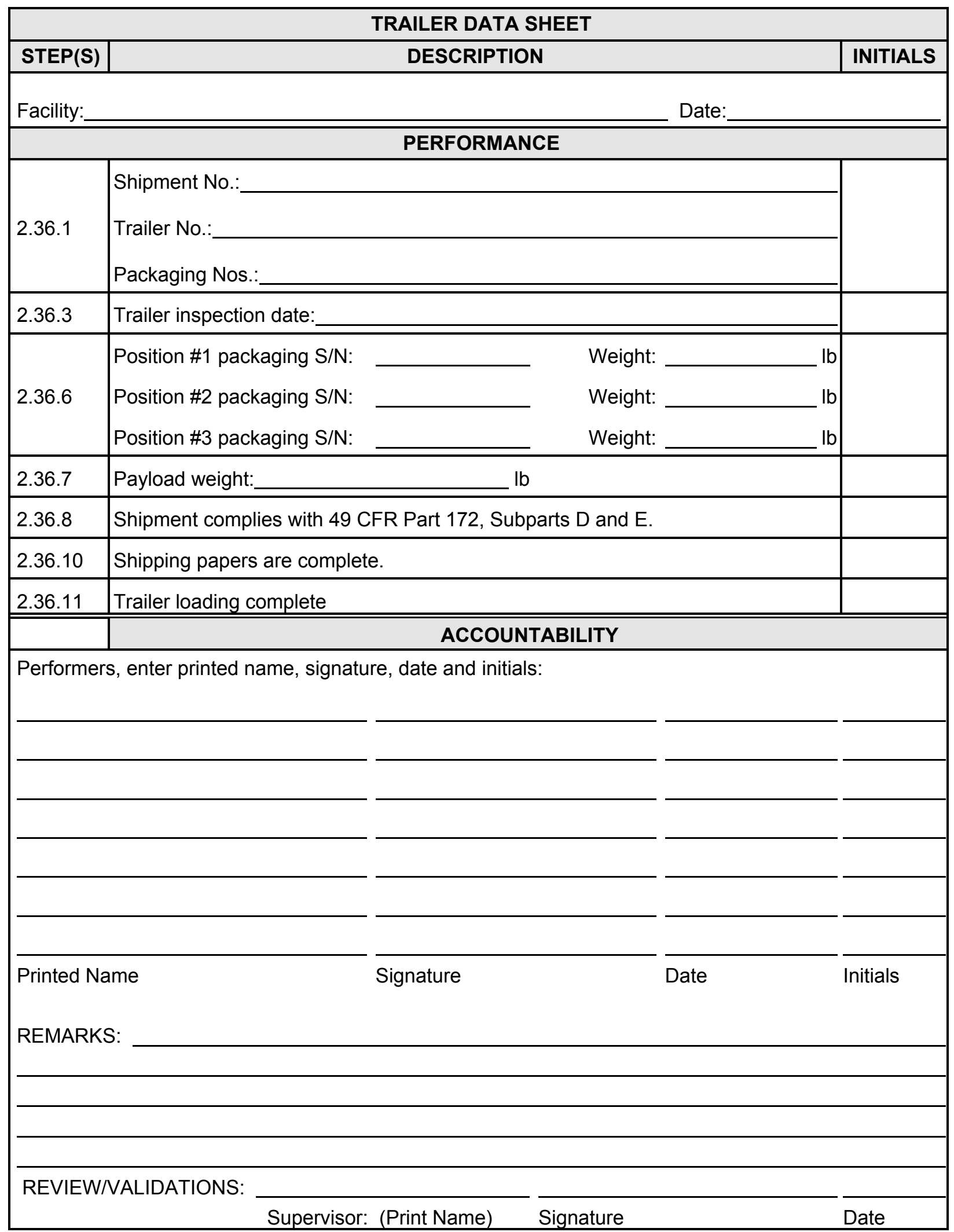




\section{Attachment 7 - ICV Preshipment Leakage-Rate Test Data Sheet}

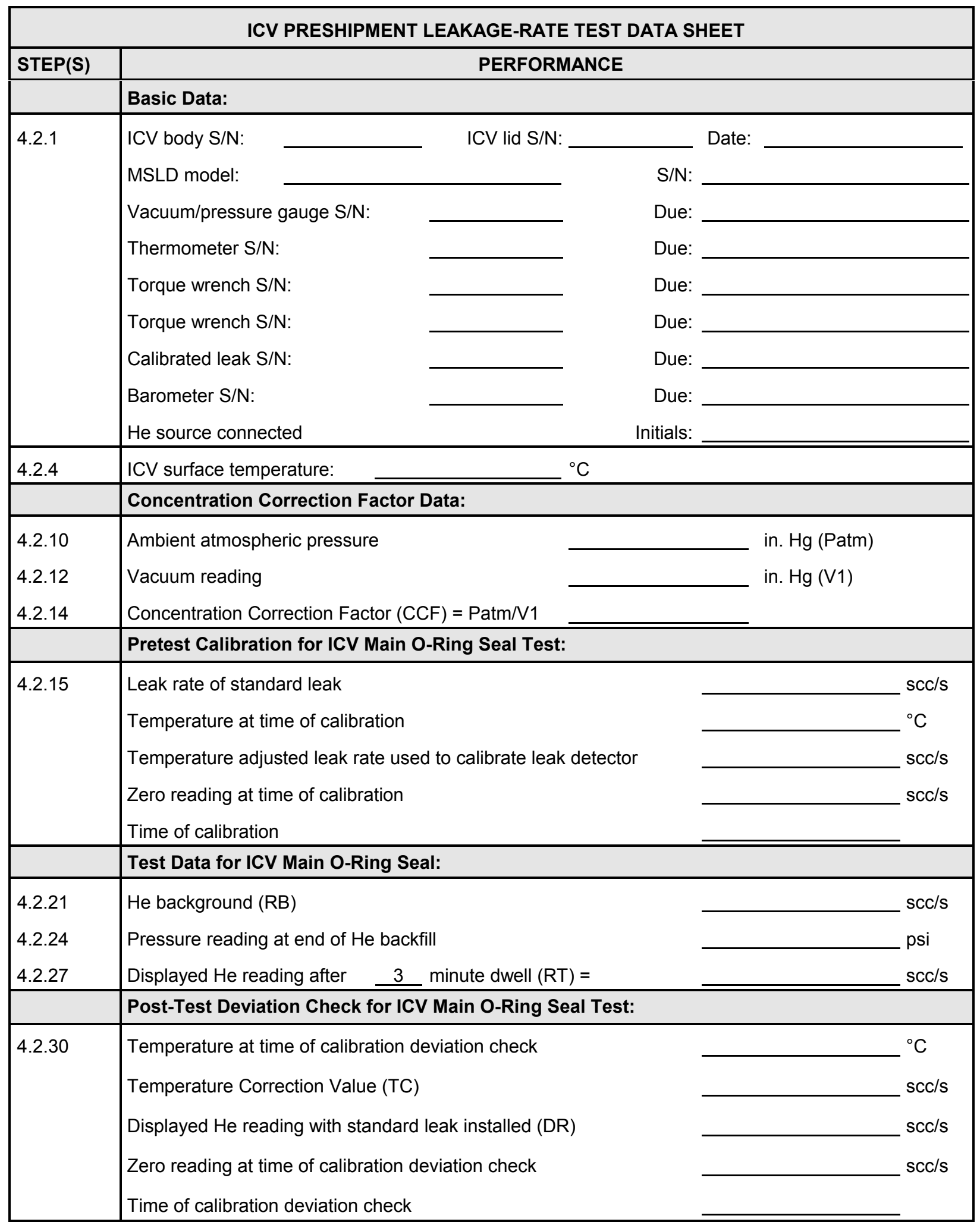




\section{Attachment 7 - ICV Preshipment Leakage-Rate Test Data Sheet}

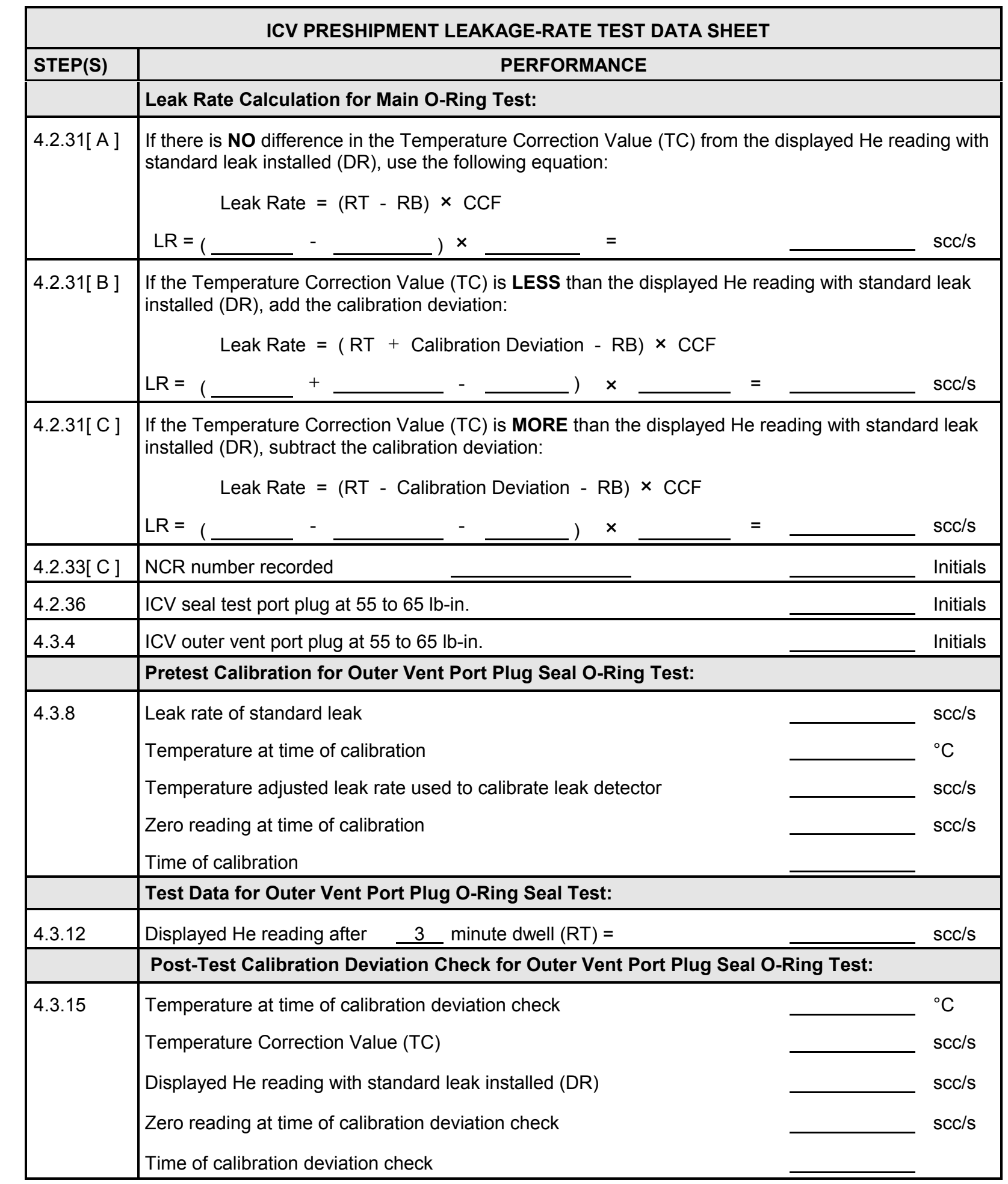




\section{Attachment 7 - ICV Preshipment Leakage-Rate Test Data Sheet}

\begin{tabular}{|c|c|}
\hline \multicolumn{2}{|r|}{ ICV PRESHIPMENT LEAKAGE-RATE TEST DATA SHEET } \\
\hline STEP(S) & PERFORMANCE \\
\hline & Leak Rate Calculation for Outer Vent Port Plug Seal O-Ring Test: \\
\hline 4.3.16[A ] & $\begin{array}{l}\text { If there is NO difference in the Temperature Correction Value (TC) from the displayed He reading with } \\
\text { standard leak installed }(D R) \text {, use the following equation: } \\
\mathrm{LR}=\end{array}$ \\
\hline 4.3.16[ B ] & $\begin{array}{l}\text { If the Temperature Correction Value }(\mathrm{TC}) \text { is LESS than the displayed He reading with standard leak } \\
\text { installed (DR), add the calibration deviation: } \\
\qquad \mathrm{LR}=(\text { Leak Rate }=(\mathrm{RT}+\text { Calibration Deviation }) \times \mathrm{CCF} \\
\end{array}$ \\
\hline 4.3.16[ C ] & $\begin{array}{l}\text { If the Temperature Correction Value }(\mathrm{TC}) \text { is MORE than the displayed He reading with standard leak } \\
\text { installed (DR), subtract the calibration deviation: } \\
\qquad \mathrm{Leak} \text { Rate }=(\mathrm{RT}-\text { Calibration Deviation }) \times \mathrm{CCF} \\
\mathrm{LR}-\mathrm{L}) \times \quad \mathrm{scc} / \mathrm{s}\end{array}$ \\
\hline 4.3.18[ C ] & NCR number recorded \\
\hline 4.3.21 & ICV vent port cover at 55 to $65 \mathrm{lb}$-in. \\
\hline & ACCOUNTABILITY \\
\hline & Test performed by/Level \\
\hline & Test reviewed by/Level \\
\hline
\end{tabular}


Attachment 8 - OCV Preshipment Leakage-Rate Test Data Sheet

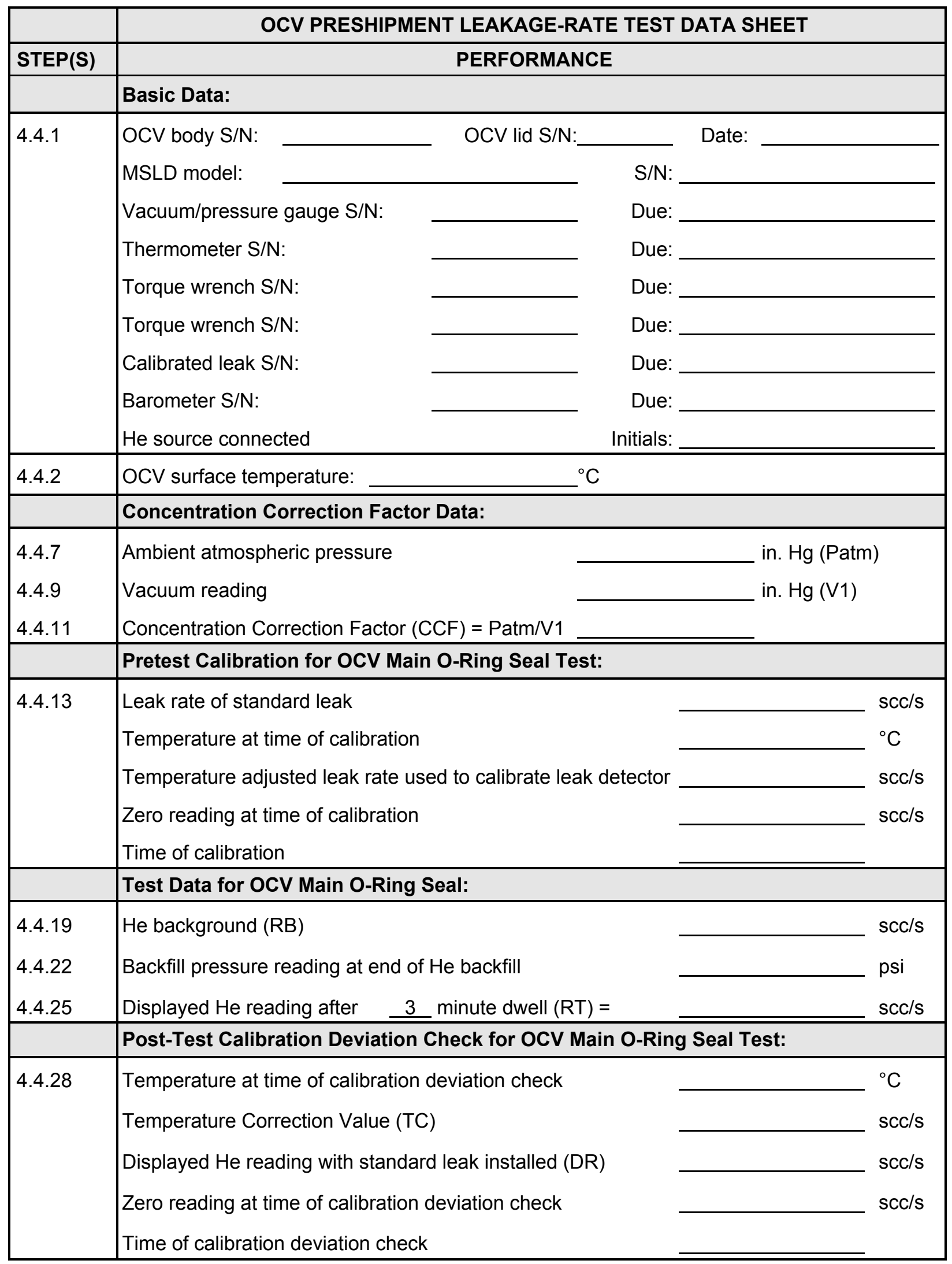


Attachment 8 - OCV Preshipment Leakage-Rate Test Data Sheet

\begin{tabular}{|c|c|}
\hline & OCV PRESHIPMENT LEAKAGE-RATE TEST DATA SHEET \\
\hline \multirow[t]{2}{*}{ STEP(S) } & PERFORMANCE \\
\hline & Leak Rate Calculation for Main O-Ring Test: \\
\hline 4.4.29[A] & $\begin{array}{l}\text { If there is NO difference in the Temperature Correction Value }(\mathrm{TC}) \text { from the displayed } \mathrm{He} \\
\text { reading with standard leak installed }(\mathrm{DR}) \text {, use the following equation: } \\
\qquad \text { Leakage Rate }=(\mathrm{RT}-\mathrm{RB}) \times \mathrm{CCF}= \\
\mathrm{LR}=(\mathrm{C}) \times \mathrm{scc} / \mathrm{s}\end{array}$ \\
\hline $4.4 .29[B]$ & $\begin{array}{l}\text { If the Temperature Correction Value (TC) is LESS than the displayed He reading with } \\
\text { standard leak installed (DR), add the calibration deviation: } \\
\qquad \text { Leak Rate }=(\mathrm{RT}+\text { Calibration Deviation }-\mathrm{RB}) \times \mathrm{CCF} \\
\mathrm{LR}=(\end{array}$ \\
\hline $4.4 .29[\mathrm{C}]$ & $\begin{array}{l}\text { If the Temperature Correction Value (TC) is MORE than the displayed He reading with } \\
\text { standard leak installed (DR), subtract the calibration deviation: } \\
\qquad \text { Leak Rate }=(\mathrm{RT}-\text { Calibration Deviation - RB }) \times C C F \\
\text { LR }=(\text { L }\end{array}$ \\
\hline $4.4 .31[\mathrm{C}]$ & NCR number recorded \\
\hline 4.4 .34 & OCV seal test port plug at 55 to $65 \mathrm{lb}$-in. \\
\hline \multirow[t]{2}{*}{4.5 .4} & OCV vent port plug at 55 to $65 \mathrm{lb}$-in. \\
\hline & Pretest Calibration for OCV Vent Port Plug Seal O-Ring Test: \\
\hline \multirow[t]{2}{*}{4.5 .8} & \begin{tabular}{|lrl} 
Leak rate of standard leak & \\
Temperature at time of calibration & \\
Temperature adjusted leak rate used to calibrate leak detector & \\
Zero reading at time of calibration & \\
Time of calibration &
\end{tabular} \\
\hline & Test Data for OCV Vent Port Plug Seal O-Ring: \\
\hline \multirow[t]{2}{*}{4.5 .12} & Displayed He reading after $\quad 3$ minute dwell $(R T)=$ \\
\hline & Post-Test Calibration Deviation Check for OCV Vent Port Plug Seal O-Ring Test: \\
\hline 4.5 .15 & $\begin{array}{l}\text { Temperature at time of calibration deviation check } \\
\text { Temperature Correction Value (TC) } \\
\text { Displayed He reading with standard leak installed (DR) } \\
\text { Zero reading at time of calibration deviation check } \\
\text { Time of calibration deviation check }\end{array}$ \\
\hline
\end{tabular}




\section{Attachment 8 - OCV Preshipment Leakage-Rate Test Data Sheet}

\begin{tabular}{|c|c|}
\hline & OCV PRESHIPMENT LEAKAGE-RATE TEST DATA SHEET \\
\hline \multirow[t]{2}{*}{ STEP(S) } & PERFORMANCE \\
\hline & Leak Rate Calculation for OCV Vent Port Plug Seal O-Ring Test: \\
\hline 4.5.16[A ] & $\begin{array}{l}\text { If there is NO difference in the Temperature Correction Value (TC) from the displayed He } \\
\text { reading with standard leak installed (DR), use the following equation: } \\
\qquad \text { Leakage Rate }=(\mathrm{RT}) \times \mathrm{CCF} \\
\mathrm{LR}=(\mathrm{L}) \times \mathrm{scc/s}\end{array}$ \\
\hline 4.5.16[B ] & $\begin{array}{l}\text { If the Temperature Correction Value (TC) is LESS than the displayed He reading with } \\
\text { standard leak installed (DR), add the calibration deviation: } \\
\qquad \text { Leakage Rate }=(\mathrm{RT}+\text { Calibration Deviation }) \times \mathrm{CCF} \\
\mathrm{LR}=(\end{array}$ \\
\hline 4.5.16[ C ] & $\begin{array}{l}\text { If the Temperature Correction Value }(\mathrm{TC}) \text { is MORE than the displayed He reading with } \\
\text { standard leak installed (DR) subtract the calibration deviation: } \\
\qquad \begin{array}{ll}\text { Leakage Rate }=(\mathrm{RT}-\text { Calibration Deviation }) \times \mathrm{CCF} \\
\mathrm{LR}=(\end{array}\end{array}$ \\
\hline $4.5 .18[\mathrm{C}]$ & NCR number recorded \\
\hline 4.5.21 & OCV vent port cover at 55 to $65 \mathrm{lb}$-in. \\
\hline 4.5 .23 & OCV seal test port access plug at 35 to $45 \mathrm{lb}-\mathrm{ft}$ \\
\hline \multirow[t]{4}{*}{4.5 .25} & OCV vent port access plug at 35 to $45 \mathrm{lb}-\mathrm{ft}$ \\
\hline & ACCOUNTABILITY \\
\hline & Tests performed by/Level \\
\hline & Tests reviewed by/Level \\
\hline
\end{tabular}


Attachment 9 - Time and Date Data Sheet for Shipment of High-Wattage Waste

\section{TIME AND DATE DATA SHEET FOR SHIPMENT OF HIGH-WATTAGE WASTE}

Shipment No.: $\quad$ Packaging OCA Body/Lid No.:

To be completed by TCO or designee for each TRUPACT-II shipping high-wattage waste.

\begin{tabular}{|c|c|c|c|c|}
\hline Step No. & Activity & Date Recorded & Time Recorded & $\begin{array}{l}\text { Completion of } \\
\text { Activity (Indicate by } \\
\text { check mark }[\boldsymbol{}] \text { ) }\end{array}$ \\
\hline 2.17 .22 & $\mathrm{~T}_{\text {start }}$ & & & \\
\hline 2.20.11 & $\begin{array}{l}\text { Record date and time of } \\
\text { departure of shipment from } \\
\text { site }\end{array}$ & & & \\
\hline 2.20.12 & $\begin{array}{l}\text { Calculate and record total } \\
\text { loading time } \\
\text { (Limit = } 24 \text { hours) }\end{array}$ & & $\mathrm{T}_{\text {loading }}=\ldots$ hrs & \\
\hline 2.20 .13 & $\mathrm{~T}_{\text {loading }}<24$ hours & & & \\
\hline \multicolumn{5}{|c|}{$\begin{array}{l}\text { I certify that the above data are accurate and compliant with the loading time limit of } 24 \text { hours, as } \\
\text { specified in this document and Appendix } 6.12 \text { of the } \mathrm{CH}-\mathrm{TRU} \text { Payload Appendices. }\end{array}$} \\
\hline \multicolumn{4}{|c|}{ Transportation Certification Official or Designee } & Date \\
\hline
\end{tabular}




\section{Attachment 10 - Time and Date Data Sheet for Receipt of High-Wattage Waste}

\section{TIME AND DATE DATA SHEET FOR RECEIPT OF HIGH-WATTAGE WASTE}

Shipment No.:

Packaging OCA Body/Lid No.:

To be completed by designated WIPP Operations Personnel for each TRUPACT-II shipping highwattage waste.

\begin{tabular}{|l|l|l|l|l|}
\hline Step No. & \multicolumn{1}{|c|}{ Activity } & Recorded Date & Recorded Time & $\begin{array}{c}\text { Completion of } \\
\text { Activity (Indicate by } \\
\text { check mark [ } \boldsymbol{V}] \text { ] }\end{array}$ \\
\hline 2.21 .2 & $\begin{array}{l}\text { Record date and time } \\
\text { that TRUPACT-II } \\
\text { arrives at WIPP }\end{array}$ & $\begin{array}{l}\text { Vent ICV within } \\
\text { 24 hours of date and } \\
\text { time recorded above } \\
\text { and record vent date } \\
\text { and time }\end{array}$ & & \\
\hline $\begin{array}{l}\text { I certify that the above data are accurate and compliant with the Unloading Time limit of 24 hours, as } \\
\text { specified in Appendix 6.12 of the CH-TRU Payload Appendices. }\end{array}$ & \\
\hline
\end{tabular}

